\title{
Identification \& functional characterization of the Arabidopsis ZINC FINGER PROTEIN 3
}

PhD thesis

\author{
Mary Prathiba Joseph \\ Supervisor: Dr. László Szabados
}

Biological Research Centre of the Hungarian Academy of Sciences, Institute of Plant Biology

Laboratory of Arabidopsis Molecular Genetics

Doctoral School of Biology

University of Szeged

Szeged, 2014 


\section{TABLE OF CONTENTS}

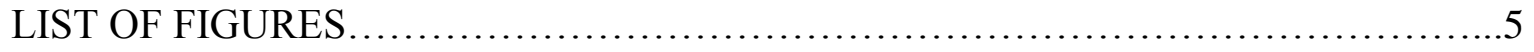

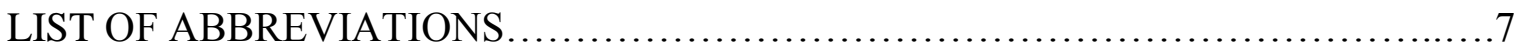

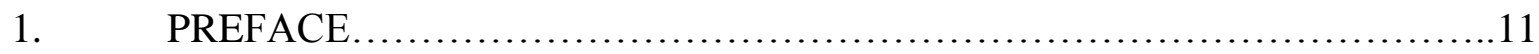

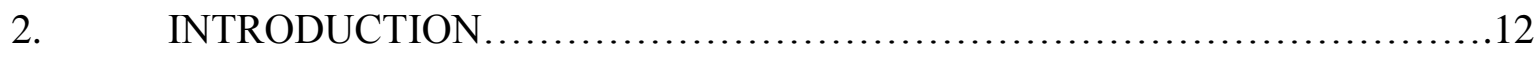

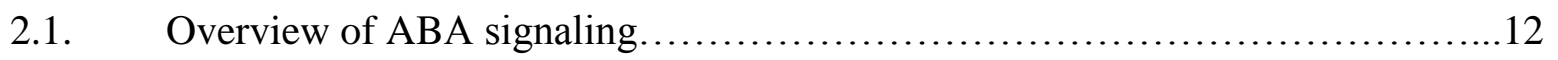

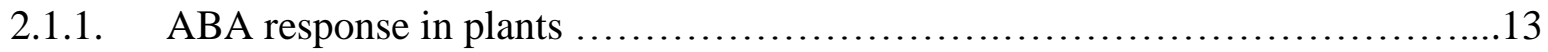

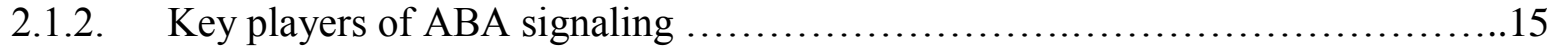

2.1.2.1. The type-2C protein phosphatases, $A B I I$ and $A B I 2$ genes......................15

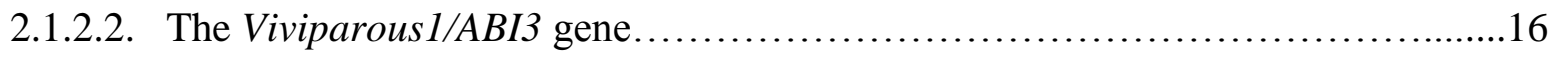

2.1.2.3. The AP2/ ERF transcription factor, ABI4 gene................................16

2.1.2.4. The bZIP transcription factor, $A B I 5$ gene.................................. 17

2.2. The COS system for screening novel ABA regulatory genes.....................17

2.3. Germination assay, an ideal tool to isolate ABA and related stress

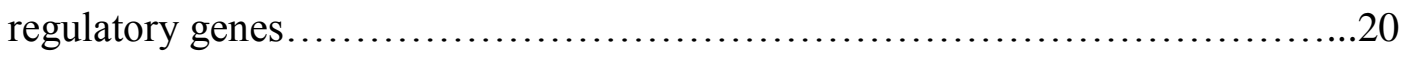

2.4. The Germination controlling networks....................................21

2.4.1. Interaction of light and hormone signals in germinating seeds..................21

2.4.2. Regulation of ABA by light.................................................. 21

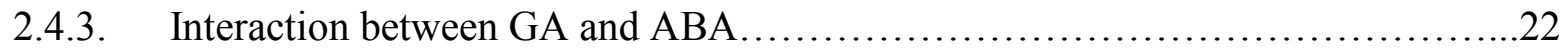

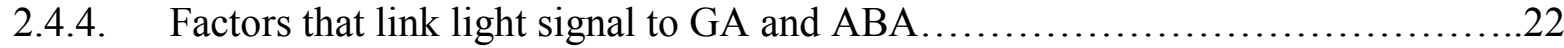

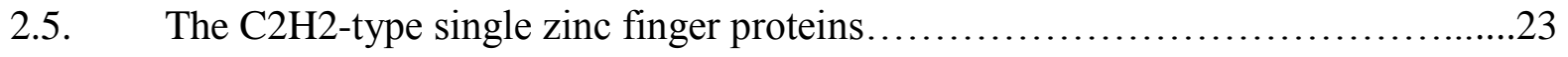

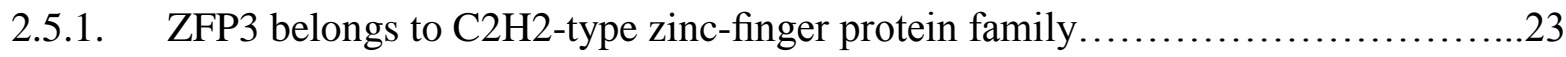

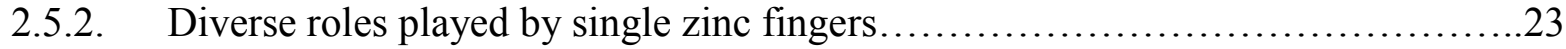

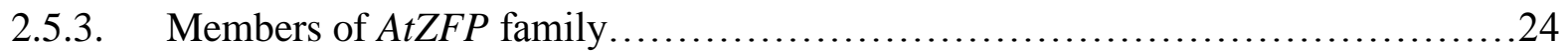

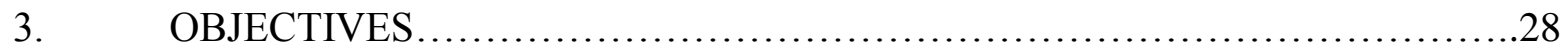

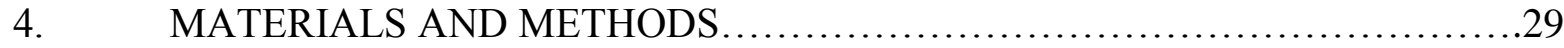

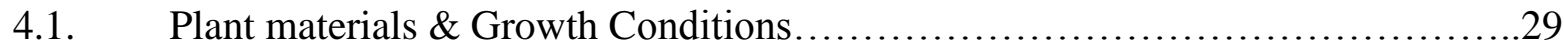

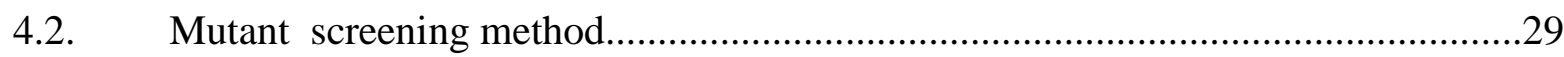




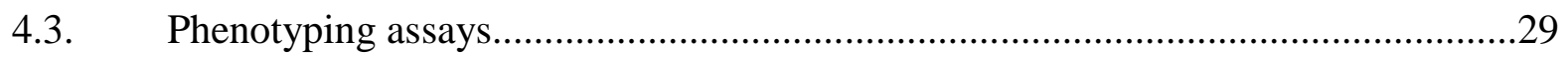

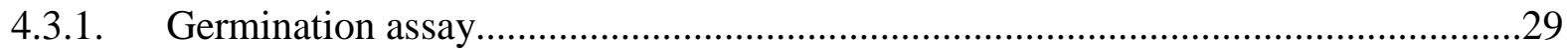

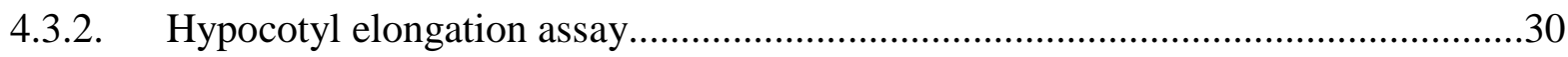

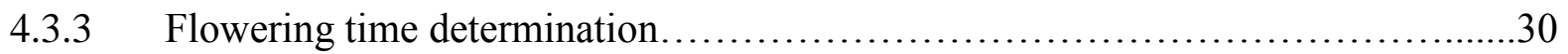

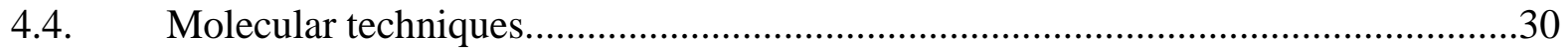

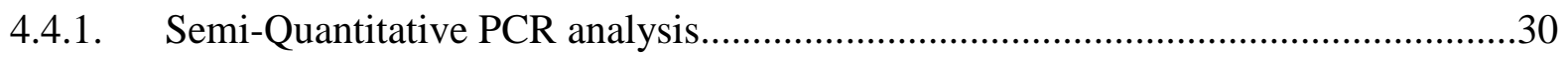

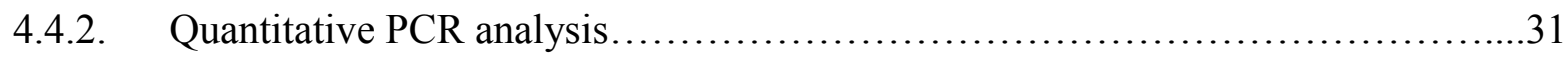

4.5. Generation of transgenic plants...........................................

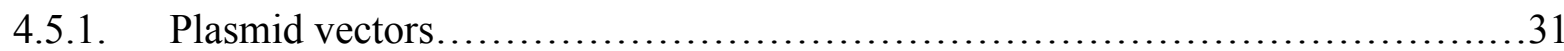

4.5.2. Promoter-reporter constructs........................................ 31

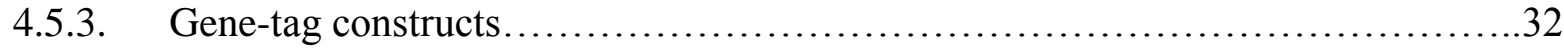

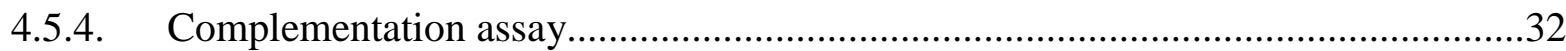

4.6. Transgene-based gene expression analyses...................................

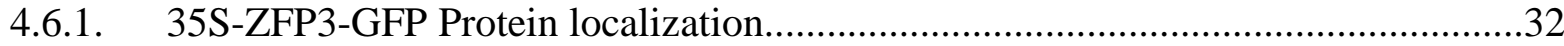

4.6.2. Preparation of Protein extracts and determination.............................. 32

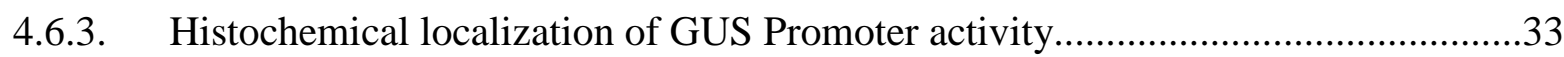

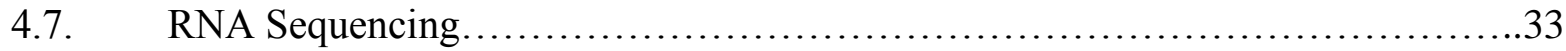

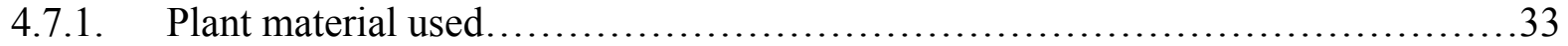

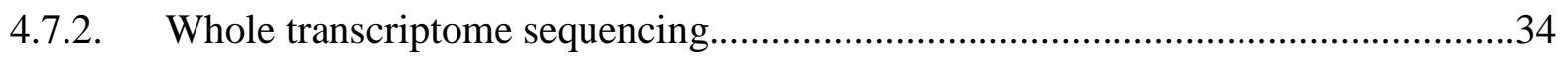

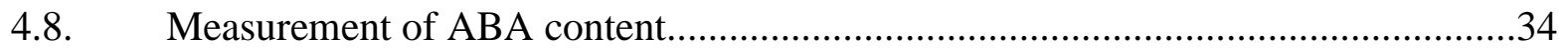

4.9. Genotyping of zfp mutants and Genetic crosses.............................................35

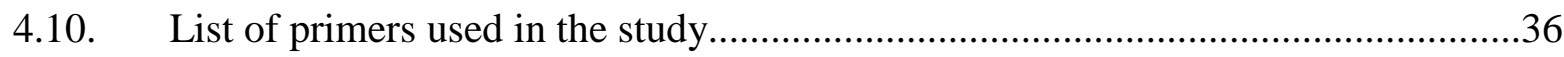

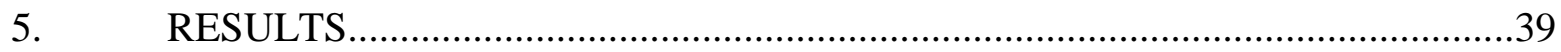

5.1. Screening for ABA insensitive lines........................................ 39

5.2. Characterization of line A26......................................... 42

5.3. Characterization of line A44 ...................................... 44

5.3.1. Germination assay on ABA and Paclabutrazol media.........................44

5.3.2. Isolation and sequencing of the A44 cDNA insert.........................45

5.3.3. Re-transformation and confirmation of ZFP3 induced ABA insensitivity.........46

5.4. ZFP3 modulates ABA sensitivity......................................48 
5.4.1. Genetic crosses and comparison of ZFP3 with abi mutants....................48

5.4.2. Influence of $\mathrm{ABA}$ on $\mathrm{ZFP} 3$ protein expression during germination...............49

5.4.3. Influence of ABA on ZFP3 transcriptional regulation during germination..........50

5.5. ZFP3 related $\mathrm{C} 2 \mathrm{H} 2$ type Zinc finger protein family....................... 51

5.5.1. Phylogenetic analysis of ZFP3 related $\mathrm{C} 2 \mathrm{H} 2$ type Zinc Finger proteins...........51

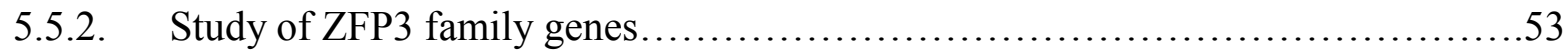

5.5.3. Transcriptional regulation of ZFP3 and related genes........................53

5.6. Spatial transcriptional regulation of ZFP3 expression........................55

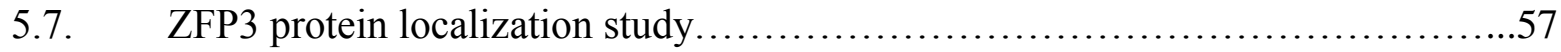

5.8. Characterization of $z f p 3$ and $z f p 4$ T-DNA insertion mutants...................58

5.8.1. Genotyping of $z f p 3$ and $z f p 4$ single and double mutants $\ldots \ldots \ldots \ldots \ldots \ldots \ldots \ldots$

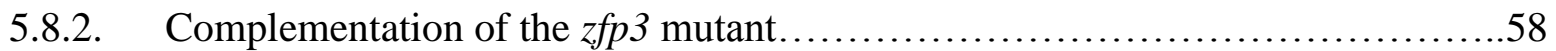

5.8.3. ABA sensitivity of $z f p 3$ and $z f p 4$ mutants and $z f p 3 z f p 4$ double mutant.............59

5.8.4. Measurement of ABA content..........................................60

5.8.5. Early flowering phenotype of $z f p 3$ mutant..................................61

5.9. Effect of ZFP3 constitutive overexpression on plant development..............62

5.10. ZFP3 modulates ABA-regulated gene expression..........................65

5.10.1. Transcript profiling using in-depth sequencing (RNA-seq) $\ldots \ldots \ldots \ldots \ldots \ldots \ldots \ldots$

5.10.2. Confirmation of selected genes by quantitative PCR ..........................71

5.10.3. Short-term gene regulation by ZFP3 induction............................. 71

5.11. ZFP3 modulates light responses in seedling development...................73

5.11.1. Hypocotyl growth is affected in ZFP3ox seedlings.........................73

5.11.2. Overexpression of ZFP related genes affects hypocotyl growth................74

5.11.3. Monochromatic light specific response on hypocotyl growth...................76

5.11.4. Genetic interaction of ZFP3 with PhyB and PhyA .............................. 78

5.11.5. Light specific genetic interaction of ZFP3 with $a b i$ genes.....................79

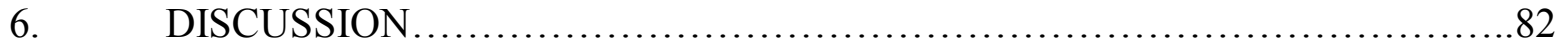

6.1. Identification of Stress Response Regulatory Genes using the COS System.......82

6.2. Overexpression of AtHSP17.6A confers ABA insensitive seed germination......82

6.3. Overexpression of ZFP3 confers ABA insensitive seed germination.............83 
6.4. ZFP3 modulates ABA sensitivity ........................................ 84

6.5. ZFP3 belongs to $\mathrm{C} 2 \mathrm{H} 2$-type zinc-finger protein family ......................... 85

6.6. Pleiotropic effects of ZFP3 gene when expressed constitutively..................86

6.7. Tissue specific expression and regulation by ABA.............................86

6.8. ZFP3 is a nuclear protein........................................................

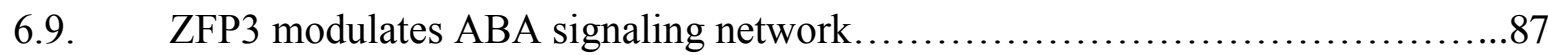

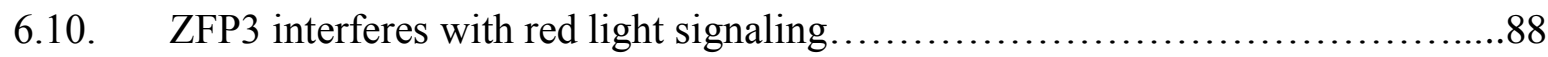

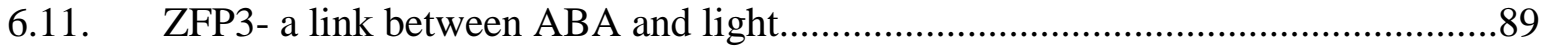

7. Model of ZFP3 action in seed germination and plant development.............90

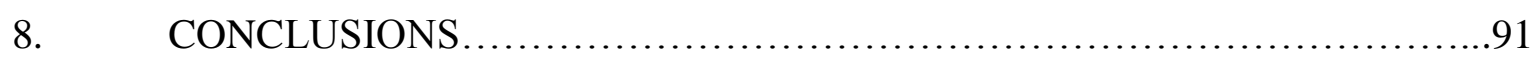

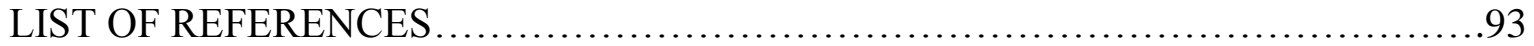

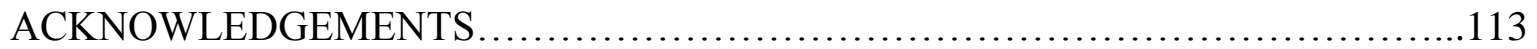

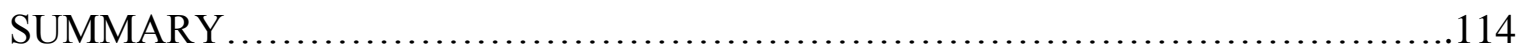

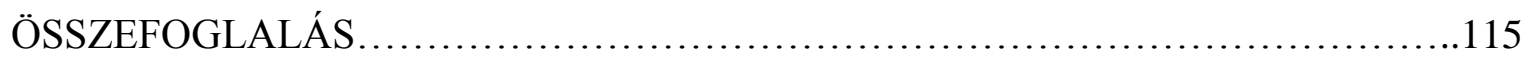

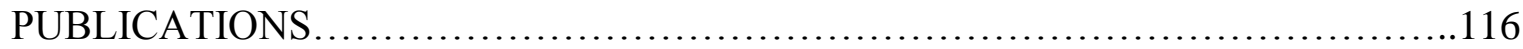

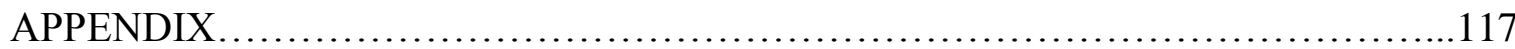




\section{LIST OF FIGURES}

Figure 1: ABA regulation in the life cycle of a plant....................................... 12

Figure 2: Transcriptional regulatory networks......................................... 14

Figure 3: Schematic representation of the COS cDNA.....................................19

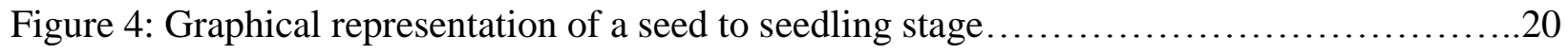

Figure 5: Germination of 156 lines...................................................... 40

Figure 6: Germination assays for the representative lines.................................42

Figure 7: Sequence analysis of the A26 cDNA insert.......................................43

Figure 8: Comparison of regulation of $A B I 3, A B I 4$ and $A B I 5$ transcripts in

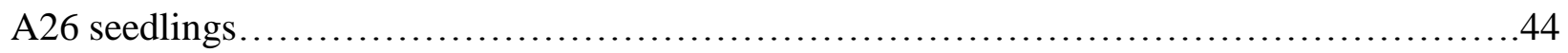

Figure 9: Germination assay with inducible A44 line and Gene induction study...............45

Figure 10: Sequence analysis of the A44 cDNA insert....................................46

Figure 11: Germination assay of independent ZFP3ox lines.............................47

Figure 12: Genetic interaction study of ZFP3 and abi genes.............................49

Figure 13: ZFP3 protein expression and stability .......................................50

Figure 14: Transcriptional regulation of ZFP3 gene....................................50

Figure 15: Phylogenetic tree of $24 \mathrm{C} 2 \mathrm{H} 2$ Zinc finger proteins belonging

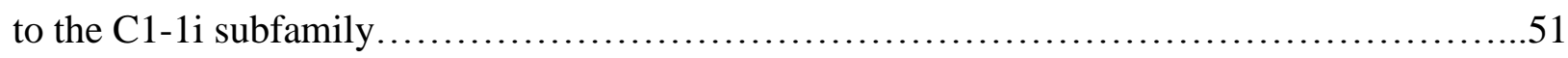

Figure 16: Multiple sequence alignment of 6 closely related proteins........................52

Figure 17: Cloning and overexpression of ZFP1, ZFP3, ZFP4, ZFP6,

ZFP7, ZFP8 factors in Arabidopsis plants..............................................53

Figure 18: Developmental regulation of 10 ZFP-related genes.............................54

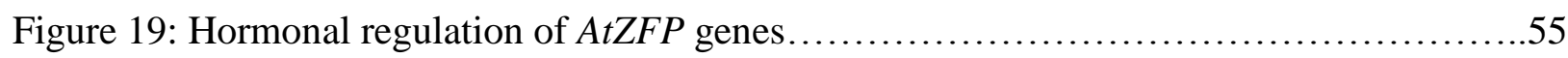

Figure 20: Histochemical assays show AtZFP3Promoter::GUS expression patterns..............56

Figure 21: Intracellular localization of the ZFP3 protein.................................57

Figure 22: Genotyping of $z f p 3$ (CS416946) and $z f p 4$ (SALK_038923)mutants.....................58 
Figure 23: Complementation of zfp3 mutant with ER8:ZFP3 construct....................59

Figure 24: ABA sensitivity of $z f p$ mutants in germination assay.........................60

Figure 25: ABA content measurement............................................61

Figure 26: Flowering determination in zfp3 mutant................................62

Figure 27: ABA insensitivity, seed yield and gene expression of 35S-ZFP3 lines............63

Figure 28: Constitutive ZFP3 over expression...................................64

Figure 29: Differentially regulated genes identified in transcript profiling experiment.........65

Figure 30: Gene Ontology terms of genes differentially regulated by ABA and ZFP3 ........69

Figure 31: ZFP3 modulates ABA-controlled gene expression..........................72

Figure 32: Expression of selected ZFP3-regulated genes in Col-0 and ZFP3ox for 3 hours.....73

Figure 33: Light regulation on hypocotyl growth................................... 74

Figure 34: Hypocotyl elongation of transgenic Arabidopsis lines overexpressing different

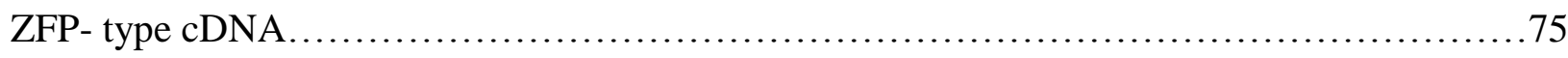

Figure 35: Relative hypocotyl lengths of wild type and ZFP3ox seedlings grown under

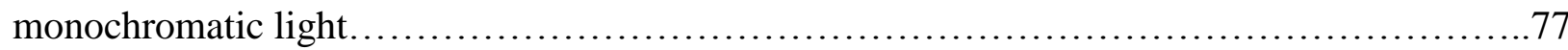

Figure 36: Genetic interaction of ZFP3 with phyB and phyA signaling components...........79

Figure 37: Hypocotyl elongation of transgenic abi mutant lines overexpressing ZFP3 .........80

Figure 38: Genetic interaction of ZFP3 and ABA signaling components...................81

Figure 39: Model of ZFP3 action in seed germination and plant development...............90

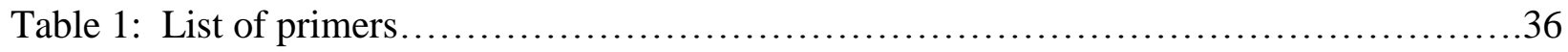

Table 2: Summary of the ABA screen................................................

Table 3: List of the identified genes, their description and length $\ldots \ldots \ldots \ldots \ldots \ldots \ldots \ldots \ldots \ldots . \ldots \ldots$

Table 4: Thirty three most ABA-induced genes.....................................67

Table 5: Expression profiles of ABA and ZFP3 regulated genes in Genevestigator transcript

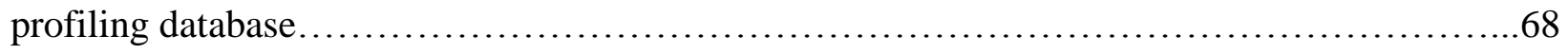

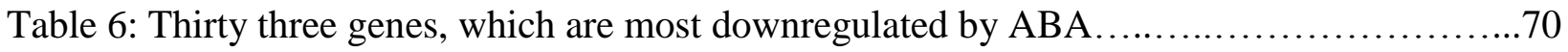


LIST OF ABBREVIATIONS

ABA

ABRE

$\mathrm{ABF} 2$

Abi

abi2-1

$\mathrm{ABI} 3$

ABI4

abi4-101

ABI5

ACC

ADH1-LUC

AP2/ERF

AREB1

At

AtHSP17.6A

AtPP2AC

AtZFP10

AtZFP11

BAC

BAP

BR

B3-

bZIP

CaMV35S

CAB
Abscisic acid

ABA response elements

ABRE-binding factor 2

abscisic acid insensitive mutants

ABA insensitive mutant, Encodes a protein phosphatase $2 \mathrm{C}$

ABA insensitive 3, The B3 domain transcription factor

ABA insensitive 4, ERF/AP2 transcription factor family

ABA insensitive 4 mutant

ABA insensitive 5, of the bZIP transcription factor family

1-Aminocyclopropane-1-carboxylic acid

alcohol dehydrogenase-luciferase

APETALA 2/ ethylene response factor transcription factor

abscisic acid-responsive element binding protein1

Arabidopsis thaliana

Heat shock protein 17.6

protein phosphatase catalytic subunit $2 \mathrm{~A}$

zinc finger protein 10

zinc finger protein 11

bacterial artificial chromosome

6-Benzylaminopurine, a cytokinin

Brassinosteriods

The B3 domain encodes a sequence-specific DNA binding

The Basic Leucine Zipper Domain

constitutive Cauliflower Mosaic Virus 35S promoter

chlorophyll $\mathrm{a} / \mathrm{b}$ binding protein 
Col-0

COS

CYP707A

Cys2His2

DELLA

DRE

DREB2A

DTT

EAR

ERF

FIS2

FR-HIR

GA

GABI

GAI

GIS

GRAS

GUS

HA

HY5

IAA

KNUCKLES

LATE

LC-MS/MS

LEA

LFR

LsABA80x 4
Arabidopsis wild type, Columbia ecotype

Controlled cDNA Overexpression System

Cytochrome P450, family 707, subfamily A, polypeptide2

two cysteines and two histidines

short stretch of amino acids (D-E-L-L-A) motif

Dehydration-responsive element

Dehydration-responsive element-binding protein 2A

dithiothreitol

ERF-associated amphiphilic repression motif

ethylene-responsive element binding factor

fertilization-independent seed

far-red high irradiance

Gibberellic acid

Genome Analysis in Biological Systems

gibberellic acid insensitive

GLABROUS INFLORESCENCE STEMS

GAI, RGA, SCR

b-glucuronidase

Human influenza hemagglutinin

LONG HYPOCOTYL 5

Indole-3-acetic acid, an auxin

$\mathrm{C} 2 \mathrm{H} 2$ type zinc finger protein

\section{LATE FLOWERING protein}

Liquid chromatography-tandem mass spectrometry

Late Embryogenesis Abundant proteins

low-fluence response

ABA 8'-hydroxylase 
MYB

MYC

NAC

NCED

pB2GW7

pER8

PIL5

PMSF

pPR97

PVDF

RGA

RGL1

RGL2

RGL3

RD29B

RAB18

JAGGED

NUBBIN

SA

SALK

SAZ

SDS

SERRATE

SNAP-LITE LED

SPINDLY

SUPERMAN transcription factor contains myb domain basic helix-loop-helix (bHLH) DNA-binding protein ABA responsive NAC domain transcription regulator 9-cis-epoxycarotenoid dioxygenase GATEWAY based CaMV 35S promoter vector Gateway based Estradiol-inducible expression vector PHYTOCHROME-INTERACTING FACTOR3-LIKE5

Phenylmethanesulfonyl Fluoride

Agrobacterium binary vector with 35 S promoter

polyvinylidene difluoride

REPRESSOR OF GA

RGA LIKE-1

RGA LIKE-2

RGA LIKE-3

RESPONSIVE TO DESSICATION 29B

RESPONSIVE TO ABA 18

$\mathrm{C} 2 \mathrm{H} 2$-zinc finger transcription factor

$\mathrm{C} 2 \mathrm{H} 2$-zinc finger transcription factor

Salicylic acid

Salk Institute Genomic Analysis Laboratory

$\mathrm{C} 2 \mathrm{H} 2$ type zinc finger protein

sodium dodecyl sulphate

$\mathrm{C} 2 \mathrm{H} 2$ type zinc finger protein

light emitting diode, Quantum Devices

$\mathrm{N}$-acetyl glucosamine transferase, GA signaling

zinc finger transcription factor 
T-DNA

$\mathrm{TF}$

VP1

WRKY

X-Gluc

ZEP transfer DNA

transcription factor

VIVIPAROUS 1 protein

zinc finger transcription factor

5-Bromo-4-chloro-3-indolyl- $\beta$-D-glucuronide

zeaxanthin epoxidase gene 


\section{PREFACE}

Plant growth and development are regulated by internal signals like hormones and by external environmental conditions such as light, touch and temperature. One important regulator that coordinates growth and development with responses to the environment is the sesquiterpenoid hormone abscisic acid (ABA). The most extensively investigated developmental and physiological effects of $\mathrm{ABA}$ are those involved in seed maturation, dormancy, and the regulation of stomata.

In addition to its role in plant development, $\mathrm{ABA}$ plays an important role in the stress response and tolerance of plants to drought, high salinity and to a certain extent cold stress. When plants perceive signals due to changes in ABA levels, either during stress or during development, they respond at the molecular level through signal transduction pathways controlling downstream cellular signaling processes. The effects on whole are manifold and can influence germination, emergence, leaf, root, tiller and stem development and growth, dry matter production, floral initiation, panicle exertion, pollination, fertilization, seed growth, seed yield, and seed quality.

ABA induces the expression of many genes whose products are positive and negative regulators of ABA signaling, transcription factors and enzymes that are involved in the synthesis of osmoprotectants. Revealing ABA induced changes in the Arabidopsis transcriptome will greatly improve our understanding of the regulatory effects of the signal transduction pathway. Therefore, our primary interest was to identify and characterize novel elements influencing ABA-mediated responses and understand the molecular mechanisms integrating ABA and stress signals. 


\section{INTRODUCTION}

\subsection{Overview of ABA regulated processes}

The phytohormone ABA, plays a variety of important roles in plant development such as synthesis of seed storage proteins and lipids, the promotion of seed desiccation tolerance and dormancy, and the inhibition of phase transitions from embryonic to germinative growth and from vegetative to reproductive growth (Leung and Giraudat 1998; Rock 2000; Rohde 2000; Zhu 2002). In addition to its involvement in developmental pathways, ABA is the most important hormone that is produced under drought stress conditions and is essential for the response such as activation of genes involved in osmotic adjustment, ion compartmentation, regulation of shoot versus root growth and modifications of root hydraulic conductivity (Hose 2000; Thompson 2007b; Thompson 2007a; Verslues and Zhu 2005; Ruggiero 2004).

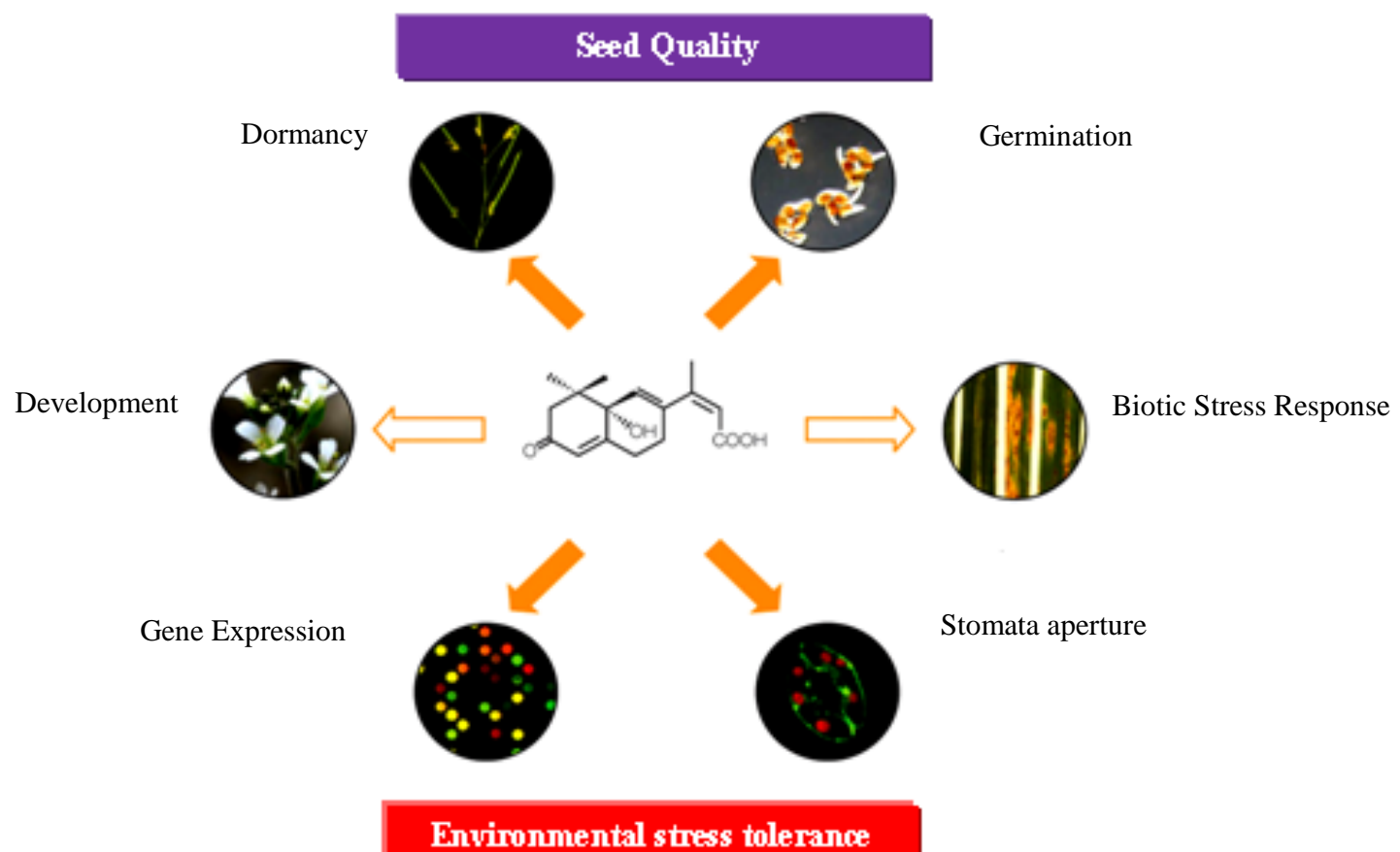

Figure 1: ABA regulation in the life cycle of a plant. Schematic outline of the importance of the plant hormone Abscisic acid (ABA), which controls a broad variety of crucial activities relating to plant development and survival (Source: RIKEN Plant Science Center). 


\subsubsection{ABA response in plants}

The products of the stress-inducible genes have been classified into two groups: those that directly protect against environmental stresses and those that regulate gene expression and signal transduction in the stress response (Shinozaki and Yamaguchi-Shinozaki 1997). The first group includes proteins that function by protecting cells against dehydration, such as the enzymes required for biosynthesis of various osmoprotectants, late-embryogenesis-abundant (LEA) proteins, antifreeze proteins, chaperones, and detoxification enzymes (Ingram and Bartels 1996; Bray 1997; Shinozaki and Yamaguchi-Shinozaki 1997, 2000, 2007; Yamaguchi-Shinozaki and Shinozaki 2006; Choudhary 2009). The second group of gene products includes transcription factors, protein kinases, and enzymes involved in phosphoinositide metabolism (Shinozaki and Yamaguchi-Shinozaki 1997, 2000; Yamaguchi-Shinozaki and Shinozaki 2006).

It is known that there are at least two distinct responses for $\mathrm{ABA}$, one for the fast reaction and one for the slow reaction. Stomatal response and closure brought about by ABA is a fast reaction, whereas the rest of the response is slower and require changes in gene expression (Milborrow 1974; Cummins 1971; Chandler 1994). Several hundred genes that respond to drought stress at the transcriptional level have been identified by transcriptome analyses and other means. ABA treatment specifically induces changes in gene expression in more than $\sim 10 \%$ of the Arabidopsis genome, resulting in the increased expression of stress associated and signaling component transcripts (Hubbard 2010; Acevedo-Hernández 2011). Many genes induced by stress challenges include those encoding transcription factors (TFs) and some of them have been shown to be essential for stress tolerance (Jin 2000; Riechmann 2000; Riechmann and Ratcliffe 2000).

Most of these TFs belong to several large TF families, such as AP2/ERF, bZIP, NAC, MYB, MYC, Cys2His2 zinc-finger and WRKY. The most important TFs playing role in stress responses are ABA-RESPONSIVE ELEMENT BINDING PROTEIN 1 (AREB1)/ABARESPONSIVE ELEMENT (ABRE)-BINDING FACTOR 2 (ABF2) and DEHYDRATIONRESPONSIVE ELEMENT (DRE)-BINDING PROTEIN 2A (DREB2A) (Fujita 2005; Furihata 2006; Sakuma 2006a; Sakuma 2006b). It has been shown that the overexpression of some 
drought-responsive transcription factors leads to the expression of downstream genes and the enhancement of drought tolerance (Zhang 2004; Aharoni 2004; Umezawa 2006; Hu 2008).

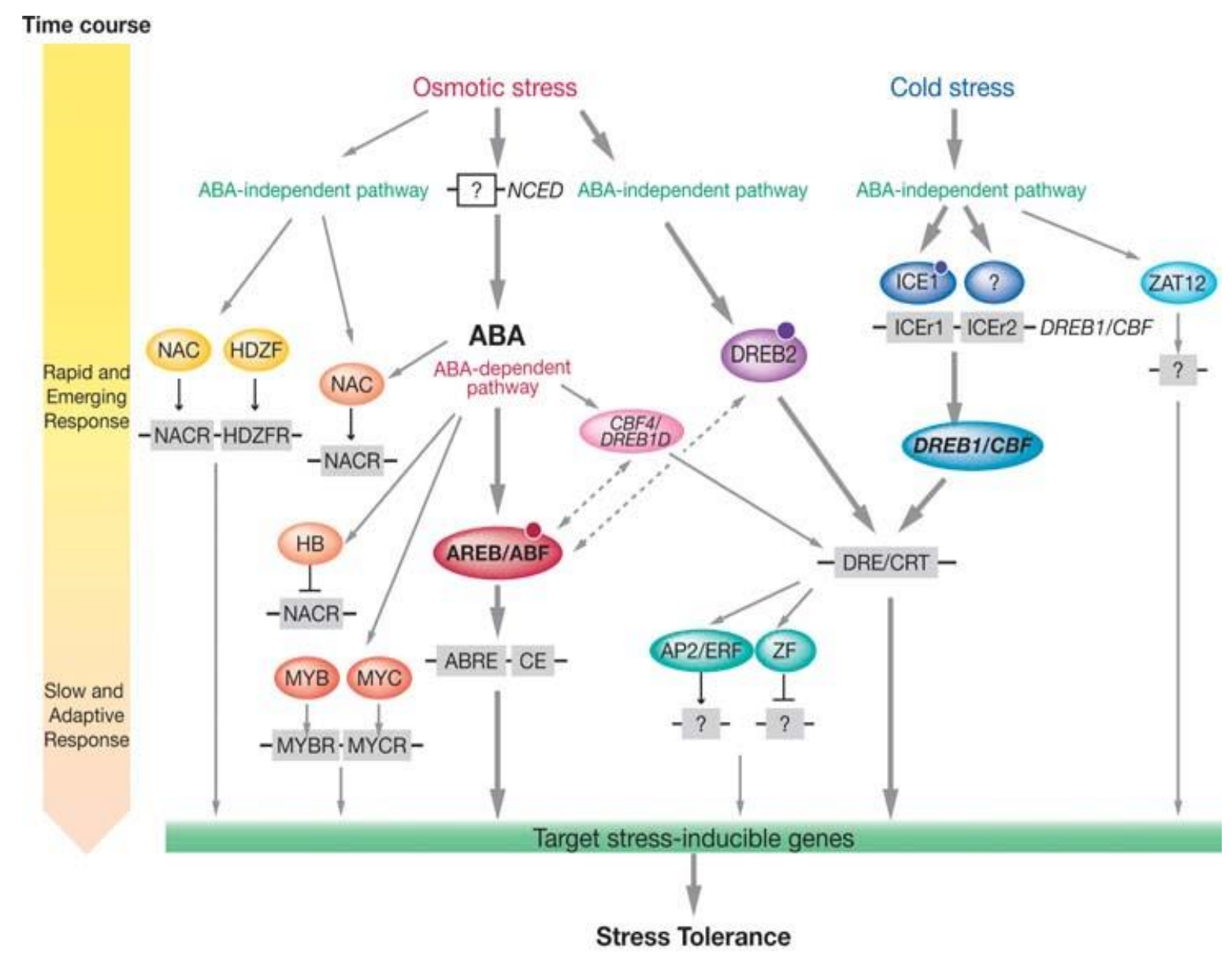

Yamaguchi-Shinozaki K, Shinozaki K. 2006.

R Annu. Rev. Plant Biol. 57:781-803

Figure 2: Transcriptional regulatory networks of cis-acting elements and transcription factors involved in abiotic (osmotic, drought, cold) responsive gene expression in Arabidopsis. Transcription factors controlling stress-inducible gene expression are shown in colored ellipses. cisacting elements involved in stress-responsive transcription are shown in boxes. Small filled circles reveal modification of transcription factors in response to stress signals for their activation, such as phosphorylation. Regulatory cascade of stress-responsive gene expression is shown from top to bottom. Early and emergency responses of gene expression are shown in the upper part, and late and adaptive responses in the bottom. Thick gray arrows indicate the major signaling pathways and these pathways regulate many downstream genes. Broken arrows indicate protein-protein interactions (YamaguchiShinozaki and Shinozaki 2006). 


\subsubsection{Key players of $A B A$ signaling}

Insight into the molecular basis of $\mathrm{ABA}$ responses was gathered by a combination of molecular-genetic, biochemical, and electrophysiological studies (Koornneef M 1984; Finkelstein 1994; Li and Assmann 1996; Umezawa 2004; Mori 2006; Seki 2007). ABA response mutants are mainly categorized into two groups: the abi mutants and the ABA-hypersensitive (enhanced response to ABA, era) mutants. So far, the characterization of 5 abi and 3 era loci has largely contributed to the understanding of ABA signal transduction. The five abi mutants of Arabidopsis were identified by their ability to germinate on inhibiting concentrations of ABA, the three era mutants showed an increased dormancy in the presence of low ABA concentrations, compared to wild type. Besides their effects on seed development and dormancy, these mutants show altered responses to drought adaptation. The abi mutants differ from $a b a$ mutants, in that they do not have reduced endogenous ABA content and their phenotype cannot be reverted by exogenously supplied ABA (Schwartz 1997). The characterization of the abi mutants revealed that at least two ABA-response pathways exist: one primarily active in vegetative tissues, involving $A B I 1$ and $A B I 2$, and a second one operating predominantly during seed development (Giraudat 1992; Leung 1994; Cutler 1996; Leung 1997; Pei 1998; Bonetta 2000; Finkelstein and Lynch 2000;).

\subsubsection{The type-2C protein phosphatases, $A B I 1$ and $A B I 2$ genes}

The ABA INSENSITIVE1 $(A B I 1)$ and $A B I 2$ genes encode homologous type-2C protein phosphatases with redundant yet distinct functions in ABA responses (Meyer 1994; Bertauch 1996; Leube 1998; Rodriguez 1998; Gosti 1999). Measurements of PP2C activity in plant extracts showed that the phosphatase activity of $\mathrm{ABI} 1$ and $\mathrm{ABI} 2$ increases in response to $\mathrm{ABA}$ (Merlot 2001). ABI1 and ABI2 act in a negative feedback regulatory loop of the ABA signaling pathway (Koornneef M 1984; Finkelstein and Somerville 1990; Vartanian 1994). The sole mutant alleles, abil-1 and abi2-1, are both missense mutations of a conserved glycine to aspartate that result in a dominant negative phenotype in vivo and in vitro (Sheen 1998). ABII and $A B I 2$ are important components of early $\mathrm{ABA}$ signaling such as, ABA induced stomatal closing (Pei 1997). The mutations affect gene expression in seeds and vegetative tissues, seed dormancy and germination, and adaptive growth (Leung and Giraudat 1998; Grill E 1998). 


\subsubsection{The Viviparous1/ ABI3 gene}

$\mathrm{ABI} / \mathrm{VP} 1$, B3 DNA binding domain-containing transcription factor that acts mainly during seed development and is the orthologue of $V P 1$ in maize (Finkelstein 1994). ABI3/VP1 mediates the ABA signal to regulate several classes of seed-specific genes, including the maturation (MAT) class and the late embryogenesis abundant (LEA) class in a range of species (Hughes DW 1989; Parcy F 1994; Jones H.D. 1997; Zeng 2003). Although ABI3/VP1 mainly functions in seed development, it also has broader functions, such as plastid development, flowering time, and outgrowth of axillary meristems (Rohde 2000). It also promotes seed maturation processes including storage reserve deposition, the acquisition of desiccation tolerance and the imposition of dormancy (McCarty 1995; Li B 1997). Seeds of severe abi3 mutants in Arabidopsis accumulate less storage protein, are desiccation-intolerant, and germinate precociously (Nambara 2000).

\subsubsection{The AP2/ ERF transcription factor, $A B I 4$ gene}

$A B I 4$ encodes a member of $\mathrm{AP} 2 / \mathrm{ERF}$ transcription factor family that is important for ABA signaling during seed development and germination (Finkelstein 1998). However, the function of this factor is also crucial for other aspects of plant development including lipid mobilization from the embryo, chloroplast retrograde signaling, and glucose responses (ArenasHuertero 2000; Huijser 2000; Laby 2000; Penfield 2006; Koussevitzky 2007). ABI4 is expressed in discreet developmental windows, namely during seed maturation and in seedlings shortly after germination (Soderman 2000; Arroyo 2003). In seedlings, its expression pattern overlaps with the establishment of autotrophic growth following a similar pattern to the one observed for the transcription factor ABI5 (Lopez-Molina 2001; Brocard 2002). The expression of ABI4 is regulated by several factors such as ABA, glucose, and trehalose (Arroyo 2003; Ramon 2007). abi4 mutant alleles display increased tolerance to osmotic and salt stress during germination and early seedling growth (Quesada 2000). $A B I 4$, and to a lesser extent $A B I 5$, are also required for the developmental arrest and anthocyanin accumulation induced by exposure to high concentrations of sugars within the first $2 \mathrm{~d}$ post-stratification. ABI4 is proven to down regulate photosynthetic genes by binding to their promoters (Acevedo-Hernandez 2005; Rook 2006). 


\subsubsection{The bZIP transcription factor, $A B I 5$ gene}

The $A B I 5$ locus encodes a basic leucine zipper transcription factor whose accumulation inhibits seed germination and early seedling establishment (Lopez-Molina and Chua 2000; Finkelstein and Lynch 2000b). ABA added exogenously or produced in response to osmotic stress prevents germination and confers osmotolerance by stimulating the de novo accumulation of ABI5. ABA dependent repression of seed germination can occur only within a limited time window of $\sim 48 \mathrm{~h}$ after imbibition (Lopez-Molina and Chua 2000; Lopez-Molina 2001). Mature seeds contain high levels of ABA and high amounts of $A B I 5$ and $L E A$ gene products. ABI5 is expressed during seed maturation, seed germination, young seedlings and the highest expression level was detected at the transition from mature seeds to seedling growth (Soderman 2000; Brocard 2002). ABI5 activates the transcription of Late Embryonic and Abundant (LEA) genes, whose products confer osmotolerance to the embryo (Finkelstein and Lynch 2000a; LopezMolina and Chua 2000).

\subsection{The COS system for screening novel ABA regulatory genes}

The plant hormone ABA regulates many key processes in plants. Cloning of genes whose expression is up-regulated by drought, cold or salt stress identified several targets and regulators of ABA signaling (Serrano R 1994; Ingram 1996; Hasegawa 2000). The majority of gene functions controlling responses to high salinity, drought, and cold were discovered using forward genetic screens of mutagenized Arabidopsis (Arabidopsis thaliana) populations. Moreover, forward genetic approaches unraveled important components of drought, cold, and ABA signaling pathways (Thomashow 1999; Yamaguchi-Shinozaki K 2006). An Arabidopsis cDNA library driven by the constitutive CaMV35S promoter has been used to generate transgenic Arabidopsis lines, showing altered developmental traits (Fukazawa 2000; Garcia-Maroto 2000; Hewelt 1994; Nandi 2000; LeClere and Bartel 2001). Transfer and expression of cDNA libraries in plants also yield gain-of-function phenotypes. The Full-length cDNA Over-eXpressing gene hunting system (FOX) in a similar way uses a normalized full-length cDNA collection under the control of the constitutive CaMV35S promoter, and offers a technique to identify novel gain-offunction phenotypes in Arabidopsis (Ichikawa T. 2006) These cDNA libraries were used in different genetic screens to identify several important regulatory factors in hormonal and stress 
signaling. AtPP2Ac gene, encoding an unknown protein phosphatase, which plays an important regulatory role in $\mathrm{ABA}$-controlled closure of stomata and thereby controls drought tolerance, was identified by screening a collection of cDNA overexpressing plants for ABA independent germination (Kuhn 2006). Three of the well characterized positive regulators of ABA signaling so far are the transcription factors encoded by $A B I 3, A B I 4$ and $A B I 5$, which were initially identified in screens for mutants exhibiting ABA-resistant germination. The gain-of-function strategy using the ectopic expression of transcription factors has been already used. Constitutive ectopic expression of SUPERMAN, AtZFP10 and AtZFP11 resulted in abnormal or lethal plants which could not be used for study (Bereterbide 2002; Dinkins 2003; Dinkins 2012). High level and constitutive expression of regulatory genes can disturb cell proliferation and development resulting in dwarf and sterile plants (Kasuga 1999; Gilmour 2000). The Controlled cDNA Overexpression System (COS) was created in our laboratory to overcome the problems caused by the constitutive gene activation. The COS system was created in a Gateway version of the Estradiol-inducible pER8 plasmid, in which transcription of the inserted cDNA is strictly controlled by the addition of the inducer (Zuo 2000). The COS system was used to identify a set of cDNAs conferring dominant stress-tolerance phenotypes in three different genetic screens: tolerance to salt stress, insensitivity to $\mathrm{ABA}$ and activation of the stress-induced ADH1-LUC reporter gene (Papdi 2008). We have shown that screening for ABA insensitive germination lead to the identification of numerous lines displaying Estradiol-dependent ABA insensitivity indicating that the COS technology could effectively support this screening strategy. 


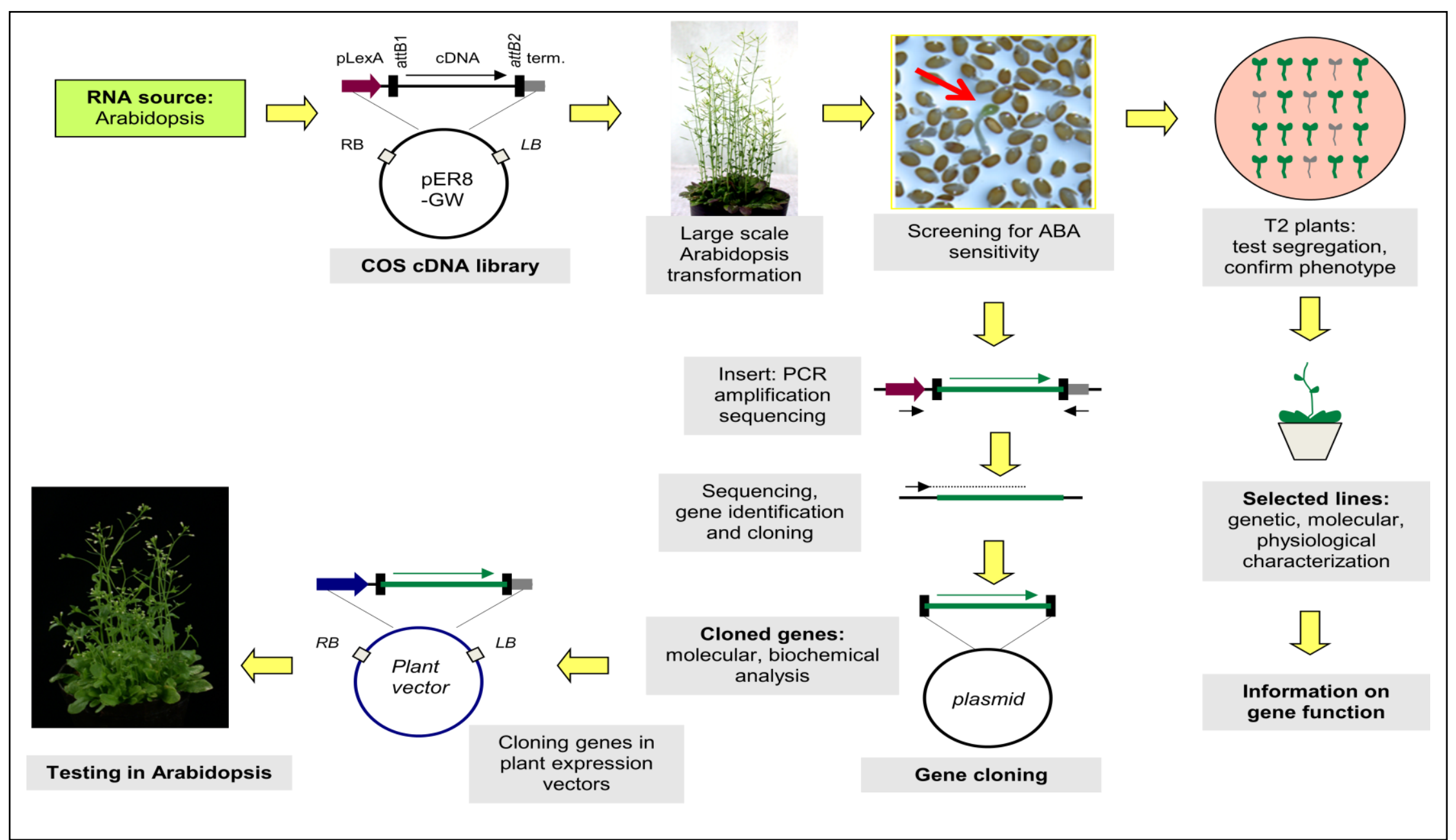

Figure 3: Schematic representation of the COS cDNA library transformation and genetic screen to identify ABA regulatory genes. An Arabidopsis cDNA library was constructed from different Arabidopsis organs, dark-grown, green, salt-stressed seedlings and cultured cells. The cDNA library was subsequently transferred into pER8GW, a Gateway version of Estradiol-inducible expression vector pER8, which carries an attR1 and attR2 recombination cassette. The COS library was introduced into Agrobacterium and was subsequently transformed into wild-type ecotype Columbia of Arabidopsis (Col-0) plants followed by screening for ABA insensitive germination of transformed T1 seeds. T2 progenies of selected plants were re-tested for ABA insensitivity(Papdi 2008). 


\subsection{Germination assay, an ideal tool to isolate $\mathrm{ABA}$ and related stress regulatory genes}

Seed germination is the first developmental process in the life cycle of a plant. The transition between dormancy and germination represents a critical stage and is an important ecological and commercial trait. Seeds are thought to carefully monitor external parameters as light, temperature and nutrient in order to maintain the protective state until external conditions become favorable for following developmental processes (Karssen 1982; Pritchard 1993; Bungard 1997). However, within the first 48 hours upon imbibition, a sudden osmotic stress or exposure to the stress hormone $\mathrm{ABA}$ can delay or block any of the developmental transition steps (Lopez-Molina 2001). It has been shown earlier that germination assays and in particular $\mathrm{ABA}$ resistant germination assays can be an excellent tool in identifying genes involved in $\mathrm{ABA}$ and related stress signaling pathways (Lopez-Molina 2001; Lopez-Molina 2002; Papdi 2008). Studying the regulation of germination can shed light also on other phases of plant development such as hypocotyl growth, plant architecture, photosynthesis, plasticity, reproduction, transition from vegetative to reproductive phase, flowering, seed development and the dynamic balance between the ABA and gibberellins (GAs) and brassinosteriods (BRs) and ethylene. Therefore the function of the germination-controlling network has wide-range of implications for plant development.

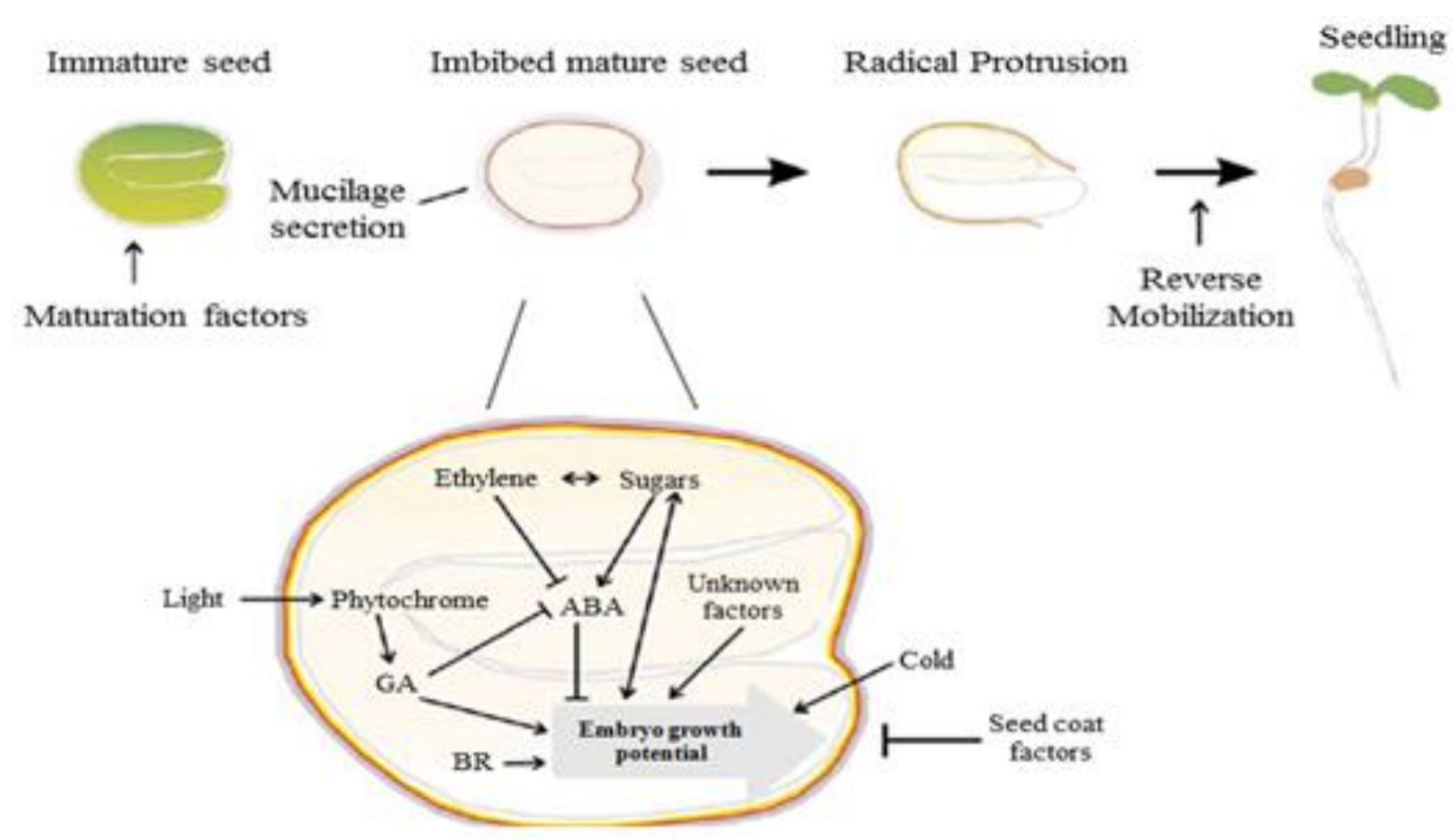

Figure 4: Graphical representation of a seed to seedling stage and overview of different controlling factors during this transition phase (Bentsink 2002). 


\subsection{The germination controlling networks}

\subsubsection{Interaction of light and hormone signals in germinating seeds}

Light, is an important regulator of seed germination, it plays a crucial role in detecting seed's position. Phytochromes are the major class of photoreceptors responsible for this process, which regulate seed germination by sensing and transmitting red and far-red light signals (Shinomura 1994). The Arabidopsis genome contains five phytochromes, PHYA to PHYE (Quail 1998), which regulate shared and also distinct physiological processes in response to different light spectra and fluences. For germination, PHYA promotes germination in response to far-red light by very low fluence response and high irradiance response (FR-HIR), while PHYB promotes germination in response to red light LFR (Shinomura 1996; Shinomura 1994). Light signals perceived by the phytochromes are converted to internal stimulus, which in turn regulate physiological process in seeds. ABA and GA are the internal signals that play central role in the regulation of seed germination. A dynamic balance between synthesis and catabolism of ABA and GAs controls the equilibrium between dormancy and germination, where ABA inhibits and GA induces seed germination (Olszewski 2002; Nambara and Marion-Poll 2005; Gutierrez 2007).

\subsubsection{Regulation of $\mathrm{ABA}$ by light}

Light quality has an important role in the control of ABA synthesis. ABA treatment inhibits germination of lettuce seeds induced by Red light or by exogenous application of bioactive GAs (Khan 1968; Sankhla 1968). In Arabidopsis, ABA-deficient mutant seeds have been shown to partially germinate even in the absence of inductive light (Seo, 2006). Red light inhibits the expression levels of ABA biosynthetic genes encoding ZEP (AtZEP1/AtABA1 in Arabidopsis) and NCED (AtNCED6 and AtNCED9 in Arabidopsis and LsNCED2 and LsNCED4 in lettuce), while far-red light has the opposite effect. On the other hand, transcript levels of ABA deactivating genes encoding CYP707A (CYP707A2 in Arabidopsis and LsABA80x4 in lettuce) are elevated by Red light treatment (Seo 2006; Oh 2007; Sawada 2008). Genetic studies

in Arabidopsis have identified roles for phytochrome, PHYB and PHYE in the R/FR reversible promotion of seed germination (Shinomura 1994; Hennig 2002). 


\subsubsection{Interaction between $G A$ and $A B A$}

In contrast to $\mathrm{ABA}$, GA levels are initially very low in dry seeds and rise upon imbibition. Genetic studies have shown that GA biosynthesis is not required for germination in an ABA-deficient mutant background (Koornneef 1982; Seo 2006). Increased GA levels lead to the degradation of DELLA protein RGA-LIKE2 (RGL2), a putative GRAS family transcription factor repressing seed germination (Lee 2002). There are four other DELLA factors present in Arabidopsis, REPRESSOR OF GA1-3(RGA), GA-INSENSITIVE (GAI), RGA-LIKE1 (RGL1) and RGA-LIKE3 (RGL3), and all are expressed during seed germination (Tyler 2004). However, RGL2 is a key element in repressing seed germination (Lee 2002). It is shown that RGA overaccumulation stimulates ABA synthesis (Ko 2006; Zentella 2007). High ABI5 levels have been reported in the absence of GA synthesis and high RGL2 levels were found in ABAtreated seeds, indicating that both ABI5 and RGL2 participates to repress seed germination (Piskurewicz 2008).

\subsubsection{Factors that link light signal to GA and ABA}

Phytochromes modulate GA and ABA metabolism through one of their interacting proteins, PHYTOCHROME-INTERACTING FACTOR3-LIKE5 (PIL5), a basic helix-loophelix transcription factor. Loss-of-function pil5 mutant seeds show reduced germination in response to red light, whereas the PIL5 overexpressor requires the higher fluence of red light for seed germination. PIL5 inhibits seed germination by lowering bioactive GA levels in the absence of light, at least partly by repressing the transcription of GA biosynthetic gene GIBBERELLIN 3ß-HYDROXYLASE1 (GA3ox1) and GA3ox2 and activating a GA catabolic gene (GA2ox2), (Oh 2004; Oh 2006; Oh 2007). PIF1/PIL5 and transcription factor SPATULA (SPT) integrate light and temperature signals to modulate germination, primarily through the transcriptional regulation of GA and ABA metabolism, catabolism and response genes. This provides a means to modulate active GA and ABA levels in the seed. DELLA genes, RGA and GAI, are direct target genes of PIL5 (Oh 2007). The role of ABI5 in light signaling is intriguing. The central light signaling regulator, HY5, mediates also ABA response in late embryogenesis-abundant (LEA) gene expression, seed germination, seedling establishment and root growth by regulating the transcription of ABI5 (Seo 2006). It has been shown that ABA specifically enhances HY5 
binding to the ABI5 promoter in the chromatin and ABI5 sensitizes light repression of hypocotyl elongation (Chen 2008).

\subsection{The C2H2-type single zinc finger proteins}

\subsubsection{C2H2-type zinc-finger protein family}

The C2H2-type zinc-finger proteins represent a large family of eukaryotic transcription factors. The majority of such proteins characterized to date are DNA-binding transcription factors, and many have been shown to play crucial roles in the development of plants, animals and fungi (Coleman 1992; Fairall 1993; Takatsuji 1998). Arabidopsis Zinc Finger Protein constitute a subfamily of C2H2-type zinc-finger proteins (ZFPs), also called the TFIIIA-type zinc-finger proteins (Miller 1985). The canonical ZF (zinc finger) sequence (CX24CX3FX5LX2HX3-5H) contains two cysteines and two histidines that coordinate a zinc atom, creating a compact nucleic acid-binding domain. A recent in silico analysis revealed that there are $176 \mathrm{C} 2 \mathrm{H} 2$-type zinc finger proteins in Arabidopsis thaliana with only 33 of them conserved with other eukaryotes and $81 \%$ of them are plant specific (Englbrecht 2004). These genes encode proteins that contain a single $\mathrm{C} 2 \mathrm{H} 2$-type zinc-finger motif with the short amino acid sequence QALGGH within the zinc-finger domain (Tague 1995; Takatsuji 1998). Other domains can include class II ethylene responsive element-binding factor (ERF)-associated amphiphilic repression (EAR) motif-like transcriptional repression domain at the carboxy-terminal region and also a leucine-rich region involved in protein-protein interaction (Kagale 2010; Ohta 2001; Takatsuji 1998).

\subsubsection{Diverse roles played by single zinc fingers}

Published experimental results have identified about $30 \mathrm{C} 2 \mathrm{H} 2$ ZFPs in higher plants. Several members of this family have been implicated in flower organogenesis, development of stamens and the carpel (Bowman 1992; Sakai 1995; Tague 1995; Tague 1996; Prigge 2001; Nakagawa 2004; Payne 2004; Takeda 2004; Satoh-Nagasawa 2006), the control of the transition from vegetative to reproductive growth, plant growth and morphogenesis, leaf initiation, lateral shoot initiation, gametogenesis and seed development (Colasanti 1998; Luo 2000; Takatsuji 1999; Chrispeels 2000; Dinkins 2002; Dinkins 2003; Ohno 2004; Nakagawa 2005; Vollbrecht 
2005; Satoh-Nagasawa 2006). Molecular functions include chromatin regulation (Luo1999; Pedone 1996; Prigge 2001), RNA binding (Friesen 2001; Machida 2011), pre-mRNA splicing and microRNA processing (Laubinger 2008) and telomerase activation (Ren 2004).

\subsubsection{Members of AtZFP family}

Until now some members of this family have been characterized. It has been reported that AtZFP1, a C2H2 transcription factor with a single $\mathrm{C} 2 \mathrm{H} 2$ zinc-finger domain is expressed at high levels in the shoot apex, including the apical meristem, developing leaves and the developing vascular system. Interestingly, AtZFPl is expressed during light-dependent development, however it does not require light for its expression. Possible role for AtZFPl in post-embryonic development and in shoot development, downstream of photomorphogenic activation has been reported (Chrispeels 2000). The SERRATE (SE) gene encodes another single zinc finger protein and is expressed in the shoot meristem, in young leaf primordia and in the margins of older leaves (Prigge 2001; Clarke 1999), the serrate mutant of Arabidopsis displays defects in the initiation and elaboration of cotyledons and post-embryonic lateral organs. SE was also suggested to regulate changes in gene expression via chromatin modification (Prigge 2001) or through modulating miRNA processing (Grigg 2005; Lobbes 2006; Yang 2006).

Fertilization-independent seed development (fis) mutants have been obtained in Arabidopsis in which some stages of seed development take place in the absence of fertilization (Chaudhury 1997). It was suggested that FIS2 might act to repress the seed development program prior to fertilization (Luo 1999). It has been suggested that SUPERMAN restricts proliferation of certain classes of cells to define whorl boundaries in the developing flower (Sakai 1995) and mutations at the SUP locus result in the production of extra stamens in the place of normal carpel development and affect the development of both ovules and pollen

(Bowman 1992; Gaiser 1995; Riechmann 2000). KNUCKLES function as a transcriptional repressor of cellular proliferation that regulates floral determinacy and relative size of basal pattern elements along the proximo-distal axis of the developing Arabidopsis gynoecium (Payne 2004). LATE FLOWERING (LATE) encodes a $\mathrm{C} 2 \mathrm{H} 2$-type zinc-finger transcriptional regulator and is expressed in the leaf vasculature and in the vegetative shoot apical meristem. Ectopic expression of LATE in all tissues results in a dose-dependent phenotype characterized by late 
flowering, altered floral organ identity and sterile flowers. Using tissue specific promoters it was shown that $L A T E$ controls the transition to flowering at two levels: first, it regulates the expression of flowering time genes in the leaf vasculature, and second, it interferes with floral meristem identity genes at the apex (Weingartner 2011). Another single zinc finger gene $S A Z$, is involved in the negative regulation of ABA-mediated signaling. $S A Z$ transcripts were expressed in the leaves and pistils of very young fower buds. In young seedlings, $S A Z$ expression was down regulated in response to environmental stresses such as drought, salt, ozone and ultraviolet-B irradiation. This down regulation was also observed in response to the phytohormones salicylic acid (SA) and abscisic acid (ABA). RNAi-mediated knockdown of $S A Z$ resulted in elevated expression of the drought- and ABA-responsive genes $R D 29 B$ and $R A B 18$ under unstressed conditions, and it enhanced the response of these genes to drought and ABA treatment (Jiang 2008). It has been shown that $J A G G E D$, another gene with a single $\mathrm{C} 2 \mathrm{H} 2$ zinc-finger domain, controls the morphogenesis of lateral organs in Arabidopsis. Loss of JAGGED function causes organs to have serrated margins and suppresses the premature differentiation of tissues, which is necessary for the formation of the distal region (Dinneny 2004). NUBBIN (NUB), a gene closely related to $J A G$, is responsible for this redundancy. $N U B$ is exclusively expressed in leaves, stamens and carpels, and is transient and can only be detected during the initial outgrowth of the primordia. $N U B$ acts redundantly with $J A G$ to promote the growth of the pollen-bearing microsporangia of the anthers and the carpel walls of the gynoecium, which enclose the ovules. $J A G$ and $N U B$ also act redundantly to promote the differentiation of adaxial cell types in the carpel walls, and in the establishment of the correct number of cell layers (Dinneny 2006). The AtZFP10 gene was found to be expressed in flowers, axillary meristems, roots and stems of Arabidopsis. Ectopic expression of the AtZFP10 gene in tobacco resulted in abnormal plants that were dwarfed, had abnormal leaf morphology, flowered early and most of the plants were sterile. In spite of the reduced size and early flowering, overexpression of $A t Z F P 10$ does not appear to affect the developmental flowering program in the plants as the number of leaves at flowering was similar in both the transgenic and wild-type plants (Dinkins 2003). The AtZFP11 promoter study demonstrated that expression was primarily in the anthers and in the carpel. Similar to AtZFP10, transgenic plants constitutively overexpressing the AtZFP11 protein displayed severe abnormalities. Microarray and RT-PCR analysis in plants overexpressing AtZFP11 revealed 
changes in expression of a number of genes involved in auxin, jasmonic acid, and stress responses suggesting that $A t Z F P 11$ plays a role in regulation of gene expression and may be functionally redundant (Dinkins 2012). Promoter ZFP2- $\beta$-glucuronidase expression was elevated in stamen, petal, and sepal abscission zones (AZs). Flower parts of transgenic lines overexpressing AtZFP2 exhibited asynchronous and delayed abscission. Abscission defects were accompanied by altered floral morphology limiting pollination and fertility. Hand-pollination restored transgenic fruit development but not the rapid abscission seen in wild-type plants, demonstrating that pollination does not assure normal rates of detachment. In wild-type stamen abscission zones, AtZFP2 is significantly up-regulated postanthesis. Phenotype data from transgene overexpression studies suggest that $A t Z F P 2$ participates in processes that directly or indirectly influence organ shed (Cai 2008). GLABROUS INFLORESCENCE STEMS (GIS) regulates shoot maturation, as loss-of-function mutations affect the epidermal differentiation of inflorescence organs, causing a premature decrease in trichome production on successive leaves, stem internodes, and branches. The discovery of GIS reveals a novel mechanism in the control of shoot maturation, through which GAs regulate cellular differentiation in plants. GIS is required for the control of trichome branching in Arabidopsis through two different pathways and acts either upstream or downstream of the negative regulator of gibberellic acid signaling SPINDLY (SPY) (Gan 2006; An 2012). It has been shown that like GIS, ZFP8 and GIS2, all encode C2H2 transcription factors, play partially redundant and essential roles in inflorescence trichome initiation and in its regulation by GA and cytokinins. These roles are reported to be consistent with their pattern of expression and with the regional influence of GA and cytokinins on epidermal differentiation (Gan 2007; Gan 2006). Recently another C2H2 zinc finger protein, ZINC FINGER PROTEIN 5 (ZFP5), has been shown playing an important role in controlling trichome cell development through GA signaling. Overexpression of ZFP5 resulted in the formation of ectopic trichomes on carpels and other inflorescence organs. zfp 5 loss-of-function mutants exhibit a reduced number of trichomes on sepals, cauline leaves, paraclades and main inflorescence stems, in comparison to wild-type plants. More importantly, it was found that ZFP5 mediates the regulation of trichome initiation by gibberellins. The molecular analyses suggest that ZFP5 functions upstream of GIS, GIS2, ZFP8, and key trichome initiation regulators GL1 and GL3. Using steroid-inducible activation of ZFP5 and chromatin immunoprecipitation 
(ChIP) assay, it has been demonstrated that ZFP8 is the direct target of ZFP5 in controlling epidermal cell differentiation (Zhou 2011). These results show that little is known about the role of this family- $\mathrm{C} 2 \mathrm{H} 2$-type ZFPs, especially the single zinc finger during germination or post embryonic growth, stress or ABA signaling and their role in light dependency. Although the number of publication has been increasing recently, further experiments are needed to clarify the precise role of individual members of this $\mathrm{C} 2 \mathrm{H} 2$ family. 


\section{OBJECTIVES}

The COS system was previously created and employed in our laboratory to identify a set of cDNAs conferring dominant stress-tolerance phenotype (Papdi 2008). Our primary interest here has been to use the COS system to identify novel regulators and to understand their role in the complex network of ABA signaling during plant development. For this purpose our goals were as follows:

I. Selection of Arabidopsis plants showing ABA insensitive germination

a. Transformation of Arabidopsis plants with the inducible COS cDNA library.

b. Screening for enhanced ABA tolerance and identification of the cDNAs.

c. Verification of the effect of the identified cDNA by generating independent transgenic lines.

II. Comparing the seedling development and hormone responses in germination and growth assays of loss-of function T-DNA insertion mutants and overexpressing lines for the studied genes.

III. Studying genes closely related to the ones identified and thereby get a better understanding of their function.

IV. Understanding the genetic interaction of the identified genes and other ABA regulatory genes in double mutants and/or double transgenic lines.

V. Identifying the molecular function of the protein of interest using system biology approaches (transcriptome analysis or proteomics).

VI. Propose a model for regulatory pathway(s) controlled by the characterized gene(s). 


\section{MATERIALS \& METHODS}

\subsection{Plant materials \& Growth Conditions}

All plant material used in the experiments was obtained from Arabidopsis thaliana (thale cress) ecotype Columbia-0 (Col-0) or mutants and transgenic lines generated in the same background. Arabidopsis (Arabidopsis thaliana) growth conditions in sterile culture and controlled growth chambers were as described earlier (Koncz C 1994) Plant transformation was performed using the in planta Agrobacterium infiltration method (Bechtold N 1993). Arabidopsis cell suspensions were established, maintained, and transformed as described by Ferrando A (2000).

\subsection{Mutant screening method}

The Controlled cDNA Overexpression System was created in a Gateway version of the Estradiol-inducible pER8 plasmid, in which transcription of the inserted cDNA is strictly controlled by the addition of the inducer(Zuo J. \& Chua N 2000). The COS system was used to identify a set of cDNAs conferring dominant insensitivity to ABA(Papdi 2008). T1 generation of Agrobacterium-infiltrated seeds were germinated on 0.5MS medium containing $0.5 \%$ sugar, $100 \mathrm{mg} / \mathrm{l} \mathrm{Cefataxim,} 30 \mathrm{mg} / \mathrm{l}$ Orthocid, supplemented with $2.5 \mu \mathrm{M} \mathrm{ABA}$ and $4 \mu \mathrm{M}$ Estradiol.

\subsection{Phenotyping assays}

\subsubsection{Germination assay}

All germination assays were performed on $0.5 \mathrm{MS}$ germination medium: half-strength Murashige and Skoog medium $(\mathrm{pH}$ 5.8), including vitamins, solidified with $0.8 \%$ plant agar (Duchefa, Haarlem, The Netherlands). Before plating, seeds were surface-sterilized in $70 \%$ (v/v) ethanol for 1 min followed by 5\% (v/v) commercial bleach (Domex) for 8-10 min, and washed four to five times with sterile water. After a 3- to 4-day stratification period at $4^{\circ} \mathrm{C}$ in the dark, $12 \mathrm{~cm}$ wide glass plates containing $0.5 \mathrm{MS}$ germination medium with $0.5 \%$ sugar with respective concentration of hormones (concentrations are described in figure legends) and $4 \mu \mathrm{M}$ Estradiol ( for over-expressing lines) were incubated in a $16 \mathrm{~h} / 8 \mathrm{~h} \mathrm{light/dark}$ cycle at $22^{\circ} \mathrm{C}$. Germination was scored for 7 to 15 days by green cotyledon emergence. Each plate contained 50-100 seeds, and every experiment was repeated three times. 


\subsubsection{Hypocotyl elongation assay}

For hypocotyl length, seeds were sown on four layers of wet filter paper and imbibed in water for $48 \mathrm{~h}$ at $4^{\circ} \mathrm{C}$. Cold-treated seeds were then irradiated with white light for $3 \mathrm{~h}$ at $22^{\circ} \mathrm{C}$ to induce seed germination and transferred back to darkness for an additional $18 \mathrm{~h}$ at $22^{\circ} \mathrm{C}$. The plates were subsequently placed under various light conditions for 4 days, as specified in the figure legends, and seedlings were laid on the surface of agar medium. Images of scanned plates were analyzed using ImageJ Software (rsbweb.nih.gov/ij). Hypocotyl lengths at different fluences of light were normalized to the corresponding dark-grown hypocotyl length to reflect solely the light-dependent regulation. A total of 25-35 seedlings were used for each line at each light intensity and experiments were repeated three times (Bauer 2004) (light sources, SNAP-LITE LED lighting system; maximal spectral outputs, B 470 nm, R 670 nm, FR 735 nm).

\subsubsection{Flowering time determination}

To determine flowering time, plants were grown in greenhouse under short-day (8/16h) or long day $(16 / 8$ h) light cycle. Flowering time was recorded as the number of rosette leaves at the time when the main stem inflorescences reached a height of $1 \mathrm{~cm}$. The experiment was repeated twice using 20-30 plants in each experiment from each genotype (Viczián A 2005).

\subsection{Molecular techniques}

\subsubsection{Semi-Quantitative PCR analysis}

For the RT-PCR analysis total RNA was isolated with TRI Reagent method (Chomczynski P1 1995 ) and then 5-10 $\mu \mathrm{g}$ of RNA was treated with DNAseI (Fermentas). The RNA was extracted with phenol-chloroform, precipitated with 3M Sodium Acetate, the RNA was quantified with a NanoDrop (ThermoScientific 2000c) and equal concentration of all the samples of approximately 1or $2 \mu \mathrm{g}$ RNA was used for cDNA Synthesis (High Capacity cDNA Reverse Transcription Kit from Applied Biosystems). RT-PCR was performed in a $50 \mu 1$ reaction using Fermentas Recombinant Taq Polymerase with $1 \mu \mathrm{l}$ cDNA following the protocol: $94^{0} \mathrm{C}-2 \mathrm{~min}$, $25-35$ cycles $\left(94^{0} \mathrm{C}-30 \mathrm{sec}, 60^{\circ} \mathrm{C}-30 \mathrm{sec}\right.$ and $\left.72^{\circ} \mathrm{C}-30 \mathrm{sec}\right)$ and $72^{\circ} \mathrm{C}-7 \mathrm{~min}$. 


\subsubsection{Quantitative PCR analysis}

For the Real-time qPCR total RNA was isolated with Qiagen RNeasy Mini Kit and about $5 \mu \mathrm{g}$ RNA was DNAseI treated with Ambion's TURBO DNA-free ${ }^{\mathrm{TM}}$ kit. The concentration of RNA was quantified with a NanoDrop (ThermoScientific 2000c) and amount of approximately $500 \mathrm{ng}$ or $1 \mu \mathrm{g}$ RNA was used for the cDNA synthesis using High Capacity cDNA Reverse Transcription Kit from Applied Biosystems. The cDNA was diluted 5 times in nuclease-free water and stored in aliquots at $-20^{\circ} \mathrm{C}$ until use. qPCR reaction was performed using the SYBR ${ }^{\circledR}$ Green RT-PCR Reagent Kit in a 96 well plate following the Two-Step qPCR protocol: $95^{\circ} \mathrm{C}-10$ min, 40 cycles of $95^{\circ} \mathrm{C}-10 \mathrm{~min}$ and $60^{\circ} \mathrm{C}-1 \mathrm{~min}$ in the ABI PRISM ${ }^{8} 7900$ HT Sequence Detection System. Gene specific primers, used for qPCR analysis, are described in Table 1. $A C T 2$ and GAPDH2 (Atlg13440) were used as internal references (Yong-Qiang An 1996). Experiments were repeated with biological replicates.

\subsection{Generation of transgenic plants}

\subsubsection{Plasmid vectors}

cDNA inserts from transgenic plants were cloned and identified as described (Papdi 2008). Full length cDNA clones of ZFP transcription factors were obtained from REGIA collection (PazAres and Regia 2002). Cloned cDNA were transferred with LR Gateway reaction into destination vectors pER8-GW and pB2GW7, which carried inducible and constitutive expression casettes, respectively.

\subsubsection{Promoter-reporter constructs}

To construct the AtZFP3 Promoter::GUS gene fusion, a fragment of $2.4 \mathrm{~kb} 5^{\prime}$ upstream region of the AT5G25160 gene was PCR amplified from the BAC clone F21J6 using pZFP3a and pZFP3b primers carrying BamHI and EcoRI cloning sites, respectively (Table 1). The PCR fragment was cloned into $\mathrm{pBSK}(+)$ vector, the nucleotide sequence was verified, the error-free promoter fragment was subcloned into pENTR-2B vector at BamHI and EcoRI sites and transferred into pMDC162 promoter testing vector using LR Clonase reaction (Curtis and Grossniklaus 2003). 


\subsubsection{Gene-tag constructs}

To have ZFP3 fused to hemagglutinin (HA) epitope at $\mathrm{C}$ terminal and $\mathrm{N}$ terminal end, ZFP3 cDNA was PCR amplified from the pDONR201 vector and cloned in frame into pPILY at NcoI and BglII sites for the $\mathrm{C}$ terminal tagging and in pMENCHU at SalI and EcoRI sites for the $\mathrm{N}$ terminal tagging (Ferrando A 2000). The ZFP3-HA (C-terminal) and HA-ZFP3 (N-terminal) gene fusions were then cut at the XhoI and SacI sites and cloned into binary vector pPR97 (Mathur 1995).

To have ZFP3 gene fused to GFP gene at $\mathrm{C}$ terminal, full length cDNA was PCR amplified with restriction enzyme sites SalI and EcoRI (without stop codons), cloned in frame into gateway pENTR-2B vector, and subsequently cloned into pGW5 (Dr. Nakagawa, Shimane University, Matsue, Japan) gateway vector using Gateway LR reaction (Invitrogen).

\subsubsection{Complementation assay}

For the complementation assay, the pER8 gateway binary vector carrying ZFP3 cDNA was transformed by Agrobacterium-mediated method into Columbia ecotype background plants, the T2 lines were checked for ABA insensitivity.

\section{6. Transgene-based gene expression analyses}

\subsubsection{S-ZFP3-GFP Protein localization}

For GFP localization, roots of T1 seedlings transformed with GW5-35S-ZFP3 construct was vizualized using Olympus confocal laser scanning microscope.

\subsubsection{Preparation of Protein extracts and determination}

To prepare total protein extracts from cell suspension and seedlings, plant material was ground in liquid nitrogen and thawed in 1:1 volume extraction buffer containing $50 \mathrm{mM}$ Tris, $\mathrm{pH} 7.5,0.5 \%$ SDS, 1mM DTT, 1mM PMSF and a protease inhibitor cocktail according to the manufacturer's instructions (Sigma). Samples were incubated on ice for $20 \mathrm{~min}$. The suspension was vortexed and centrifuged at $13,000 \mathrm{rpm}$ (Heraeus Centrifuge) at $4^{\circ} \mathrm{C}$ for $15 \mathrm{~min}$. The concentration of extracted proteins was determined with the Bio-Rad protein assay. $30 \mu \mathrm{g}$ of total protein was 
boiled for $5 \mathrm{~min}$ in sample buffer containing $100 \mathrm{mM}$ Tris-HCl, $\mathrm{pH}$ 6.8, 4\% SDS, $0.2 \%$ bromophenol blue, $20 \%$ glycerol, and $100 \mathrm{mM}$ DTT, the proteins were separated on 10\% SDSpolyacrylamide gels (Schagger and von Jagow 1987) and blotted to Polyvinylidene fluoride (PVDF) membranes by wet electroblotting (Mini-Protean II system; Bio-Rad), then incubated with a peroxidase-coupled monoclonal anti-HA antibody (Roche). The HA epitope-tagged proteins were detected using the Lumi-Light western blotting substrate (Millipore).

\subsubsection{Histochemical localization of GUS Promoter activity}

Histochemical localization of GUS activity was performed by incubating whole transgenic plants or different organs in $1 \mathrm{mM} \mathrm{X}$-Gluc (5-bromo-4-chloro-3-indolyl glucuronic acid, Duchefa) at $37^{\circ} \mathrm{C}$ for $3 \mathrm{~h}$ to overnight, and then incubating in $70 \%$ ethanol for fixing and clearing the samples (Weigel D. 2002),. For embryos clearing was done in chloral hydrate solution (8:1:2, chloral hydrate:glycerol:water; w/v/v). Stained samples were observed under a stereomicroscope (MZ16F, Leica Microsystems, Germany) and photographed with a DXM1200C digital camera (Nikon, Japan).

\subsection{RNA Sequencing}

\subsubsection{Plant material used}

For the RNAseq analysis, 2 sets of experiments were done and compared. In the first experiment ZFP3 over expressing line and Columbia wild type control seeds were sterilized and directly grown on Estradiol and ABA+ Estradiol. After the imbibition period in cold and dark for 3 days they were transferred to $16 \mathrm{~h} / 8 \mathrm{~h}$ light/dark cycle at $22^{\circ} \mathrm{C}$. Seedlings growing on Estradiol containing media were harvested after 36 hours and seedlings kept on ABA+ Estradiol were harvested after 84 hours to obtain physiologically identical radical stage for both conditions.

In the second experiment, ZFP3 over expressing and Columbia wild type control seeds were sterilized and placed on the Estradiol and ABA+ Estradiol media after the 3 days of imbibitions period without any prior treatment. The seedlings were harvested after 72 hours from both Estradiol and $\mathrm{ABA}+$ Estradiol media together. Total RNA was isolated using Qiagen Plant RNeasy Kit, followed by DNaseI treatment using Ambion's TURBO DNA-free ${ }^{\mathrm{TM}} \mathrm{kit}$ 


\subsubsection{Whole transcriptome sequencing}

RNA quality and quantity measurements were performed on Bioanalyzer (Agilent Technologies) and Qubit (Life Technologies). High quality (RIN >8.5) total RNA samples from three biological replicates were pooled and processed using the SOLiD total RNA-Seq Kit (Life Technologies), according to the manufacturers suggestions. Briefly, $5 \mu \mathrm{g}$ of pooled RNA was DNaseI treated and the ribosomal RNA depleted using RiboMinus Plant Kit for RNA-Seq and RiboMinus Concentration Module (Life Technologies). The leftover was fragmented using RNaseIII, the 50200nt fraction size selected, sequencing adaptors ligated and the templates reverse transcribed using ArrayScript RT. The cDNA library was purified with Qiagen MinElute PCR Purification Kit (Qiagen) and size-selected on a 6\% TBE-Urea denaturing polyacrylamide gel. The 150-250nt cDNA fraction was amplified using AmpliTaq polymerase and purified by AmPureXP Beads (Agencourt). Concentration of each library was determined using the SOLID Library TaqMan Quantitation Kit (Life Technologies). Each library was clonally amplified on SOLiD P1 DNA Beads by emulsion PCR (ePCR). Emulsions were broken with butanol, and ePCR beads enriched for template-positive beads by hybridization with magnetic enrichment beads. Template-enriched beads were extended at the $3^{\prime}$ end in the presence of terminal transferase and 3 ' bead linker. Beads with the clonally amplified DNA were deposited onto SOLiD sequencing slide and sequenced on SOLiD V4 Instrument using the 50-base sequencing chemistry (Next generation sequencing was performed by István Nagy and Balázs Horváth).

\subsection{Measurement of ABA content}

Seven days-old seedlings were frozen in liquid nitrogen and stored in $-80^{\circ} \mathrm{C}$ until processing. Samples (30mg) were extracted in triplicates. ABA content was determined with LC-MS/MS as described (López-Carbonell M 2009). The HPLC system consisted of a Perkin Elmer Series 200 (Norwalk, CT, USA) quaternary pump equipped with a thermostated $\left(4^{\circ} \mathrm{C}\right)$ autosampler. For extract analysis, we employed a XBridge C18 column (Waters) equipped with a Securityguard C18 Phenomenex. MS and MS/MS analysis was performed on an API 3000 triple quadrupole mass spectrometer (PE Sciex, Concord, Ontario, Canada). All the analyses were performed using the Turbo Ionspray source in negative ion mode. LC-MS/MS analysis was performed by Marta López-Carbonell (University of Barcelona, Spain). 


\subsection{Genotyping of $z f p$ mutants and Genetic crosses}

All the T-DNA insertion mutants were obtained from Arabidopsis Biological Resource Center $(\mathrm{ABRC})$ and genotyped by PCR using gene specific primers and Left border T-DNA primer. The zfp3 mutant (At5g25160, GABI_177E02) carries insertion 25bp downstream from ATG. The zfp4 mutant (At1g66140, SALK_038923) has insertion in 5' UTR at 38bp upstream ATG. The homozygous zfp3 mutant was crossed with homozygous zfp4 mutant. The double mutants were genotyped with the same primer sets. Genetic crosses were made to obtain ZFP3 overexpression in, abi2-1, abi5, abi4, phyA-201, and phyB-9 background by crossing the ZFP3ox line with respective mutants. Double homozygous lines were used for further analysis. 


\subsection{Primers used in the study}

Table 1: List of primers

\begin{tabular}{|c|c|c|}
\hline CODE & SEQUENCE & USE \\
\hline \multicolumn{3}{|c|}{ CLONING \& SEQUENCING } \\
\hline zfp3_prom_5' & GACGGATCCGATCTAGTAATGATGTAATACACAACC & promoter cloning (BamHI-EcoRI) \\
\hline zfp3_prom_3' & AGAGAATTCAGCTAAAAAGGGATAGATTTTTTCAGG & \\
\hline zfp3_prom_seq1 & GACGAATCAAATCTCTCTACATACA & promoter sequencing \\
\hline zfp3_prom_seq2 & TGATCTTGCCGATGTGGCTTCC & promoter sequencing \\
\hline zfp3-3Xtag-F & GACTGTCGACATGGACGCTTCAATAGTTTCCTC & ZFP3 cDNA cloning to p3xtag vector (SalI-BglII) \\
\hline zfp3-3Xtag-R & TAGCAGATCTAAGCTTGAGGGACAAGTCAAG & \\
\hline 35S-HA-A44-F & GACTGTCGACTCATGGACGCTTCAATAGTTTC & ZFP3 cDNA cloning into pMenchu(SalI-EcoRI) \\
\hline 35S-HA-A44-R & GATCGAATTCTCAAAGCTTGAGGGACAAGTC & \\
\hline 35S-A44HA-F & ACTGCCATGGACGCTTCAATAGTTTCCTCAT & ZFP3 cDNA cloning into pPily (NcoI-BglII) \\
\hline 35S-A44HA-R & TAGCAGATCTAAGCTTGAGGGACAAGTCAAG & \\
\hline $\begin{array}{l}\text { pENTR-zfp3- } \\
\text { NoStop-R }\end{array}$ & CATGCTCGAGCAAAGCTTGAGGGACAAGTCAA & $\begin{array}{l}\text { ZFP3 cDNA cloning into pENTR2A (XhoI), primer pair used this } \\
\text { PCR reaction: 35S-HA-A44-F(salI) - pENTR-zfp3-NoStop-R } \\
\text { (XhoI) } \\
\text { ZFP3 cDNA cloning into pENTR2A (XhoI), primer pair used this }\end{array}$ \\
\hline pENTR-zfp3-R & CATGCTCGAGGTTCAAAGCTTGAGGGACAAGTCAA & PCR reaction: 35S-HA-A44-F(salI) - pENTR-zfp3-R (XhoI) \\
\hline ZFP3-F & ACGGGTTTGGTGGTCACTATGG & RT-PCR \\
\hline ZFP3-R & GGGCTATCGATGTTATTGGACCGTG & RT-PCR \\
\hline ZFP3-F & TAGCTCTCATGGACGCTTCA & designed for zfp3 mutant genotyping \\
\hline
\end{tabular}

\section{REAL-TIME GENE EXPRESSION}

$\begin{array}{llll}\text { RGL2-F } & \text { GGCTGCACAGTGGAGGATTC } & \text { q-PCR } & \text { Kun Yuan ,2006 } \\ \text { RGL2-R } & \text { CGCGCTAGATCCGAGATGA } & \text { q-PCR }\end{array}$









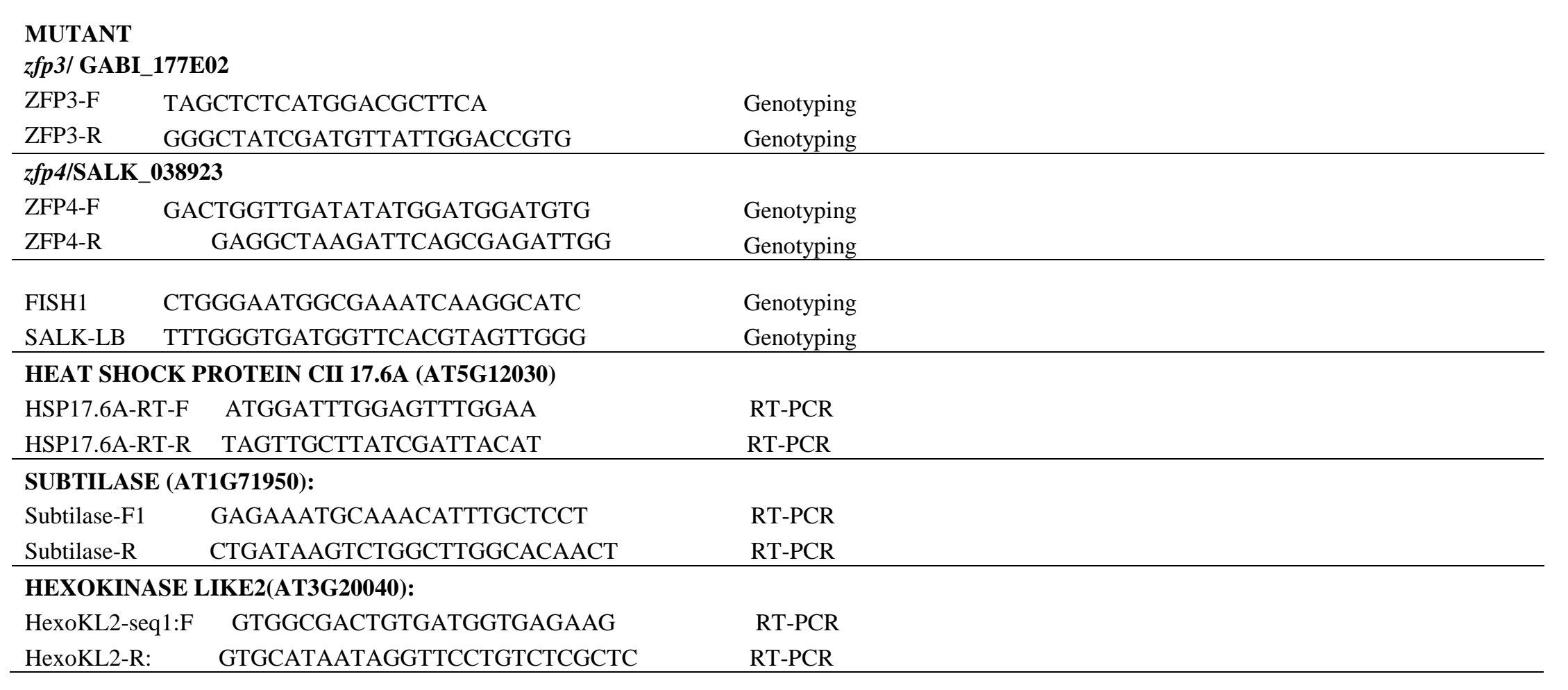




\section{Results}

\subsection{Screening for $A B A$ insensitive lines}

Abscisic acid transmits stress signals, blocks germination, controls dormancy, and root growth. In order to understand the complicated regulatory web of ABA signaling the Controlled cDNA Overexpression System have been developed (Papdi 2008). Arabidopsis Col-0 wild type plants were transformed with the COS library and their seeds were screened for ABA insensitivity in the presence or absence of Estradiol in germination assays (Figure 3). Screening one million seeds (approximately 45,000 transformed seeds), of T1 generation resulted in 156 plants, which were selected based on their germination capacity on media supplemented with high concentration of $\mathrm{ABA}$ and Estradiol, followed by the confirmation of their hygromycin resistance. In order to identify dominant ABA insensitive lines, $156 \mathrm{~T} 2$ generation lines named as $\mathrm{A} 1, \mathrm{~A} 2, \mathrm{~A} 3$ upto A156 ( ' $\mathrm{A}$ ' for $\mathrm{ABA}$ screen) were screened for Estradiol dependent germination on media supplemented with $2.0 \mu \mathrm{M}$ ABA and with or without $4 \mu \mathrm{M}$ Estradiol. Among the 156 lines, Estradiol dependent ABA insensitivity was observed in 35 lines, cDNA was rescued and identified from $33 \mathrm{~T} 2$ lines (Table2).

Table 2: Summary of the ABA screen.

\begin{tabular}{|c|l|c|}
\hline & \multicolumn{1}{|c|}{ Steps Followed } & No.s \\
\hline I & T1 seeds screened & $\sim 45,000$ \\
\hline II & Selected on $2.5 \mu \mathrm{M}$ ABA + Estr then on Hyg selection & 156 \\
\hline III & ABA insensitivity \& segregation confirmed in T2 lines & 35 \\
\hline & \multicolumn{2}{|c|}{35} \\
\hline IV & cDNA insert identified & 33 \\
\hline V & Estradiol dependent induction and gene characteriztion & 4 \\
\hline
\end{tabular}


As mentioned above, genomic DNA was isolated from 33 ABA insensitive lines followed by PCR amplification of the inserted cDNA fragment from the vector T-DNA. Sequence analysis of the PCR fragment unraveled the gene identity ( Table 3). The germination rate on ABA varied among the different lines (Figure 5). The line A44 carrying a Zinc finger protein (ZFP3) could germinate even on $4 \mu \mathrm{M}$ ABA in the presence of Estradiol. Estradiol dependent gene induction was tested by semi-quantitative RT-PCR in the selected lines as shown below (Figure 6).
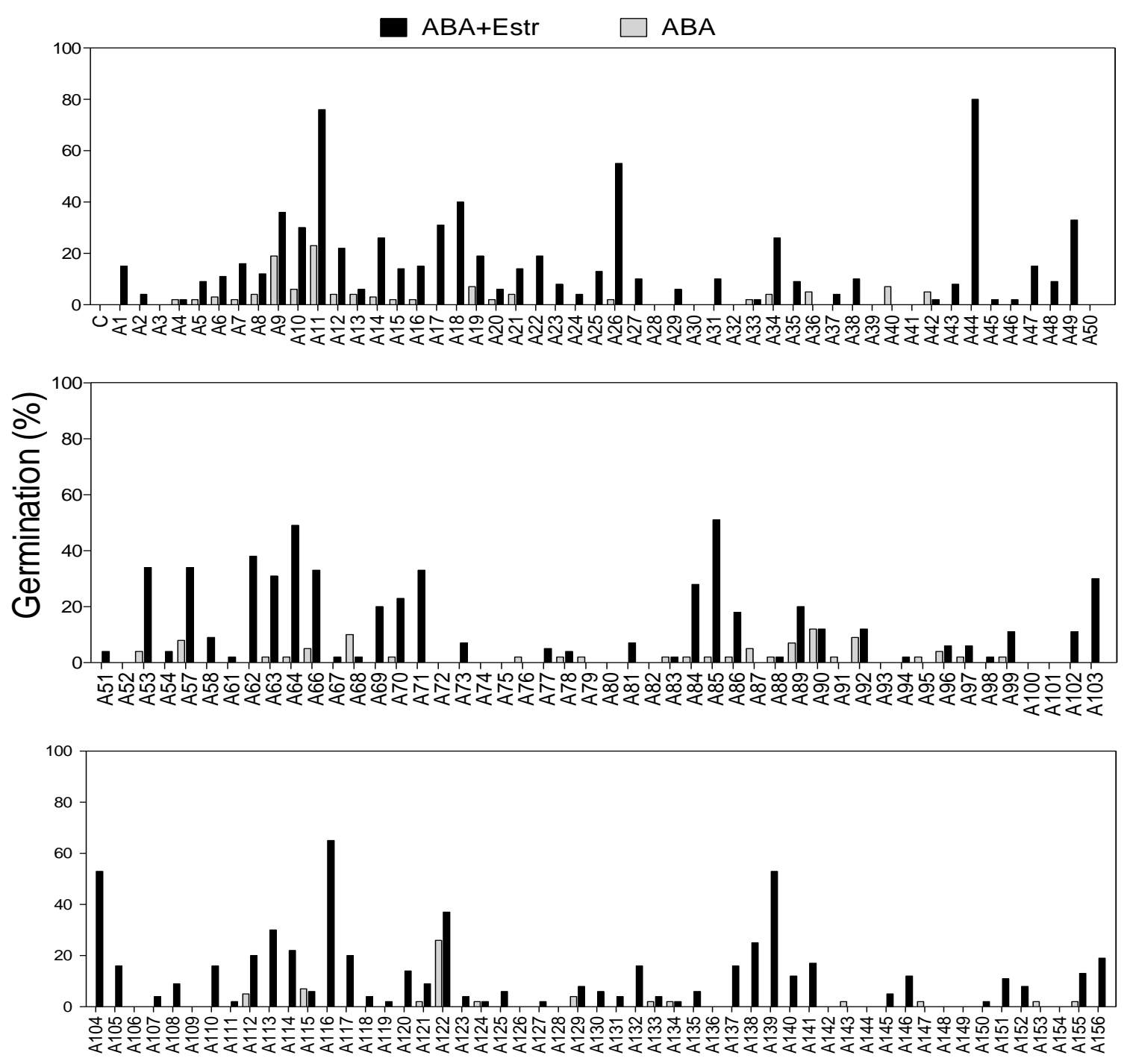

Figure 5: Germination of 156 lines from the screen on germination media in the presence of $2 \mu \mathrm{M}$ ABA with or without Estradiol as observed in 2 weeks old seedlings. 
Table 3: List of the identified genes, their description and length.

\begin{tabular}{|c|c|c|c|c|c|}
\hline No.s & Line & Encoded protein & $\begin{array}{c}5 \text { 'end } \\
\text { from } \\
\text { ATG(bp) }\end{array}$ & $\begin{array}{l}\text { Insert } \\
(\mathrm{kb})\end{array}$ & Gene ID \\
\hline 1 & A9 & phosphoric monoester hydrolase & -76 & 1.17 & AT1G73010 \\
\hline 2 & A10 & peptidyl-prolyl cis-trans isomerase & 1373 & 0.57 & AT5G48570 \\
\hline 3 & A11 & glutathione S-transferase 8 (GST8) & -69 & 0.97 & At1g78380 \\
\hline 4 & A12 & unknown expressed protein & 699 & 0.66 & AT $1 G 28400$ \\
\hline 5 & A14 & rubber elon gation factor (REF) family prote in & -178 & 1.19 & At1g67360 \\
\hline 6 & A17 & tubby like protein 3 (TLP3) & 768 & 0.4 & At $2 g 47900$ \\
\hline 7 & A18 & unknown expressed protein & -49 & 1.42 & At5g59960 \\
\hline 8 & A19 & protease inhibitor/seed storage/ (LTP) & -30 & 0.65 & AT $2 \mathrm{G} 45180$ \\
\hline 9 & A 22 & unknown expressed protein & -15 & 0.77 & AT1G65720 \\
\hline 10 & A26 & he at shock protein CII 17.6A (HSP17.6A) & -54 & 0.63 & At5g12030 \\
\hline 11 & A34 & NAC domain containing protein 27 & -25 & 0.59 & AT1G64105 \\
\hline 12 & A44 & $\mathrm{C} 2 \mathrm{H} 2$ type zinc finger prote in & -66 & 0.96 & At5g25160 \\
\hline 13 & A49 & subtilase family protein & 67 & 0.61 & At1g71950 \\
\hline 14 & A53 & $\begin{array}{l}\text { SNF1-related prot. kinase } \gamma \text { regulatory subunit } \\
\text { (KING 1) }\end{array}$ & -118 & 1.56 & At3g48530 \\
\hline 15 & A57 & F-box family protein & 860 & 0.4 & At2g17690 \\
\hline 16 & A62 & protease inhibitor/seed storage/ (LTP) & -26 & 0.65 & At2g45180 \\
\hline 17 & A64 & subtilase family protein & 67 & 0.61 & At1g71950 \\
\hline 18 & A66 & $\begin{array}{l}\text { dehydrin family protein, similar to aldose } 1- \\
\text { epimerase }\end{array}$ & -62 & 0.62 & At1g54410 \\
\hline 19 & A70 & GLUTATHIONE S-TRANSFERASETAU 19 & 18 & 0.78 & AT1G78380 \\
\hline 20 & A84 & 2-oxoglutarate-dependent dioxygenase & -9 & 1.35 & AT1G14130 \\
\hline 21 & A85 & similar to cytochrome coxidase subunit $6 \mathrm{~b}$ & 252 & 0.24 & AT4G28060 \\
\hline 22 & A89 & plasma membrane intrinsic protein 1 (PIP1) & -37 & 1.12 & AT3G61430 \\
\hline 23 & A90 & starch-related \{alpha\}-glucan/water dikinase (GWD1) & 734 & 3.64 & AT 1610760 \\
\hline 24 & A92 & unknown expressed protein & -49 & 1.49 & AT5G18420 \\
\hline 25 & A98 & HEXOKINASE-LIKE 2 & 3 & 0.44 & AT3G20040 \\
\hline 26 & A103 & Unknown protein & 11 & 0.52 & AT4G16450 \\
\hline 27 & A110 & alcohol dehydrogenase-like 6 & -30 & 1.52 & AT5G24760 \\
\hline 28 & A112 & FK506 binding protein (FKBP) family protein & 540 & 1.39 & AT3G25230 \\
\hline 29 & A113 & thiore doxin 3 & -95 & 0.65 & AT5G42980 \\
\hline 30 & A116 & F-box/Kelch-repeat protein & 872 & 0.73 & AT1G25211 \\
\hline 31 & A122 & unknown expressed protein & 165 & 0.47 & AT1G56580 \\
\hline 32 & A138 & similar to DNA-directed RNA polymerase II & -58 & 0.72 & AT2G04630 \\
\hline 33 & A139 & xylose isomerase & 1609 & 0.29 & AT5G57655 \\
\hline
\end{tabular}




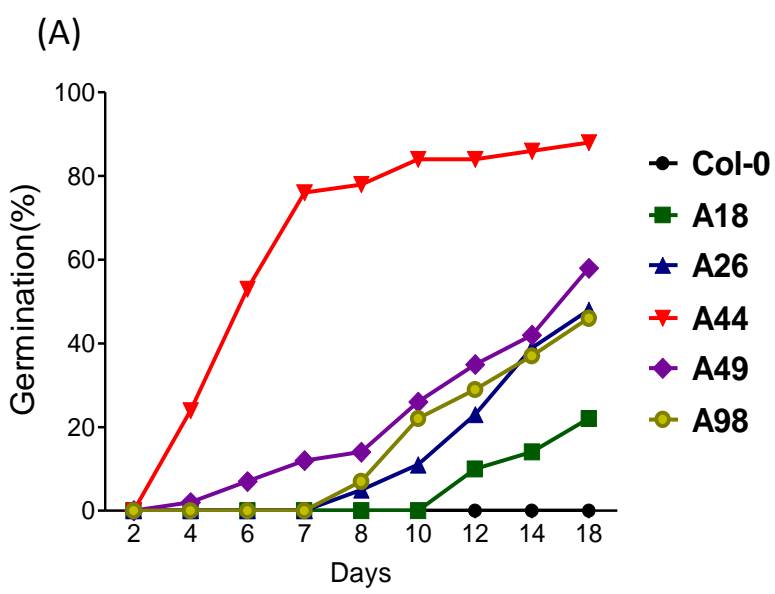

(B)

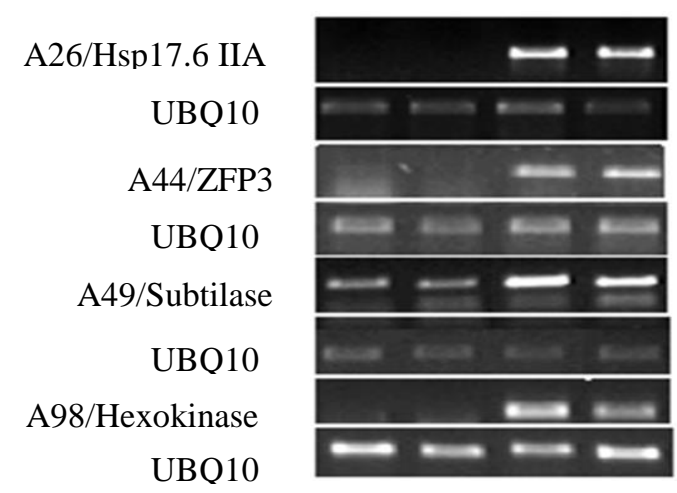

(C)

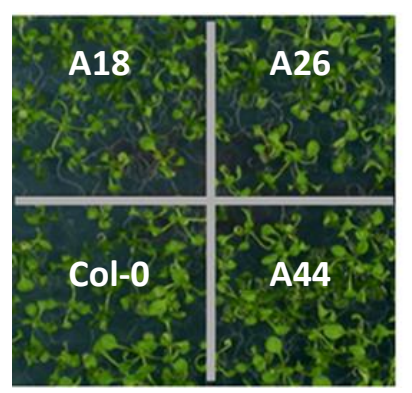

Control

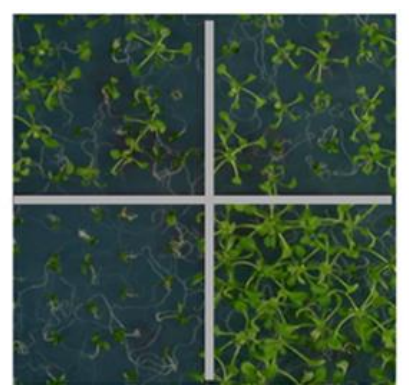

$2 \mu \mathrm{M}$ ABA

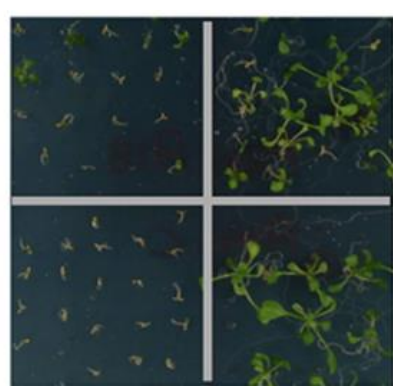

$3 \mu \mathrm{M}$ ABA

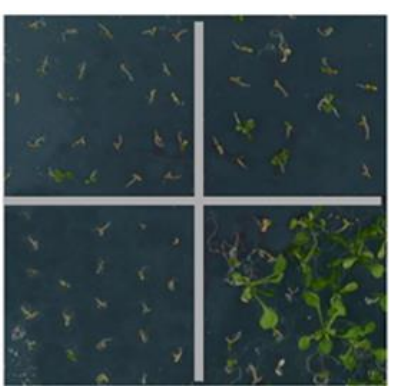

$4 \mu \mathrm{M}$ ABA

Figure 6: Germination assays for the representative lines from the screen. (A) Germination of Col-0 wild type, A18, A26, A44, A49 and A98 seedlings on 0.5 MS media supplemented with $2 \mu \mathrm{M}$ ABA and Estradiol. (B) Semi-Quantitative RT-PCR analysis of the 2 weeks old seedlings induced for 24 hours with ABA (A), with Estradiol (E), with ABA and Estradiol (A+ E) and Control (C). (C) Photos of line A18, A26, A44 and Col-0 growing on different ABA concentrations as seen on day 15.

\subsection{Characterization of line A26}

Further study of line A26 lead to the identification of a full-length cDNA of class II small heatshock protein 17.6A gene including a 5'-untranslated leader of $53 \mathrm{bp}$ and 3'-UTR sequences of $127 \mathrm{bp}$ (Figure 7). In the T2 generation, the conditional ABA insensitivity of line A26 was dominant, and 3:1 segregation of hygromycin resistant and sensitive offsprings indicated that this trait is linked to a single T-DNA insertion. A26 seeds germinated in the presence of $3 \mu \mathrm{M}$ ABA 
and $4 \mu \mathrm{M}$ Estradiol, while their ABA sensitivity was similar to wild-type seeds in the absence of Estradiol (Figure 6 A \& C).

A) Insert sequence in the A26 line
Gene: AT5G12030, full length cDNA
AATCAAACCAAAGAAAAGCCAAGAAGCAAGAAAGTTAACACAACAGCTAAGAATGGATTTGGAGTTT
GGAAGGTTCCAATATTTCAATCCTCGAAGACATGCTTGAAGCCCTGAAGAACAAACCGAGAAGAC
TCGTAACAACCCTTCAAGAGCTTACATGCGAGACGCAAAGGAATGGCTGCTACACCAGCTGACGTTA
TCGAGCACCCGGATGCGTACGTTTCGCCGTGGACATGCCTGGATCAAAGGAGATGAGATTCAGGTC
CAGATAGAGAAGAGAACGTCTTGTGGTAGTGGCAAAAACAGAGGGACAACAAGAGGATGAGG
TGTGAAGTTTGGAGGATGGAGAGGAGGATGGGGAAGTTATGAGGAAGTTTCAGTTACCTGATAATG
CAGATTTGGAGAAGATCTCTGCGGCTTGTAATGACGGTGTGTTGAAAGTGACTATTCCGAAACTTCCT
CCTCCTGAGCCAAAGAACCAAAGACTATACAAGTTCAAGTCGCTTGAGTTTGTTGTGATCGTTTT
TTGTGTTTAATGAATGAATCGATAAGCACTACCTCTTGGTGTCGTTGTAAAATGAAAAAAAT
AGTTTTCTCTGTACAAAAAAAAAAAAAAAAAAAAAAA
B) Encoded protein
Protein: ATHSP17.6A, Small heat shock protein 17.6A
MDLEFGRFPIFSILEDMLEAPEEQTEKTRNNPSRAYMRDAKAMAATPADVIEHPDAYVFAVDMPGIKG
DEIQVQIENENVLVVSGKRQRDNKEDGVKFVRMERRMGKFMRKFQLPDNADLEKISAACNDGVLKVT
IPKLPPPEPKKPKTIQVQVA

Figure 7: Sequence analysis of the A26 cDNA insert. A) The A26 cDNA sequence corresponds to the AT5G12030 gene. Green color indicates the 5' UTR, yellow shows the open reading frame, and blue marks the 3'-UTR. The start and stop codons are highlighted in black. B) Amino acid sequence of A26 cDNA encoded HSP17.6A protein. The HSP20 domain is highlighted in grey color.

Semi quantitative RT-PCR analysis confirmed that HSP17.6A expression in line A26 was indeed induced only by Estradiol, but not by ABA (Figure 6B). The transcription of HSP17.6A was activated by heat-shock and salt stress in wild-type plants (Figure 8D). ABA sensitivity of seed germination is controlled by the transcription factors ABI3, ABI4 and ABI5 (Finkelstein 2002).We tested the transcript levels of these key transcription factors in A26 plants treated with or without ABA and Estradiol. As in wild-type, ABA treatment of A26 seeds lead to the induction of expression of $A B I 3, A B I 4$ and $A B I 5$ genes, whereas Estradiol-treatment alone had no effect on their transcription. However, the 8 hours combined ABA and Estradiol treatment, triggering co-expression of HSP17.6A with these transcription factors, resulted in $85 \%$ reduction of $A B I 5$ transcription compared to $\mathrm{ABA}$ treatment alone (Figure $8 \mathrm{~A} \mathrm{~B} \& \mathrm{C}$ ). 
(A)

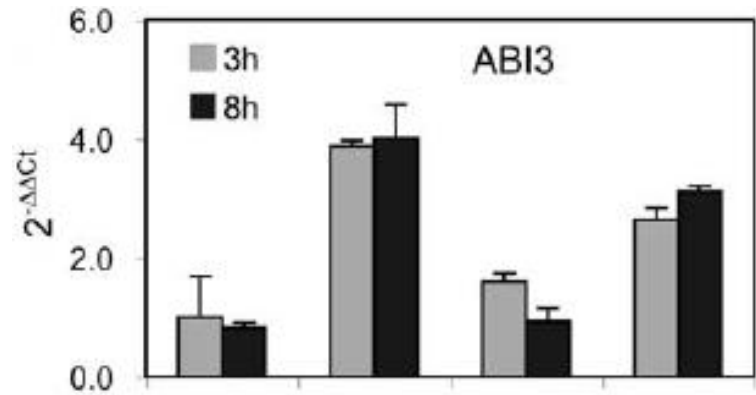

(B)
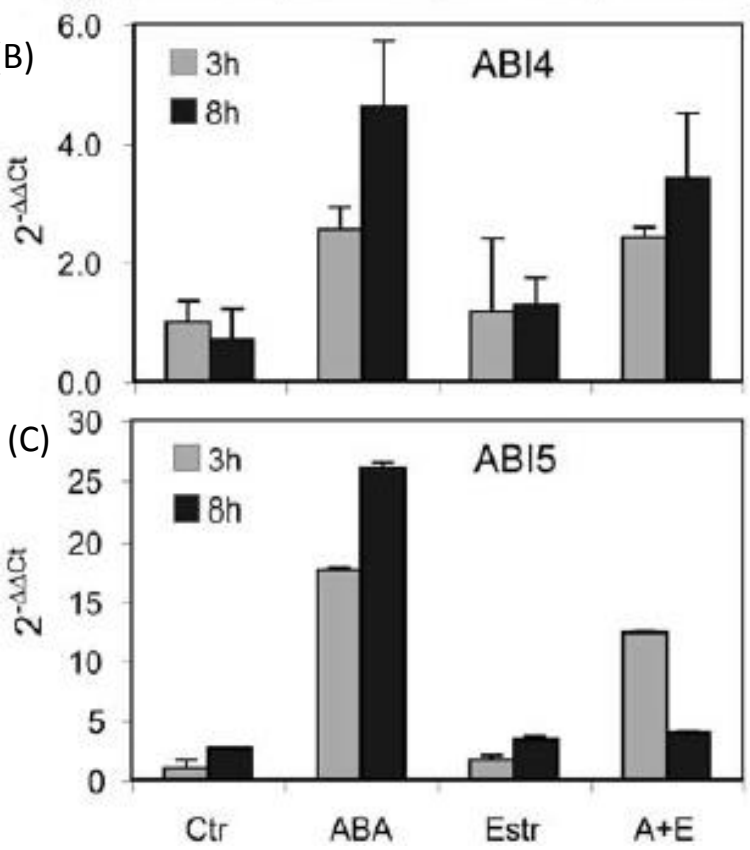

(D)

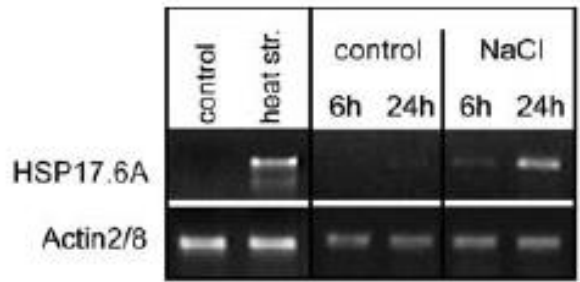

Figure 8: Comparison of regulation of $A B I 3$, $A B I 4$ and $A B I 5$ transcript levels in A26 seedlings (A: $A B I 3, \mathrm{~B}: A B I 4, \mathrm{C}: A B I 5$ ). Quantitative RTPCR analysis was performed with RNA templates isolated from 3 days old A26 seedlings treated with either $20 \mu \mathrm{M}$ ABA, or $4 \mu \mathrm{M}$ estradiol, or their combination $(\mathrm{A}+\mathrm{E})$ for 3 and 8 hours. Ctr: untreated. control. Relative values are shown using GAPDH2 as internal reference.

(D) Induction of HSP17.6A transcription with heat-shock at $37^{\circ} \mathrm{C}$ and salt stress with $150 \mathrm{mM}$ Sodium Chloride $(\mathrm{NaCl})$ in leaves of wild-type plants.

\subsection{Characterization of line A44}

\subsubsection{Germination assay on ABA and Paclobutrazol media}

Germination of the line A44 was insensitive to $5 \mu \mathrm{M}$ ABA in the presence of Estradiol while it was similar to the wild type in the absence of it (Figure 9 B \& D). A44 was insensitive to paclobutrazol (PAC) an inhibitor of gibberellin biosynthesis (Figure 9C), suggesting that GA is not essential to initiate germination of this line. Expression of ZFP3 in A44 was detected only in Estradiol-treated 2-weeks-old plantlets, which was not influenced by ABA (Figure 9E). 
(A)

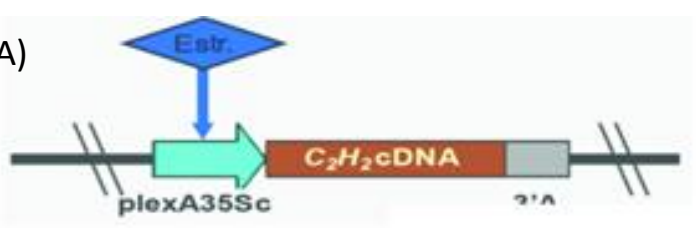

(B)

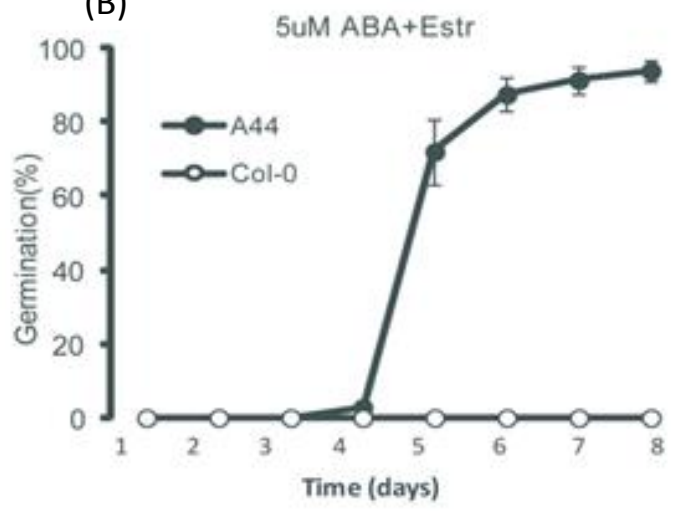

(D)

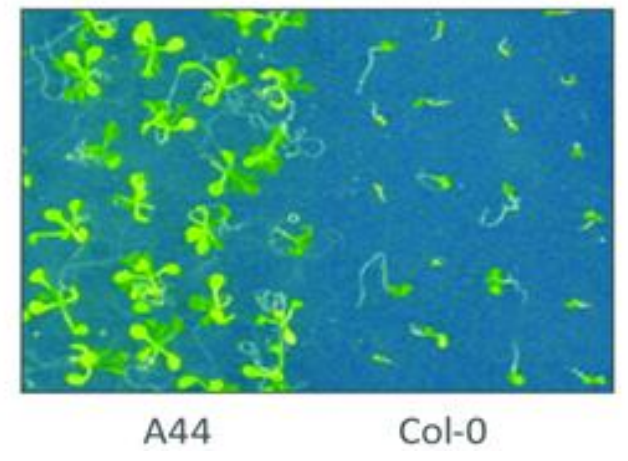

(C)

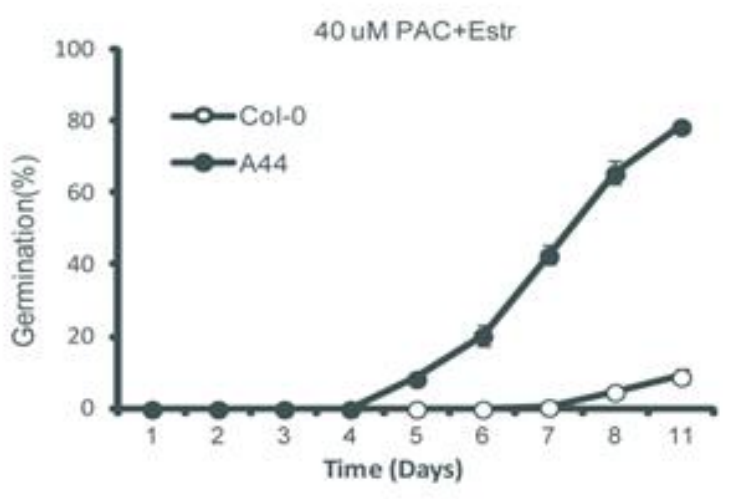

(E)

$$
\text { ZFP3 gene expression in A44 and Col-0 }
$$

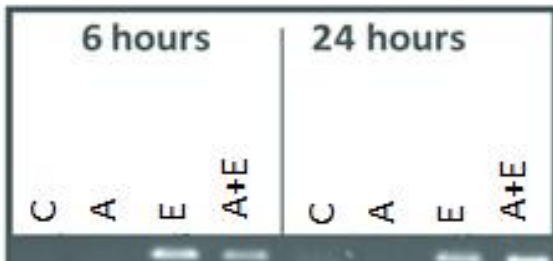

Zfp3 / A44

Zfp3 / Col-0

Ubq/ A44

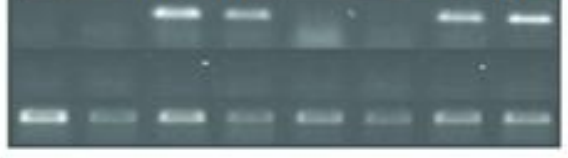

Figure 9: Germination assay with inducible A44 line and Gene induction study. (A) Schematic diagram of the C2H2-ZFP3 cDNA controlled by inducible promoter. (B) Time course of germination of Col-0 wild type and A44 seeds on media containing $5 \mu \mathrm{M} \mathrm{ABA}$ and $4 \mu \mathrm{M}$ Estradiol. C) Time course of germination of Col-0 wild type and A44 seeds on media containing $40 \mu \mathrm{M}$ paclobutrazol and $4 \mu \mathrm{M}$ Estradiol. (D) Photo of 2 weeks old seedlings growing on media supplemented with $2.5 \mu \mathrm{M}$ ABA and Estradiol. (E) Expression of ZFP3 gene in A44 plants. Transcripts were detected by RT-PCR in 2 weeksold plantlets treated with ABA (A), with Estradiol (E), with ABA and Estradiol (A+E) and Control (C).

\subsubsection{Isolation and sequencing of the $A 44$ cDNA insert}

A single PCR fragment was amplified from genomic DNA of A44 plants using ER8A and ER8B primers flanking the cDNA insert (Papdi, 2008). Nucleotide sequence of the recovered fragment showed $100 \%$ identity with the full-length cDNA of the AT5G25160 gene, encoding the previously uncharacterized Zinc Finger Protein 3 (ZFP3). The fragment included a 
5'-untranslated region of 66bp, 3'-UTR region of $118 \mathrm{bp}$ and the poly (A) tail (Figure $10 \mathrm{~A} \& \mathrm{~B}$ ). Propagation of T2 generation of line A44 resulted in 3:1 segregation of hygromycin resistant and sensitive offspring indicating that this trait is linked to a single T-DNA insertion.

\begin{abstract}
A) Insert sequence in the A44 line
Gene: $A T 5 G 25160$, full length cDNA

AGAAAGAGACAGAGAAAGAGAAAGAAAAAAATCATCTCCTGAAAAAATCTATCCCTTTTTAGCTCTCATG

GACGCTTCAATAGTTTCCTCATCCACTGCTTTTCCATATCAAGATTCTCTAAACCAGAGCATCGAAGACG

AAGAAAGAGACGTTCATAATTCTAGTCACGAACTCAATCTCATCGACTGCATAGACGACACAACGAGTAT

CGTTAACGAATCTACAACATCCACAGAACAAAAGCTTTTCTCATGCAACTATTGTCAAAGAACTTTCTAT

AGCTCACAAGCACTTGGTGGTCACCAAAACGCACACAAGAGAGAGAGAACGTTGGCGAAGAGAGGACAAC

GTATGGCAGCGTCAGCCTCAGCTTTTGGACATCCTTACGGTTTCTCTCCACTTCCTTTCCACGGACAGTA

CAACAACCATAGGTCTTTAGGGATCCAAGCGCATTCGATAAGCCACAAGCTAAGTTCTTATAACGGGTTT

GGTGGTCACTATGGTCAGATCAACTGGTCAAGACTTCCATTTGATCAACAACCAGCCATAGGTAAATTTC

CCTCAATGGATAATTTTCATCATCATCATCATCAGATGATGATGATGGCTCCTTCAGTAAATTCACGGTC

CAATAACATCGATAGCCCAAGCAACACAGGACGGGTTCTAGAAGGGTCACCGACTCTTGAACAATGGCAC

GGAGACAAAGGATTGTTGTTAAGTACAAGTCATCATGAAGAGCAGCAGAAACTTGACTTGTCCCTCAAGC

TTTGAGATTCTTTTTCTTGATTCTTGAATTTAGTGTCTTTTTACTGTTTTTTCATGTGATTGTTAGTACT

ATTTTGTGTATATTTTTTCTAGTAAAGATAATCTAATGTACATCTTTTTCACAAAAAAAAAAAAAAAAA

AAAAAAAAAAAGTCCTCTGCGTTGACCCAGCTTTCTTGTACAAAGTTGGCATTATAAGAAAGCATTGCTT

B) Encoded protein

Protein: AT5G25160, ZINC FINGER PROTEIN 3

MDAS IVSS STAF PYQDSLNQS IEDEERDVHNSS HELNL I DC I DDTTS IVNESTTSTEQKLFSCNYCQRTF

YSSQALGGHQNAHKRERTLAKRGQRMAASASAFGHPYGFS P LPFHGQYNNHRS LGIQAHS ISHKLSSYNG

FGGHYGQINWSRLPFDQQPA IGKF PSMDNFHHHHHQMMMMAP SVNSRSNN I DS P SNTGRVLEGSPTLEQW

HGDKGLLLSTSHHEEQQKLDLSLKL
\end{abstract}

Figure 10: Sequence analysis of the A44 cDNA insert. A) The A44 cDNA sequence corresponds to the AT5G25160 gene. Green color indicates the 5' UTR, yellow shows the open reading frame, and blue marks the 3'-UTR. The start and stop codons are highlighted in black. B) Amino acid sequence of A44 cDNA encoded ZINC FINGER PROTEIN 3. The Zinc finger domain is highlighted in grey color.

\title{
5.3.3. Re-transformation and confirmation of ZFP3 induced ABA insensitivity
}

To verify that ABA insensitivity of A44 is indeed caused by ZFP3 overexpression, we produced transgenic lines expressing the full-length cDNA of ZFP3 under the control of Estradiol-inducible promoter (ZFP3ox lines). Germination of seven out of ten independent ZFP3ox lines was less sensitive to ABA in the presence of Estradiol (Figure 11), thereby confirmed that ABA insensitivity of A44 seeds was indeed caused by ZFP3 overexpression. 


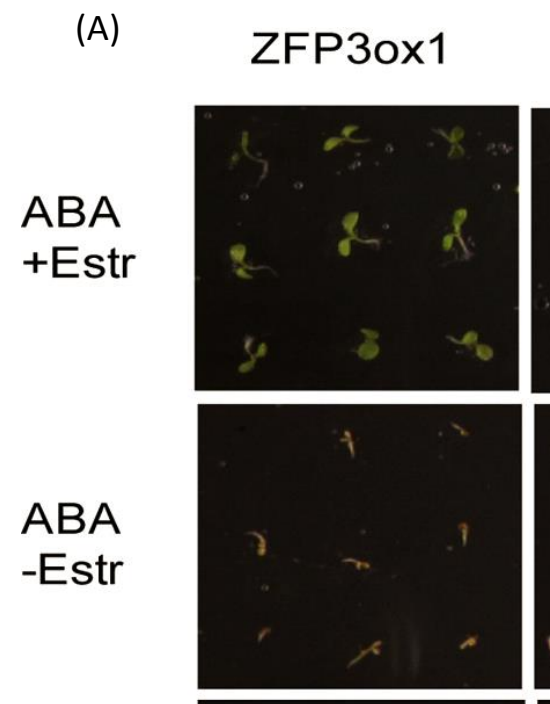

\section{ZFP3ox3}
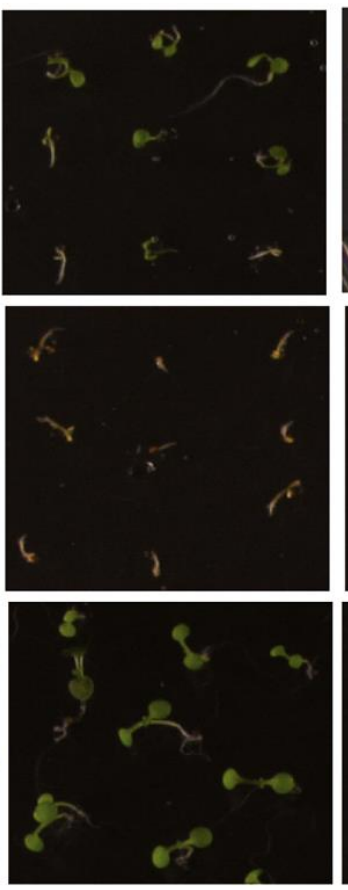

ZFP30x5
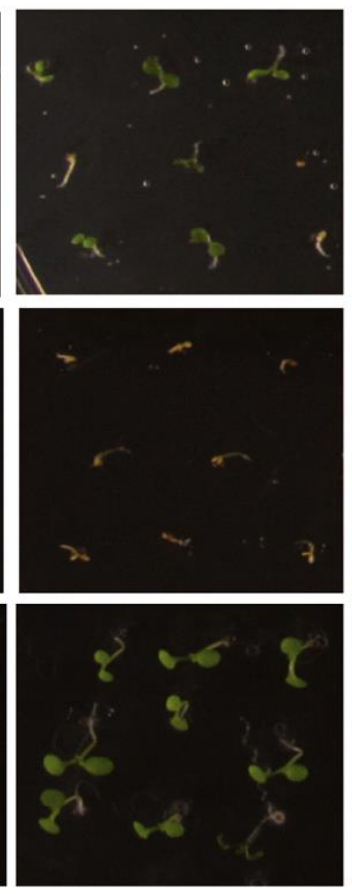

Col-0
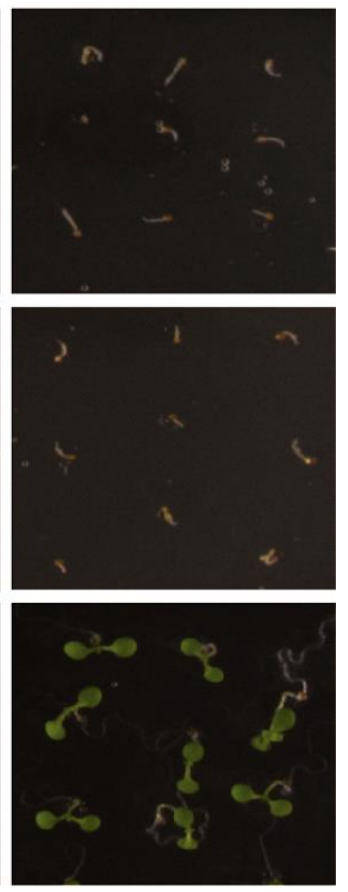

(B)

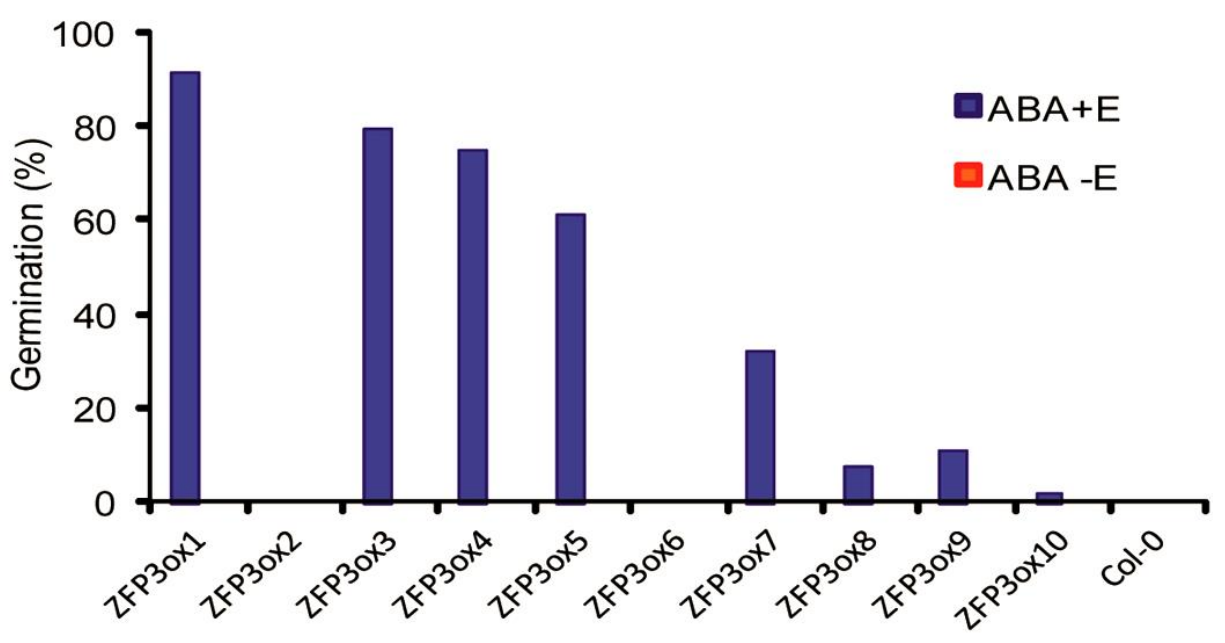

Figure 11: Germination assay of independent ZFP3ox lines. (A) Germination of three ZFP3ox lines and Col-0 wild type seeds on germination media containing $2 \mu \mathrm{M}$ ABA and $4 \mu \mathrm{M}$ Estradiol (upper row), 2 $\mu \mathrm{M}$ ABA (middle row) or only $4 \mu \mathrm{M}$ Estradiol (lower row). (B) Germination efficiencies of 10 independent ZFP3ox lines and Col-0. Germination frequencies were determined 15 days after plating the seeds on media containing $2 \mu \mathrm{M}$ ABA with or without $4 \mu \mathrm{M}$ Estradiol. 


\subsection{ZFP3 modulates ABA sensitivity}

\subsubsection{Genetic crosses and comparison of $Z F P 3$ with abi mutants}

We compared the ABA responses of ZFP3ox lines and known ABA signaling mutants and found that in germination assays the ABA insensitivity of ZFP3ox line was similar or even more pronounced than the tested abi2-1, abi4-101 and abi5-1 mutants (Figure 12). To analyze genetic interactions between ZFP3 and these ABI genes, ZFP3ox and abi2-1, abi4-101 and abi5-1 mutant plants were crossed. Germination of the hybrid abi/ZFP3ox lines had reduced sensitivity to ABA when compared to abi mutants or to the ZFP3ox line. The hybrids were able to germinate even in the presence of $20 \mu \mathrm{M}$ ABA and $4 \mu \mathrm{M}$ Estradiol (Figure 12), suggesting that ABA insensitivity of the abi mutants and ZFP3ox is additive. These data suggested that ZFP3 is a negative regulator of $\mathrm{ABA}$-mediated suppression of seed germination and acts in a signaling pathway, which is independent of ABI2, ABI4, and ABI5. 
$(\Delta)$

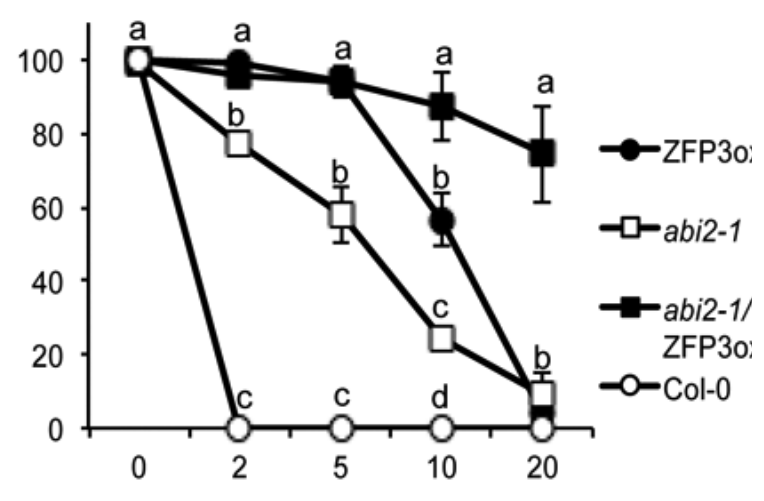

(B)

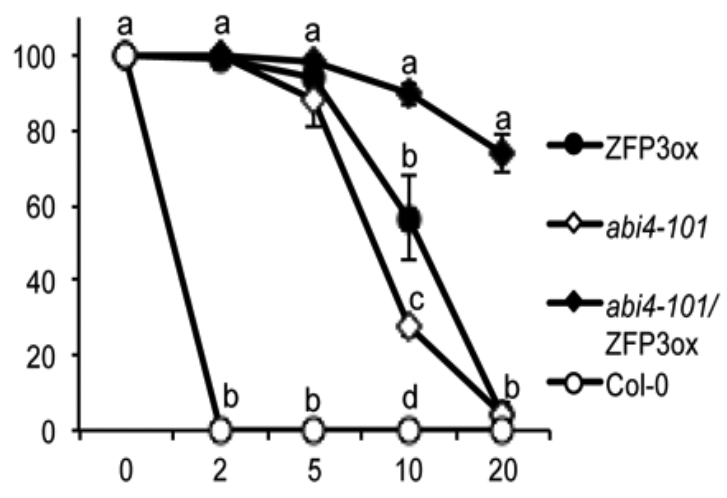

(C)

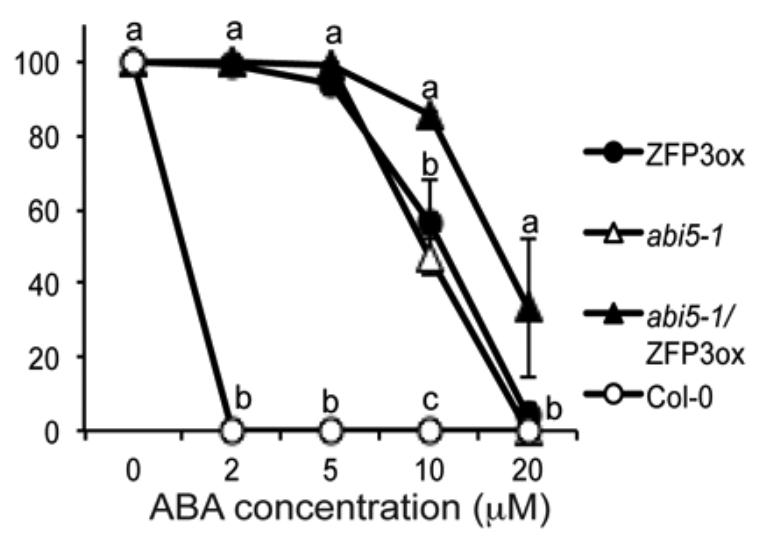

Figure 12: Genetic interaction study of ZFP3 and abi genes. (A) Comparison of ABA insensitivity of Col-0, ZFP3ox, abi2-1 mutant, and the crossed abi2-1/ZFP3ox line in germination assay (B) Comparison of ABA insensitivity of Col-0, ZFP3ox, abi4-101 mutant, and the crossed abi4-101/ZFP3ox line in germination assay. (C) Comparison of ABA insensitivity of Col-0, ZFP3ox, abi5-1 mutant, and the crossed abi5-1/ZFP3ox line in germination assay. Germination percentage was scored eight days after plating the imbibed seeds on germination media containing different concentrations of $\mathrm{ABA}(0-20 \mu \mathrm{M})$ and $4 \mu \mathrm{M}$ Estradiol. Averages of germination rates of two independent lines are shown. Bars on diagrams indicate standard errors, different letters show significant differences at $\mathrm{p}<0.05$ (Duncan-test). 


\subsubsection{Influence of $\mathrm{ABA}$ on $\mathrm{ZFP3}$ protein expression during germination}

To characterize the ZFP3 protein expression and stability, we produced transgenic lines expressing the full length cDNA of ZFP3 fused to HA tag under the control of 35S CaMV constitutive promoter. Western blotting confirmed the presence of the HA-ZFP3 fusion protein in germinating seedlings and indicated that the amount of the synthesized protein was influenced by ABA (Figure 13).

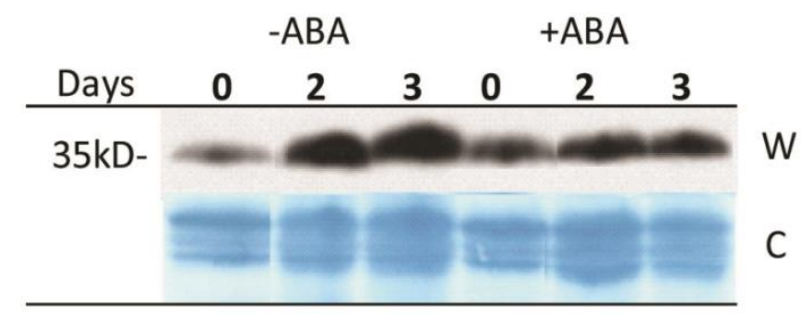

Figure 13: ZFP3 protein expression and stability. Western blot detection of ZFP3-HA fusion protein in extracts of transformed Arabidopsis seedlings (ZFP3ox) germinated in light. Protein extracts were prepared from imbibed seeds (day 0 ) and seedlings germinated for 2 or 3 days in the presence or absence of $2 \mu \mathrm{M}$ ABA. W- Western blot; C- Protein samples stained with Coomassie brilliant blue.

\subsubsection{Influence of $\mathrm{ABA}$ on $\mathrm{ZFP} 3$ transcriptional regulation during germination}

To test the expression of ZFP3 during germination, transcript levels were monitored in imbibed seeds and young Col-0 seedlings. After a slight decline, ZFP3 transcript levels increased steadily during germination. When seeds were germinated on ABA containing medium, ZFP3 transcription was reduced (Figure 14), showing good correlation with the public transcript data (Figure 19). 


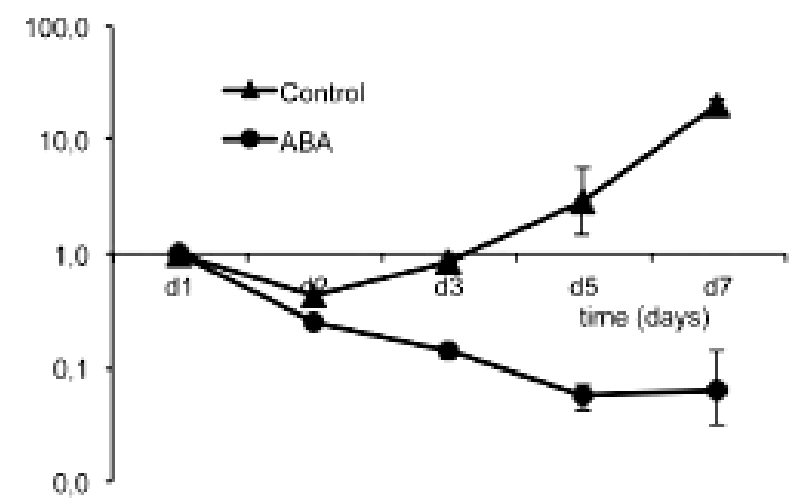

Figure 14: Transcriptional regulation of ZFP3 gene. Quantitative RT-PCR analysis of ZFP3 expression during germination. Wild type seeds were germinated in the absence (Control) or presence of $2 \mu \mathrm{M} \mathrm{ABA}$ (ABA). GAPDH2 (Atlg13440) was used as constitutive reference. Relative transcript values are shown, where 1 equals transcript levels at the start of germination.

\subsection{ZFP3 related $\mathrm{C} 2 \mathrm{H} 2$ type Zinc finger protein family}

\subsubsection{Phylogenetic analysis of ZFP3 related $\mathrm{C} 2 \mathrm{H} 2$ type Zinc Finger proteins}

ZFP3 is a member of the large $\mathrm{C} 2 \mathrm{H} 2$ Zinc finger protein family comprising 176 members in Arabidopsis (Englbrecht 2004). According to phylogenetic classification, ZFP3 belongs to the C1-1i subfamily, and is closely related to ZFP1, ZFP4, ZFP7 and the hypothetical protein encoded by AT5G10970 (Figure 15).

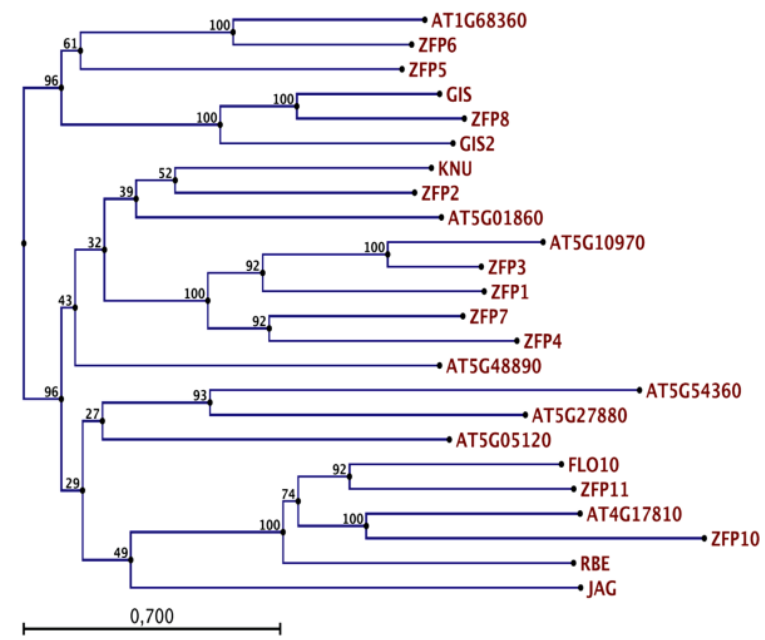

Figure 15: Phylogenetic tree of $24 \mathrm{C} 2 \mathrm{H} 2$ Zinc finger proteins belonging to the $\mathrm{C} 1-1 \mathrm{i}$ subfamily (Englbrecht 2004). 
Multiple sequence alignment of the most closely related proteins revealed that each protein is unique (Figure 16). They have very little identity apart from the zinc finger domain and their flanking regions. Presence of Serine/Threonine residues at the N-terminal region, leucine stretches at $\mathrm{N} \& \mathrm{C}$ terminal regions and the zinc finger domain suggest role in transactivation and protein- protein interaction. All 8 proteins have a putative NLS and DNA binding domains suggesting that they are targeted to the nucleus.

\begin{tabular}{|c|c|c|}
\hline $\mathrm{ZFP} 4$ & --MRPILDLEIEASSGSSSSQVASNLSPVGEDYKPIS-------- & 35 \\
\hline ZFP7 & 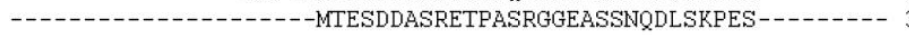 & 30 \\
\hline ZFP2 & - - - - - - & 31 \\
\hline ZFP3 & MDAS----------IVSSSTAFPYQDSLNQSIE-------DEERDVHN--------- & 31 \\
\hline AT5G10970 & MDSSSGKPRSSDSSCI ISASTSLQFSDSPKLSLENYNIDTVAAQEEDDHDQKEGVEGIKL & 60 \\
\hline ZFP1 & MEPS---------IKGDQEMLKIKKQGHQDLELG----LTLLSRGTATS-------- & 36 \\
\hline ZFP4 & 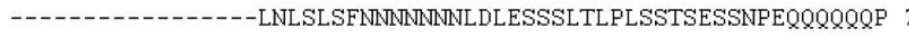 & 78 \\
\hline ZFP7 & 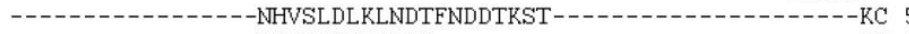 & 52 \\
\hline ZFP2 & 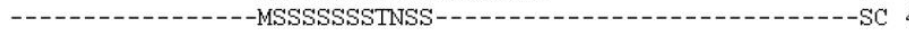 & 45 \\
\hline ZFP3 & 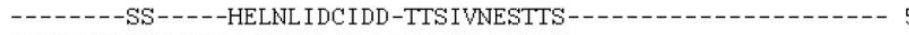 & 55 \\
\hline AT5G10970 & 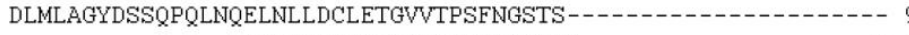 & 98 \\
\hline \multirow[t]{2}{*}{ ZFP1 } & 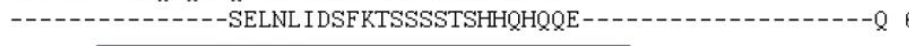 & 61 \\
\hline & ZnF_C2H2 domain & \\
\hline $\mathrm{ZFP} 4$ & SVSKRVESCNYCQRKFYSSQALGGHQNAHKRERTLAKRAMRM PLAGVF PGRGSSSNYAAA & 138 \\
\hline ZFP7 & EANPRVESCNYCRRKFYSSQALGGHQNAHKRERTMAKRAMHM/:RMFGH--HHRPYTYTSS & 110 \\
\hline ZFP2 & LEQPRVESCNYCQRKFYSSQALGGHQNAHKLERTLAKKSREL & 96 \\
\hline ZFP3 & -TEQKLFSCNYCQRTFYSSQALGGHQNAHKRERTLAKRGQ-- & 104 \\
\hline AT5G10970 & -TEQKLESCNYCQRTFYSSQALGGHQNAHKRERTLAKRGQ-- & 146 \\
\hline \multirow[t]{2}{*}{ ZFP1 } & LADPRVESCNYCQRKFYSSQALGGHQNAHKRERTLAKRGQYY |MTLS---SLPSSAFAFG & 118 \\
\hline & $\cdot::: * * * * * *: *, * * * * * * * * * * * * * * * * * *: * *:$ & \\
\hline ZFP 4 & ATAAALSCLPLHGSGNGNMTSF RTLGI RAHSSAHDVSMTRQTPETL I RNIARFNQGYFGN & 198 \\
\hline ZFP7 & S---1--1 & 143 \\
\hline ZFP2 & 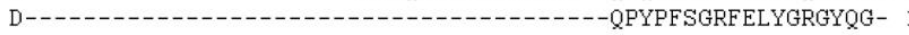 & 115 \\
\hline ZFP3 & HP-----YGFSPLPFHGQYNNHRSLGIQAHS ISHKLSSYNGFGGHYGQINWSRLPFDQQP & 159 \\
\hline AT5G10970 & HP-----YGFAPVPFHGQYSN-RTLGIQAHSMSHKPSSYNVYGGEYGQINWSRIPLVQQP & 200 \\
\hline ZFP1 & HGSVSRFASMASLPLHGSVNNRSTLGIQAHSTIHKPSFLGRQTTSLSHV--FKQSIHQKP & 176 \\
\hline ZFP4 & CIPFYVE----------DDEAEMLWPGSFRQATNAVAVEAGNDNLGERKMDFLDVKQ--A & 246 \\
\hline ZFP7 & TVPLFFD--Y-----DDGGSDFFWPGSFRQVVEEAEAPVVVVASTESGLDLNSVAANGG & 195 \\
\hline ZFP2 & 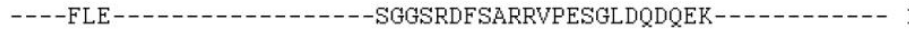 & 141 \\
\hline ZFP3 & AI GKFPSMDNFHHHHHQMMMMAPSVNSRSNNIDSPSNTGRVLEGSPTLEQWHGDKGLLLS & 219 \\
\hline AT5G10970 & AIAKLTSTEN--HYNHHQMMIAPPLTSTCENIGR-FDVGRIPVEFPTSELWQRGE-ELLK & 256 \\
\hline \multirow[t]{2}{*}{$\mathrm{ZFP} 1$} & TIGKMLPEKF--------------HLEVAGNNNSNMVAAKLERIGHFKSNQ ----- & 213 \\
\hline & NLS domain & \\
\hline ZFP4 & MDMES--SLPPLTLKL 260 & \\
\hline ZFP7 & VDNNS--SKPPLTLRL 209 & \\
\hline ZFP2 & ------SHLPLSLRL 150 & \\
\hline ZFP3 & TSHHEEQQKLPLSLKL 235 & \\
\hline AT5G10970 & PAEEEKQKNLPLSLKL 272 & \\
\hline ZFP1 & $\begin{array}{c}-E D H N Q F K K I P L T L K L \\
\cdot * *: * *\end{array}$ & \\
\hline
\end{tabular}

Figure 16: Multiple sequence alignment of 6 closely ZFP related proteins. Predicted Zinc finger domains and the nuclear localization signals are boxed. 


\subsubsection{Study of ZFP3 family genes}

The ZFP1, ZFP3, ZFP4, ZFP7 and ZFP8 cDNA's were cloned into gateway pER8-GW vector (Figure 17A), and were transformed into Col-0 plants. The seeds of T2 lines were tested for ABA tolerance (Figure 17 B). Estradiol-dependent overexpression of ZFP1, ZFP4, ZFP6 and ZFP7 in Arabidopsis led to ABA insensitive germination, comparable to the ZFP3ox line, while enhanced expression of ZFP8 had only minor effect on ABA sensitivity (Figure 17 B).

(A)

Regia TF factor cDNA collection

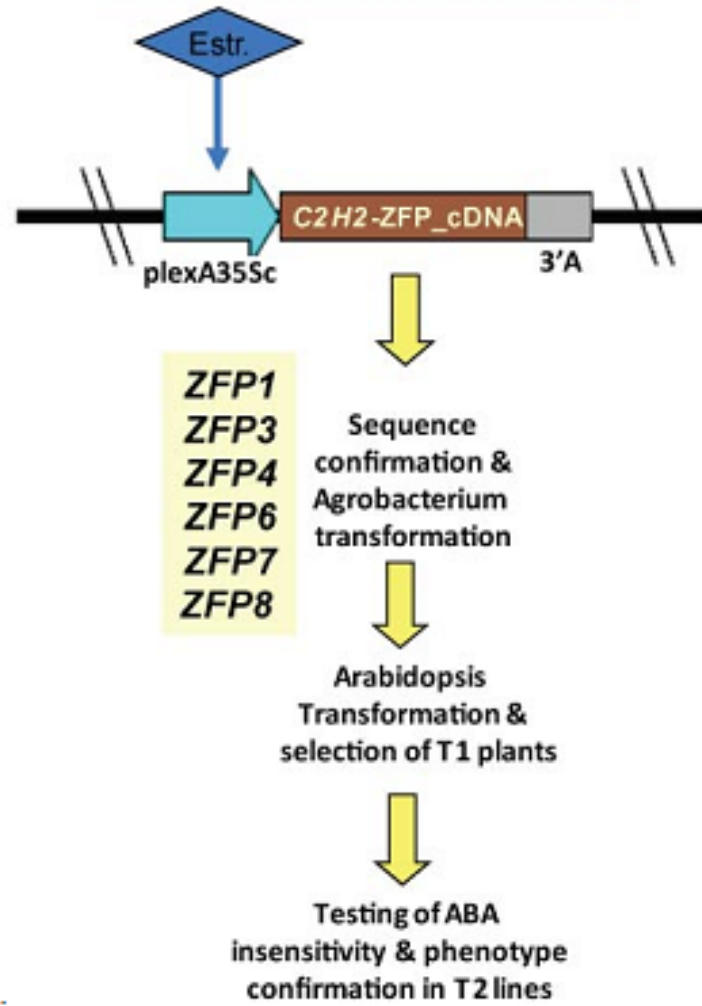

(B)

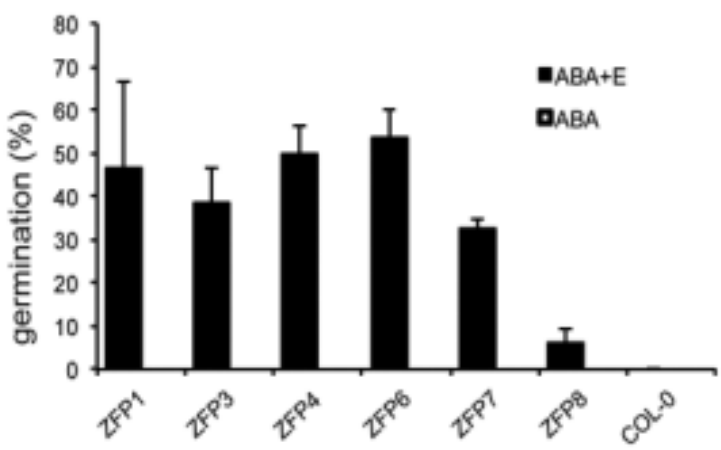

Figure 17: Cloning and overexpression of ZFP1, ZFP3, ZFP4, ZFP6, ZFP7, ZFP8 factors in Arabidopsis plants. (A) Schematic Diagram of cloning $\mathrm{C} 2 \mathrm{H} 2-\mathrm{ZFPs}$ into pER8 Vectors. (B) Germination of T2 generation seeds of ZFP overexpressing lines on $2.5 \mu \mathrm{M}$ ABA with or without $4 \mu \mathrm{M}$ Estradiol.

\subsubsection{Transcriptional regulation of $\mathrm{ZFP3}$ and related genes}

Public transcript profiling data (http://bar.utoronto.ca/efp_arabidopsis/cgibin/efpWeb.cgi) provided preliminary information about the expression of ZFP3 and its related genes. Transcript profiles of ten ZFP3-related genes showed considerable developmental and organ specific variation (Figure 18). ZFP3 is expressed in hypocotyl, roots, and to a less extent 
in young leaves, shoot apices, and flowers. Expression of ZFP1, ZFP5, ZFP10 and ZFP11 is very low in most organs. ZFP2 transcription is high in flowers and developing seeds, ZFP6 expression is high in hypocotyls, roots and stems, while ZFP4, ZFP7 and ZFP8 transcripts were detected mostly in leaves, roots, cotyledons and shoot apices.

\begin{tabular}{|c|c|c|c|c|c|c|c|c|c|c|}
\hline Tissue & ZFP1 & ZFP2 & ZFP3 & ZFP4 & ZFP5 & ZFP6 & ZFP7 & ZFPB & ZFP10 & ZFP11 \\
\hline Dry seed & 1.28 & 0.75 & 2.33 & 2.56 & 5.81 & 9.63 & 10.98 & 24.17 & 2 & 2.24 \\
\hline Imbibed seed, 24 h & 0.39 & 3.04 & 0.75 & 19.18 & 0.47 & 8.08 & 33.89 & 33.14 & 3.09 & 2.17 \\
\hline Hypocotyl & 4.75 & 13.58 & 36.26 & 54.35 & 55.28 & 100.21 & 178.43 & 18.64 & 18.76 & 3.63 \\
\hline Cotyledon & 4.28 & 5.59 & 4.68 & 44.95 & 11.23 & 7.63 & 74.36 & 156.96 & 8.81 & 4.3 \\
\hline Root, seedling & 12.81 & 4.06 & 92.83 & 116.48 & 95.93 & 133.48 & 97.03 & 12.86 & 17.34 & 3.06 \\
\hline Leaf $1+2$ & 2.91 & 3.51 & 1.96 & 27.39 & 12.13 & 12.25 & 61.98 & 116.38 & 4.68 & 6.48 \\
\hline Rosette Leaf 2 & 2.15 & 9.48 & 7.51 & 104 & 9.18 & 9.36 & 87.76 & 219.96 & 8.06 & 3.83 \\
\hline Rosette Leaf 4 & 1.29 & 6.53 & 9.58 & 73 & 8.31 & 7.55 & 72.86 & 232.41 & 3.81 & 3.3 \\
\hline Rosette Leaf 6 & 2.6 & 4.83 & 9.78 & 53.61 & 8.25 & 8.85 & 77.55 & 222.48 & 6.53 & 3.79 \\
\hline Leaf 7, Petiole & 5.36 & 7.19 & 9.53 & 44.8 & 11.18 & 8.04 & 86.5 & 223.16 & 7.28 & 5.11 \\
\hline Leaf 7, Distal Half & 2.33 & 7.25 & 7.58 & 55.58 & 6.8 & 7.71 & 61.96 & 244.58 & 5.48 & 5 \\
\hline Leaf 7, Proximal Half & 5.26 & p.56 & 1.53 & 50.3 & 8.31 & 11.98 & 63.78 & 272.98 & 7.81 & 3.13 \\
\hline Rosette Leaf 8 & 3.83 & 5.16 & 3.76 & 44.08 & 7.38 & 8.88 & 64.78 & 171.36 & 2.55 & 3.28 \\
\hline Rosette Leaf 10 & 4.56 & 4.25 & 3.28 & 63.75 & 13.21 & 7.86 & 62.6 & 204.05 & 5.63 & 3.73 \\
\hline Rosette Leaf 12 & 2 & 8.76 & 2.68 & 62.96 & 12.06 & 10.1 & 70.73 & 186.89 & 3.08 & 6.03 \\
\hline Cauline Leaf & 1.33 & 31.16 & 2.48 & 39.3 & 7.6 & 15.94 & 99.33 & 302.96 & 5.26 & 2.95 \\
\hline Vegetative Rosette & 2.31 & 1.46 & 2.28 & 52.71 & 11.45 & 9.15 & 105.43 & 113.28 & 3.5 & 5.34 \\
\hline Rosette During Flowering & 5.33 & 5.81 & 10.93 & 72.08 & 9.98 & 10.36 & 71.41 & 195.21 & 5.85 & 4.78 \\
\hline Senescing leaf & 0.53 & 2.83 & 3.86 & 39.31 & 7.01 & 10.73 & 147.68 & 78.11 & 7.23 & 2.78 \\
\hline Root, plant & 12.35 & 2.66 & 95.65 & 81.6 & 87.9 & 82.5 & 115.76 & 12.2 & 6.83 & 1.85 \\
\hline Stem, 2nd Internode & 18.4 & 221.9 & 6.03 & 87.4 & 29.36 & 271.96 & 80.58 & 47 & 5.03 & 4.8 \\
\hline 1st Node & 18 & 34.86 & 26.31 & 156.66 & 21.96 & 197.68 & 93.35 & 48.68 & 2.18 & 4.93 \\
\hline Shoot Apex, Vegetative & 8.44 & 11.8 & 20.9 & 25.28 & 10.41 & 11.91 & 112.06 & 67.98 & 3.88 & 6.26 \\
\hline Shoot Apex, Transition & 7.65 & 2.16 & 19.18 & 22.16 & 8.51 & 8.29 & 66.98 & 50.8 & 5.95 & 5.15 \\
\hline Shoot Apex, Inflorescence & 5.09 & 4.89 & 7.55 & 5.93 & 4.33 & 5.65 & 36.94 & 20.13 & 1.41 & 9.83 \\
\hline Flower Stage 9 & 4.21 & 8.13 & 2.91 & 0.61 & 2.28 & 6.7 & 13.98 & 7.33 & 1.55 & 18.18 \\
\hline Flower Stage 10/11 & 5.55 & 9.94 & 2.21 & 0.71 & 6.98 & 5.65 & 10.45 & 13 & 4.96 & 17.45 \\
\hline Flower Stage 12 & 8.08 & 14.46 & 4.86 & 1.15 & 7.78 & 6.23 & 12.98 & 14.11 & 4.81 & 27.98 \\
\hline Flower Stage 15 & 2.8 & 96.51 & 3.88 & 7.3 & 3.91 & 8.95 & 25.2 & 12.7 & 3.16 & 24.58 \\
\hline Flower Stage 12, Carpels & 7.36 & 8.33 & 0.96 & 0.93 & 8.25 & 6.86 & 14.86 & 21.88 & 9.11 & 62.98 \\
\hline Flower Stage 12, Petals & 2.61 & 3.83 & 3.56 & 0.96 & 8.21 & 5.78 & 13.65 & 11.05 & 4.68 & 2.25 \\
\hline Flower Stage 12, Stamens & 0.75 & 3.26 & 4.28 & 0.68 & 4.28 & 5.51 & 15.63 & 8.56 & 2.98 & 1.63 \\
\hline Flower Stage 12, Sepals & 0.54 & 62.25 & 3.18 & 1.31 & 2.03 & 6.93 & 11.86 & 13.33 & 4.35 & 3.43 \\
\hline Flower Stage 15, Carpels & 2.01 & 91.06 & 0.83 & 1.13 & 7.36 & 7.98 & 14.33 & 42.98 & 8.29 & 36.69 \\
\hline Flower Stage 15, Petals & 0.96 & 174.56 & 10.16 & 6.15 & 6.18 & 8.21 & 53 & 9.78 & 2.13 & 2.88 \\
\hline Flower Stage 15, Sepals & 1.04 & 156.41 & 3.81 & 1.51 & 3.86 & 11.76 & 16.26 & 12.33 & 2.15 & 2.29 \\
\hline Flower Stage 15, Stamen & 2.48 & 123.73 & 12.96 & 3.9 & 4.21 & 9.29 & 30.38 & 13.4 & 5.21 & 3.36 \\
\hline Flowera Stage 15, Pedicels & 20.21 & 49.26 & 2.84 & 17.91 & 11.85 & 34.19 & 71.8 & 53.55 & 4.16 & 4.93 \\
\hline Mature Pollen & 5.08 & 2.86 & 7.16 & 1.58 & 7.91 & 23.03 & 34.33 & 50.45 & 9.58 & 8.13 \\
\hline Seeds Stage $3 \mathrm{w} /$ Siliques & 6.81 & 327.48 & 0.8 & 14.6 & 15.49 & 22.35 & 26.85 & 86.51 & 5.41 & 11.35 \\
\hline Seeds Stage $4 \mathrm{w} /$ Siliques & 0.68 & 474.71 & 2.71 & 5.09 & 12.61 & 13.28 & 8.79 & 63.78 & 9.06 & 6.34 \\
\hline Seeds Stage $5 \mathrm{w} /$ Siliques & 2.13 & 495.83 & 1.61 & 4.28 & 9.81 & 15.55 & 10.68 & 91.81 & 7.13 & 3.45 \\
\hline Seeds Stage $6 \mathrm{w} / \mathrm{o}$ Siliques & 3.81 & 17.76 & 7.48 & 4.38 & 10.31 & 10.78 & 9.66 & 89.68 & 9.06 & 6.68 \\
\hline Seeds Stage $7 \mathrm{w} / \mathrm{o}$ Siliques & 2.91 & 7.85 & 13 & 3.76 & 11.5 & 28.33 & 11.8 & 45.95 & 9.9 & 6 \\
\hline Seeds Stage $8 \mathrm{w} / 0$ Siliques & 10.04 & 17.68 & 4.25 & 12.16 & 17.53 & 19.09 & 16.2 & 36.88 & 7.34 & 8.9 \\
\hline Seeds Stage $9 \mathrm{w} / 0$ Siliques & 11.86 & 5.15 & 9.35 & 4.31 & 19.7 & 29.76 & 23.05 & 32.71 & 6.7 & 10.91 \\
\hline Seeds Stage $10 \mathrm{w} / \mathrm{o}$ Siliques & 6.15 & 9.03 & 14.8 & 5.53 & 20.28 & 26.2 & 21.23 & 37.55 & 15.91 & 5.2 \\
\hline
\end{tabular}

Figure 18: Developmental regulation of 10 ZFP-related genes. Expression profiles were extracted from databases of public microarray data (eFP Browser tool,bar.utoronto.ca/efp_arabidopsis/cgibin/efpWeb.cgi). Color code indicate low (green),medium (yellow) and high (red) expression levels. 
Responses to plant hormones of these ZFP genes varied considerably too. While ABA reduced the transcript levels of most ZFP genes, it enhanced the expression of ZFP5 (Figure 19). Expression of ZFP3 was reduced mostly by ABA and MeJa.

\begin{tabular}{|c|c|c|c|c|c|c|c|c|c|c|c|}
\hline Hormone & time & ZFP1 & ZFP2 & ZFP3 & ZFP4 & ZFP5 & ZFP6 & ZFP7 & ZFP8 & ZFP10 & ZFP11 \\
\hline $\mathrm{ACC}$ & $0.5 \mathrm{~h}$ & -1.42 & -0.17 & -0.25 & -0.1 & 0.47 & 0.4 & 0.38 & 0.13 & 0.85 & 0.15 \\
\hline $\mathrm{ACC}$ & $1.0 \mathrm{~h}$ & 0.41 & 1.14 & -0.22 & 0.14 & 0.89 & 0.2 & 0.31 & 0.08 & -0.04 & 1.96 \\
\hline $\mathrm{ACC}$ & $3.0 \mathrm{~h}$ & 0.32 & 0.84 & -0.5 & 0.37 & 0.57 & -0.22 & -0.57 & -0.28 & -0.41 & 0.09 \\
\hline Zeatin & $0.5 \mathrm{~h}$ & 0.37 & -2.18 & 0.76 & 0.37 & 1.17 & 0.54 & -0.41 & 0.06 & 1.38 & -0.47 \\
\hline Zeatin & $1.0 \mathrm{~h}$ & 0.8 & -0.46 & 0.2 & 0.84 & 0.69 & 0.43 & 0.28 & 0.39 & -0.56 & 1.61 \\
\hline Zeatin & $3.0 \mathrm{~h}$ & 0.88 & -0.32 & -0.14 & 0.4 & 0.88 & 0.26 & -0.23 & 0.19 & -0.29 & -0.3 \\
\hline IAA & $0.5 \mathrm{~h}$ & 1.2 & 0.89 & 0.18 & -0.03 & -0.56 & -0.63 & -0.02 & -0.07 & 0.34 & -0.31 \\
\hline IAA & $1.0 \mathrm{~h}$ & 2.01 & 2.02 & -0.28 & -0.33 & -1.76 & -0.57 & 0.06 & 0.18 & -1.23 & 1.24 \\
\hline IAA & $3.0 \mathrm{~h}$ & 1.08 & 3.09 & -0.81 & -0.17 & 0.45 & -0.66 & -0.01 & -0.38 & -0.05 & 0.12 \\
\hline$A B A$ & $0.5 h$ & -0.08 & -0.58 & -0.69 & -0.37 & -0.62 & 0.21 & -0.1 & -0.39 & -0.03 & -0.17 \\
\hline$A B A$ & $1.0 h$ & 0.07 & -0.64 & -0.71 & -0.69 & 0.33 & 0.22 & -0.48 & -0.59 & -0.53 & 1.51 \\
\hline$A B A$ & $3.0 h$ & -0.21 & 1.33 & -0.21 & -0.69 & 2.85 & -0.72 & -0.75 & -1.52 & -1.73 & -0.72 \\
\hline MeJa & $0.5 \mathrm{~h}$ & -0.72 & 0.84 & -1.44 & -0.22 & 0.02 & -0.29 & 0.73 & -0.32 & 0.21 & -0.64 \\
\hline MeJa & $1.0 \mathrm{~h}$ & 0.97 & -0.33 & -1.79 & -0.12 & 0.27 & -0.86 & 0.57 & -0.21 & 0.02 & 1.8 \\
\hline MeJa & $3.0 \mathrm{~h}$ & 0.26 & -1.04 & -1.55 & 0.05 & 0.81 & -0.07 & 0.48 & -0.1 & -0.18 & 0.31 \\
\hline GA3 & $0.5 \mathrm{~h}$ & -0.42 & -0.05 & -0.48 & -0.1 & 0.11 & -0.24 & -0.19 & 0.07 & 0.24 & -0.5 \\
\hline GA3 & $1.0 \mathrm{~h}$ & -0.03 & -0.02 & -0.28 & -0.14 & 0.1 & -0.32 & -0.05 & 0.2 & 0.42 & 2.08 \\
\hline GA3 & $3.0 \mathrm{~h}$ & -0.14 & -0.22 & -1.28 & 0.03 & 0.76 & -0.17 & -0.16 & 0.18 & 0.5 & 0.49 \\
\hline $\mathrm{BL}$ & $0.5 \mathrm{~h}$ & -0.36 & 1.54 & 0.02 & -0.27 & -0.08 & 0.52 & 0.37 & 0.59 & 0.05 & 0.06 \\
\hline $\mathrm{BL}$ & $1.0 \mathrm{~h}$ & -0.04 & 0.26 & -0.09 & 0.18 & 0.33 & 0.01 & 0.59 & 0.71 & 0.67 & 1.03 \\
\hline $\mathrm{BL}$ & $3.0 \mathrm{~h}$ & 0.85 & -1.16 & -0.28 & 0.28 & 0.61 & 0.12 & 0.25 & 0.21 & -0.01 & -0.32 \\
\hline
\end{tabular}

Figure 19: Hormonal regulation of AtZFP genes. Expression profiles were extracted from databases of public microarray data (eFP Browser tool, bar.utoronto.ca/efp_arabidopsis/cgi-bin/efpWeb.cgi). Color codes indicate repression (green), no change (yellow) and induction (red) by a particular treatment.

\subsection{Spatial transcriptional regulation of ZFP3 expression}

Spatial transcriptional regulation of ZFP3 expression was investigated by testing the activity of the ZFP3 promoter GUS reporter gene construct (pZFP3-GUS) in transgenic Arabidopsis plants using X-gluc histochemical staining. GUS activity was present in chalaza/micropylar axis in developing and mature seeds, but not in the embryo itself (Figure 20 a-c \& s), it could be detected in emerging radicles and later in hypocotyl and cotyledons of germinating seedlings (Figure $20 \mathrm{~d}$-e). In young seedlings pZFP3-GUS activity was present in roots and in hypocotyls of dark-germinated seedlings (Figure $20 \mathrm{f}-\mathrm{i}$ ). In older plants GUS was detectable in leaves and in roots, in particular in emerging lateral roots (Figure $20 \mathrm{j}-\mathrm{n}$ ). GUS activity was present in flowers, in particular in pedicels, stamen and stigma (Figure 20 o-r). 
These data suggest that ZFP3 is expressed in most organs, showing certain tissue specificity and developmental regulation.

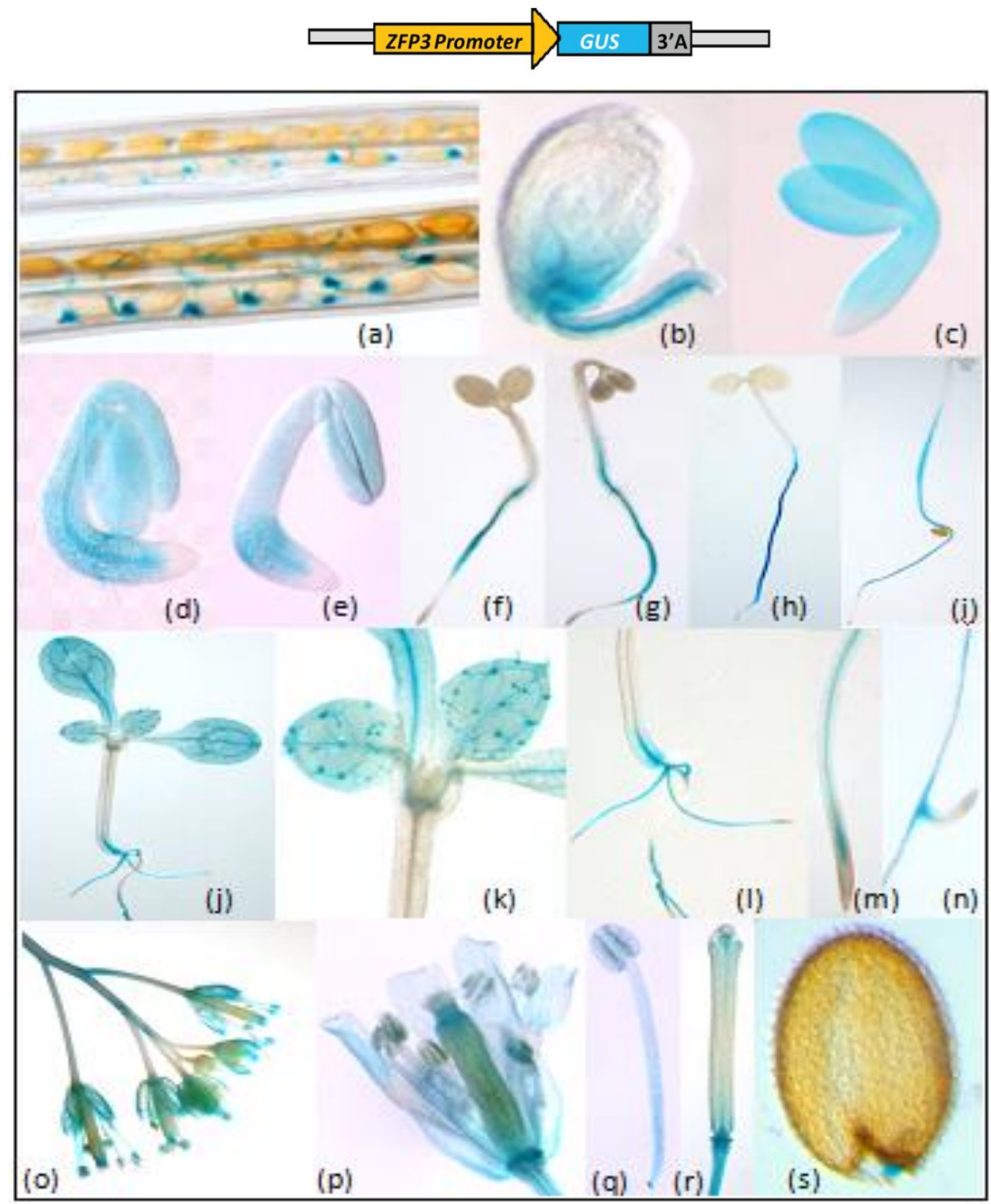

Figure 20: Histochemical assays show AtZFP3Promoter::GUS expression patterns at different stages of development grown under normal growth conditions. (a) Siliques; (b) Heart stage embryo; (c) Upturned U stage embryo; (d) 1 day old seedling in light; (e) 1 day old seedling in dark; (f) 2 day old seedling in light; (g) 2 day old seedling in dark; (h) 1 day old seedling in light; (i) 1 day old seedling in dark; (j) 10 day old seedling in light; (k) Primary leaves \& Shoot apex; (l) A part of the primary root close to the hypocotyl; (m) A primary root tip; (n) Developing lateral roots; (o) pedicels; (p) flower; (q) stamen; (r) stigma;(s) Imbibed seeds-72 hours. 


\subsection{ZFP3 protein localization study}

Nuclear localization signals were found in ZFP3 and in the related ZFP proteins (Figure16). To verify its intracellular localization, ZFP3 was fused to enhanced green fluorescent protein (eGFP) marker gene and expressed in cultured cells or transgenic plants under the control of the CaMV35S promoter. Fluorescence pattern of eGFP suggested that the ZFP3 protein is localized in nuclei but not in the nucleolus (Figure 21A-D). To confirm these data, both $\mathrm{N}$ or $\mathrm{C}$ terminal HA tagged ZFP3 fusion proteins were expressed in Arabidopsis under the control of the CaMV35S promoter and abundance level of ZFP3-HA was determined in sub cellular fractions separated by differential centrifugation. Western blotting detected the HA-ZFP3 fusion protein only in nuclear but not in the cytoplasmic fractions thereby confirmed nuclear localization of ZFP3 protein (Figure 21E).
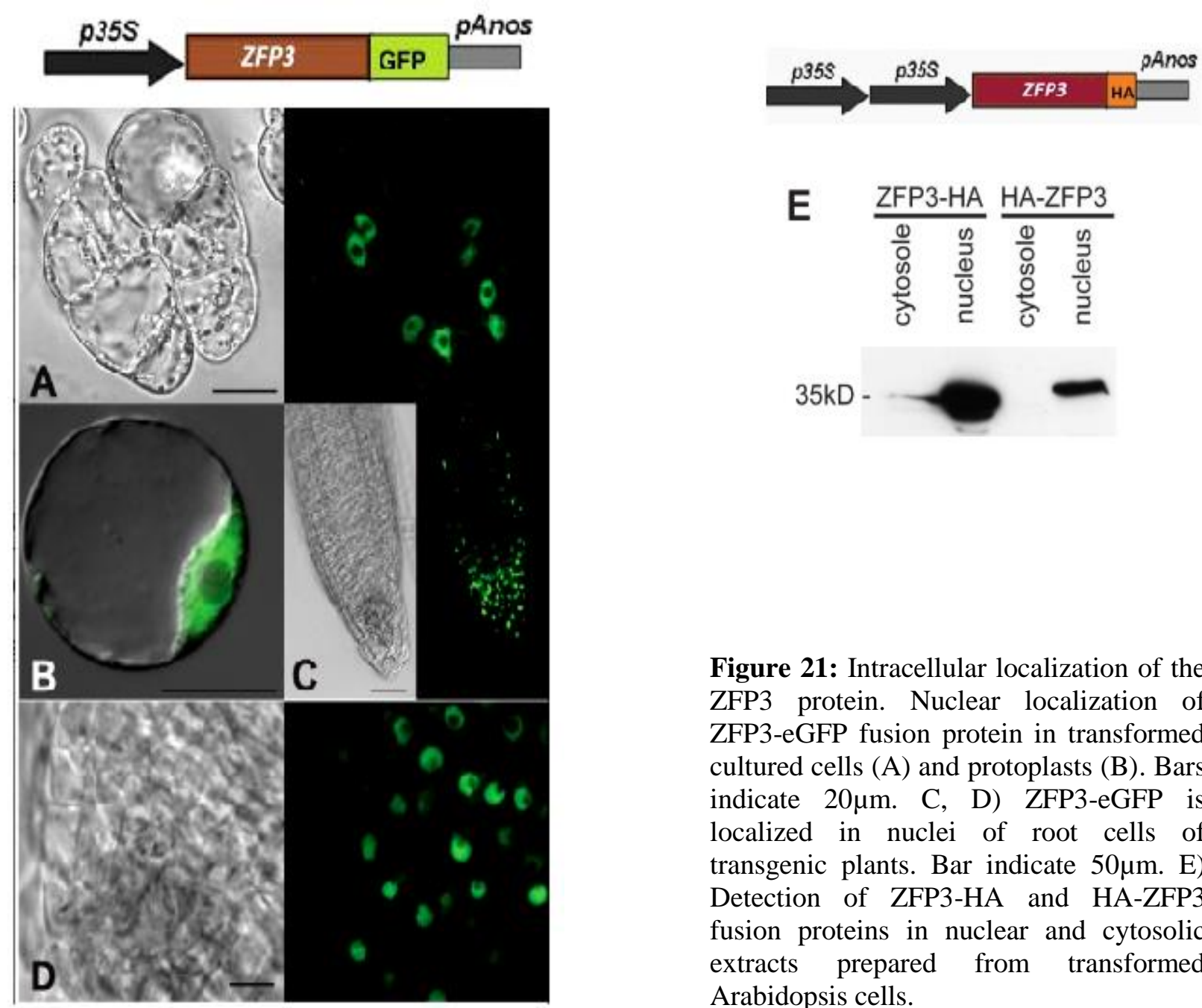

Figure 21: Intracellular localization of the ZFP3 protein. Nuclear localization of ZFP3-eGFP fusion protein in transformed cultured cells (A) and protoplasts (B). Bars indicate $20 \mu \mathrm{m}$. C, D) ZFP3-eGFP is localized in nuclei of root cells of transgenic plants. Bar indicate $50 \mu \mathrm{m}$. E) Detection of ZFP3-HA and HA-ZFP3 fusion proteins in nuclear and cytosolic extracts prepared from transformed Arabidopsis cells. 


\subsection{Characterization of $z f p 3$ and $z f p 4$ T-DNA insertion mutants}

\subsubsection{Genotyping of $z f p 3$ and $z f p 4$ single and double mutants}

To obtain more precise data on the function of individual ZFP genes, T-DNA insertions in ZFP3 and ZFP4 were obtained from the public mutant collections (Figure $22 \mathrm{~A}$ ). Quantitative real-time (qRT-PCR) analysis showed that the T-DNA insertion mutations reduced the corresponding transcripts in homozygous zfp3 and $z f p 4$ mutants by at least one order of magnitude. Therefore the homozygous zfp3 and zfp4 mutants were crossed and the segregated homozygous double mutant was confirmed for the insertions and expression levels (Figure $22 \mathrm{~B}$ ).

(A)

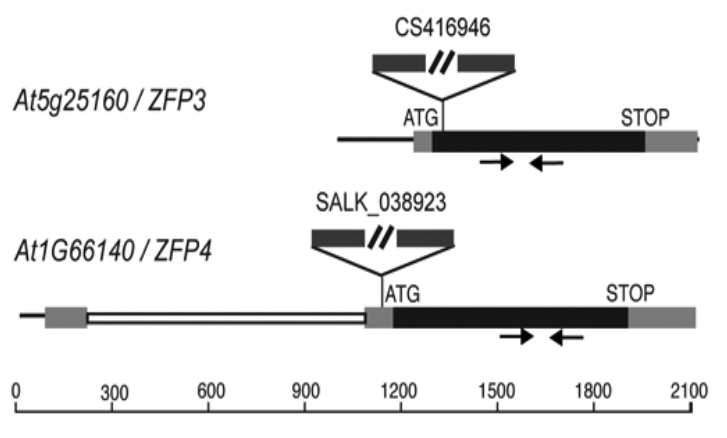

(B)

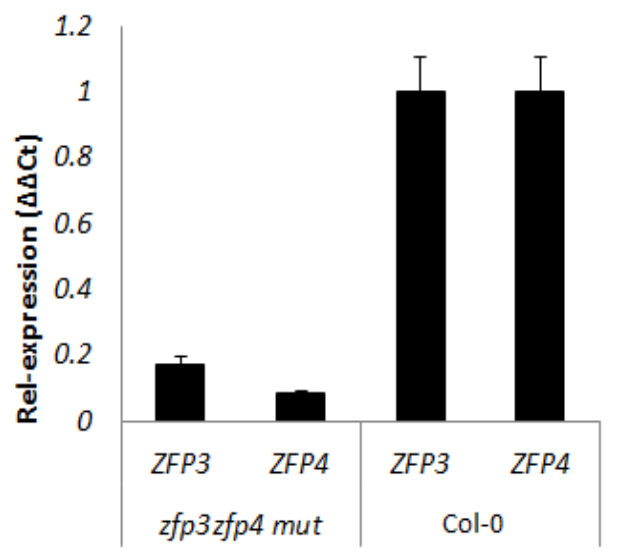

Figure 22: Genotyping of zfp3 (CS416946) and zfp4 (SALK_038923)mutants. (A) Schematic map of TDNA insertions in $z f p 3$ and $z f p 4$ mutants. Positions of PCR primers used for monitoring the transcription of mutant alleles are indicated below the maps. B) Transcript levels of ZFP3 and ZFP4 in homozygous double mutant zfp3 zfp4, determined by quantitative RT-PCR. Reference: GAPDH2 gene (At1g13440).

\subsubsection{Complementation of the $z f p 3$ mutant}

To perform genetic complementation of the zfp3 mutant, the ZFP3 gene construct in the Estradiol inducible pER8-GW vector was introduced into the homozygous zfp3 mutant by Agrobacterium-mediated transformation. Eight transgenic lines were subjected to characterization. ABA hypersensitivity of the zfp3 mutant was restored to different levels of insensitivity in 6 examined genetically complemented zfp3 lines (Figure 23). 


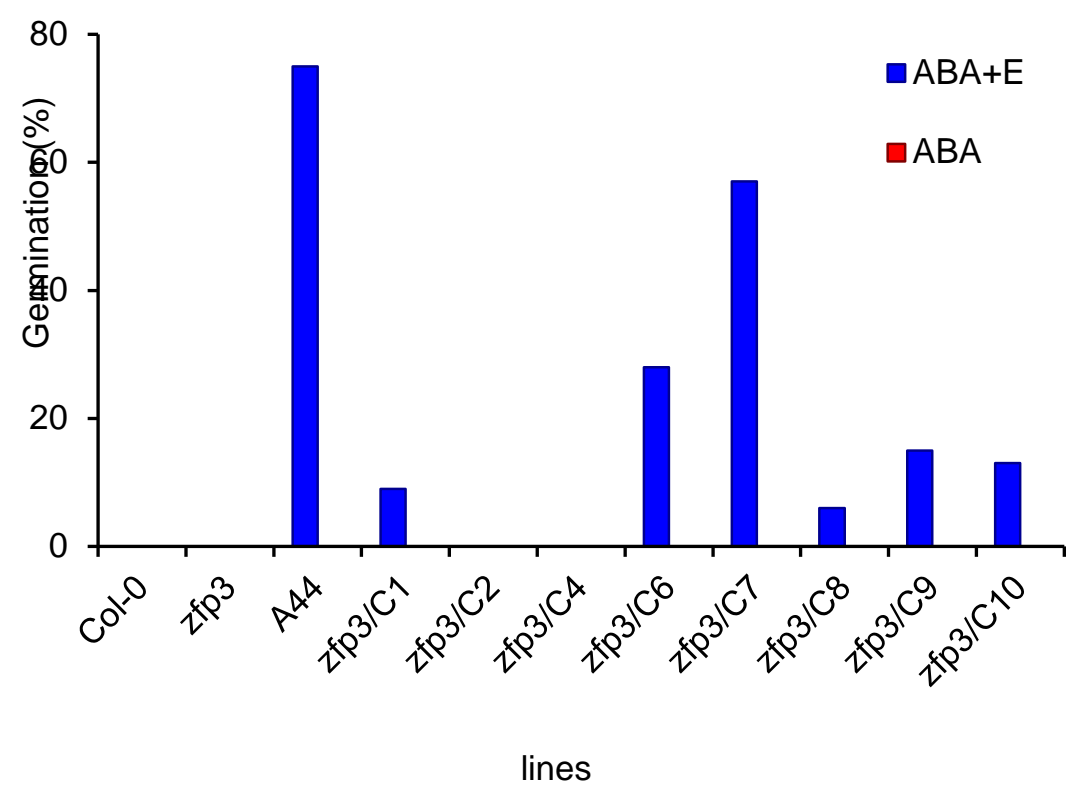

Figure 23: Complementation of $z f p 3$ mutant with ER8:ZFP3 construct. Germination assay of Col-0 wild type, zfp 3 mutant and eight complemented lines on media supplemented with $2.5 \mu \mathrm{M}$ ABA with or without $5 \mu \mathrm{M}$ Estradiol (E). Germination frequencies were scored 12 days after plating the seeds.

\subsubsection{ABA sensitivity of $z f p 3$ and $z f p 4$ mutants and $z f p 3 z f p 4$ double mutant}

To test whether they have distinct or overlapping functions in the germination process, $z f p 3$ and $z f p 4$ single and double mutant were tested for ABA sensitivity. The sensitivity of $z f p 3$ and $z f p 4$ mutants to ABA was higher compared to wild type, whereas the double zfp3 zfp 4 mutant displayed more pronounced ABA hypersensitivity since its germination efficiency was reduced to $40 \%$ and $15 \%$ of wild type in the presence of 0.4 and $0.6 \mu \mathrm{M} \mathrm{ABA}$, respectively (Figure $24 \mathrm{~A}, \mathrm{~B}$ ). Enhanced ABA sensitivity of the double zfp 3 z.fp4 mutant suggests that other members of the ZFP gene family might analogously control ABA responses in germination, having at least partially redundant biological function. 

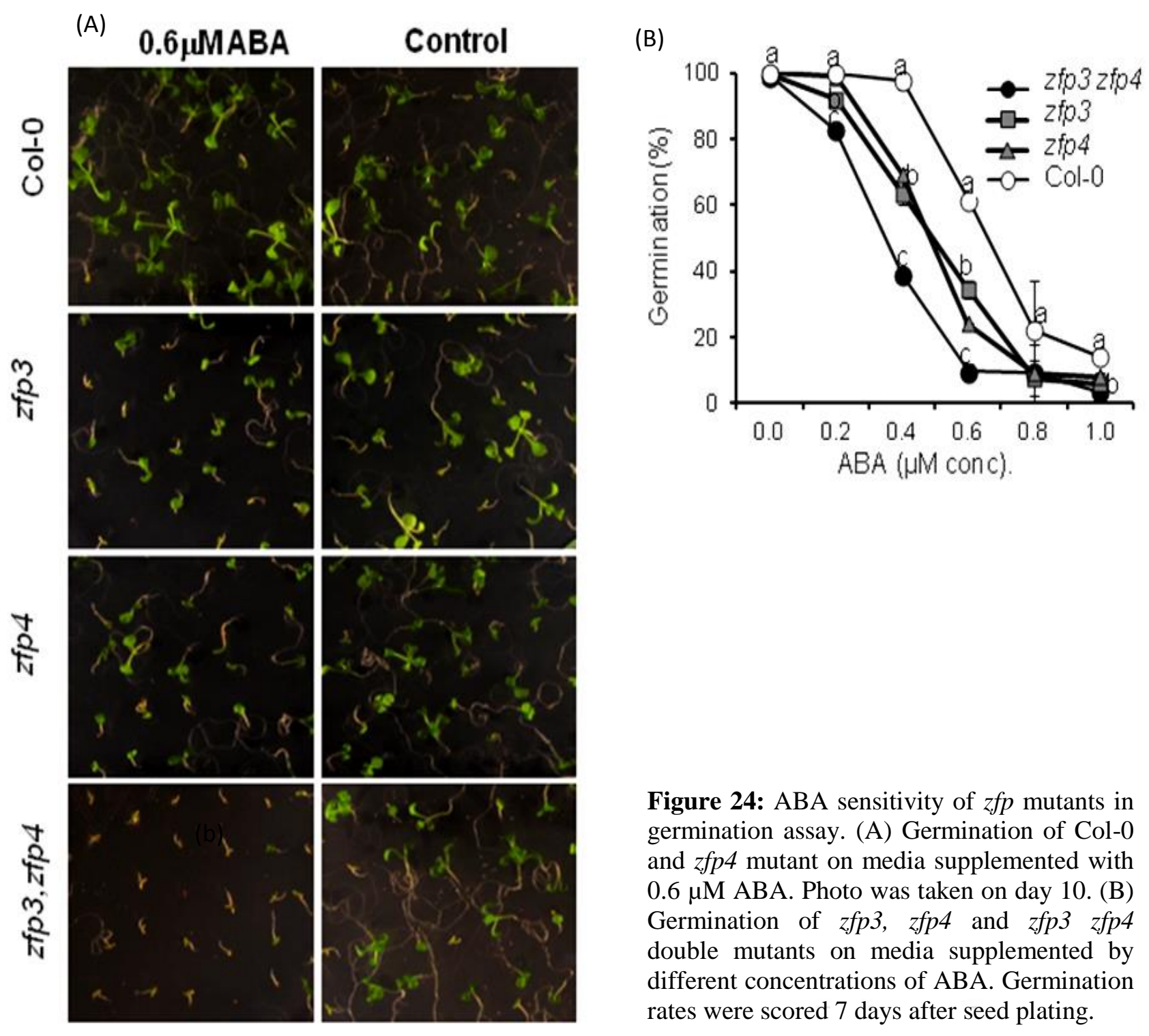

Figure 24: ABA sensitivity of $z f p$ mutants in germination assay. (A) Germination of Col-0 and $z f p 4$ mutant on media supplemented with $0.6 \mu \mathrm{M}$ ABA. Photo was taken on day 10. (B) Germination of zfp3, zfp4 and zfp3 zfp4 double mutants on media supplemented by different concentrations of ABA. Germination rates were scored 7 days after seed plating.

\subsubsection{Measurement of $A B A$ content}

To test whether the different germination response to ABA observed in the ZFP3 overexpressing and mutant lines is due to altered ABA metabolism, the ABA content of ZFP3ox and $z f p 3$ mutant was determined. There was no significant change in ABA levels of ZFP3ox and zfp3 plants compared to wild type (Figure 25), suggesting that the observed germination phenotype was the result of a change in either ABA perception or signal transduction. 


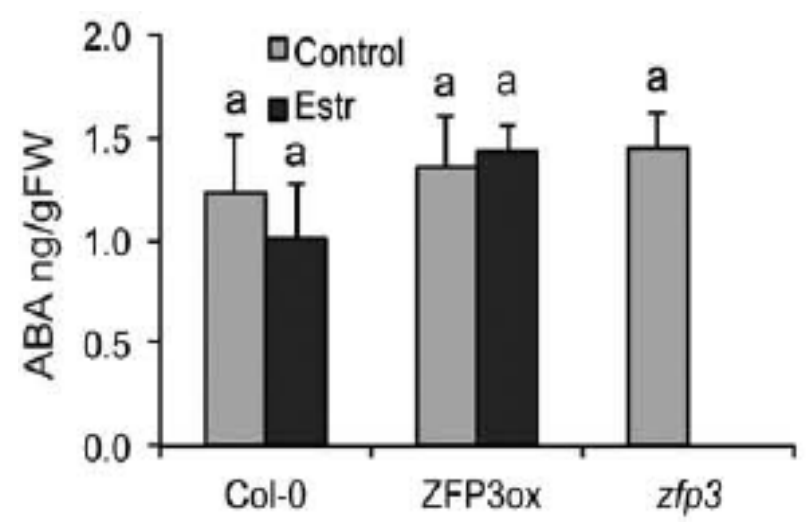

Figure 25: ABA content measurement of 7 days-old Col-0, ZFP3ox and zfp3 knockout mutant plants.

\subsubsection{Early flowering phenotype of $z f p 3$ mutant}

To further analyze the biological role of the ZFP3 gene we conducted flowering experiments with one of the homozygous mutant line and compared to Col-0 wild type plants in two independent experiments. The zfp 3 mutant showed an early flowering phenotype only in short days (SD; $8 \mathrm{~h}$ light/16 h dark) but not in long days (LD; $16 \mathrm{~h}$ light/8 h dark). However the rosette leaf number in the mutant line was not significantly different at the time of bolting compared to Col-0 (Figure 26). 
(A)
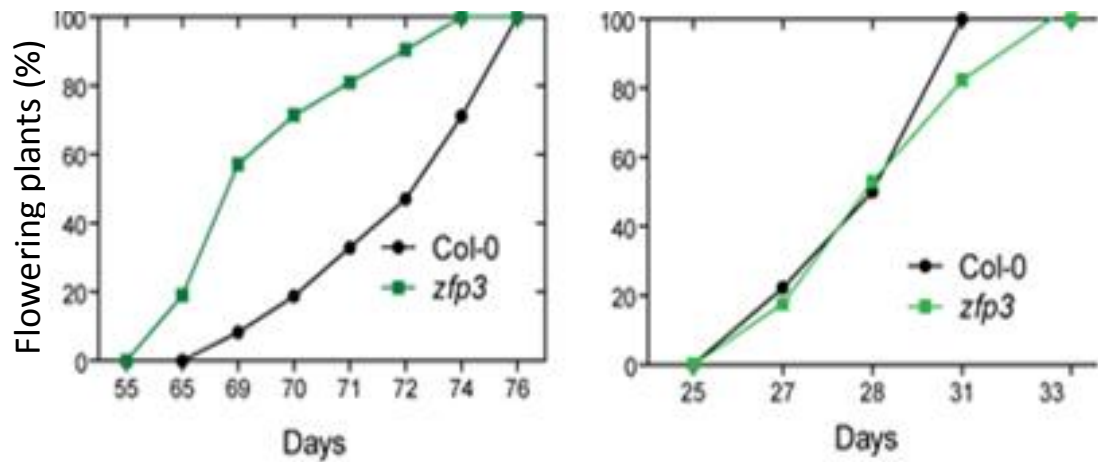

(B)

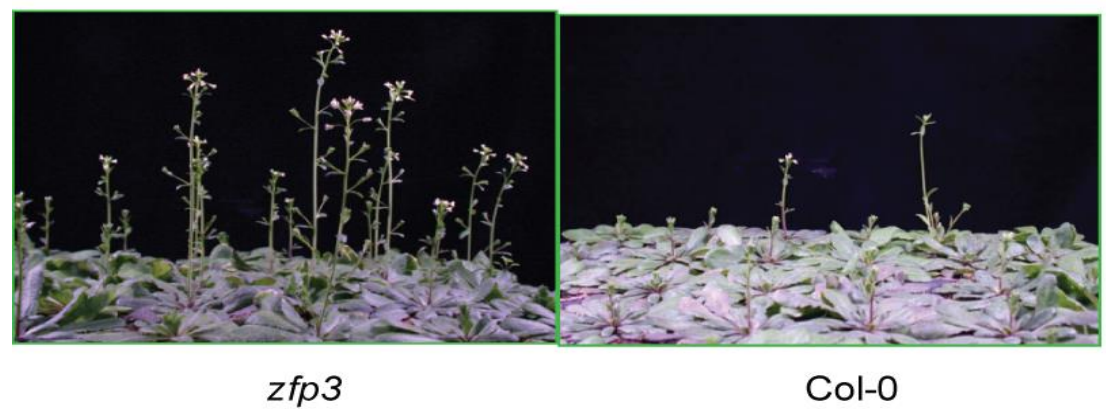

(C)

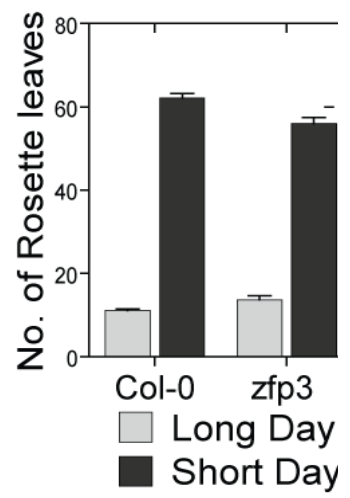

Figure 26: Flowering determination in zfp3 mutant. (A) Percentage of Col-0 and zfp3 mutant flowering plants in short day period and in long day period. (B) Photo taken from the trays in greenhouse when flowering during short day period. (C) Number of rosette leaves was recorded when plants flowered in long and short day photoperiod.

\subsection{Effect of ZFP3 constitutive overexpression on plant development}

In order to understand the effect of ZFP3 overexpression on vegetative and generative plant development, the ZFP3 gene was cloned into constitutive 35S-GW14 gateway vector. T2 lines after Basta selection were transferred to greenhouse. Out of 24 plants only 10 plants survived, however the samples from the growing plants were collected and RT-PCR was performed to measure the ZFP3 gene expression level (Figure $27 \mathrm{~A}$ ). Seeds from the plants were also collected and were weighed (Figure 27 B). Seed yields appeared to inversely correlate with 
ZFP3 transcript levels in transgenic lines. Germination assay on media supplemented with ABA was done for 8 lines that produced seeds. ABA insensitive germination was seen only in lines $1 \&$ 6 showing very high ZFP3 expression (Figure 27 C). Germination of 35S-ZFP3_1 line was also compared to Col-0 on control germination media (Figure $27 \mathrm{D}$ ), although 35S-ZFP3 was insensitive to $\mathrm{ABA}$ their rate of germination on normal germination media (half strength MS) was slower compared to Col-0.

(A)

(B)
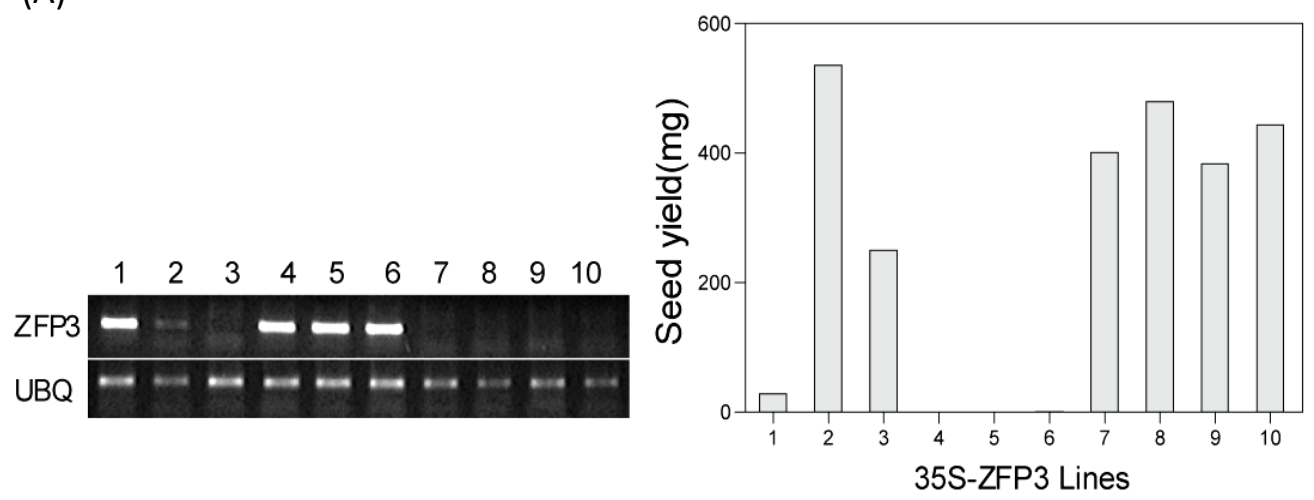

(C)

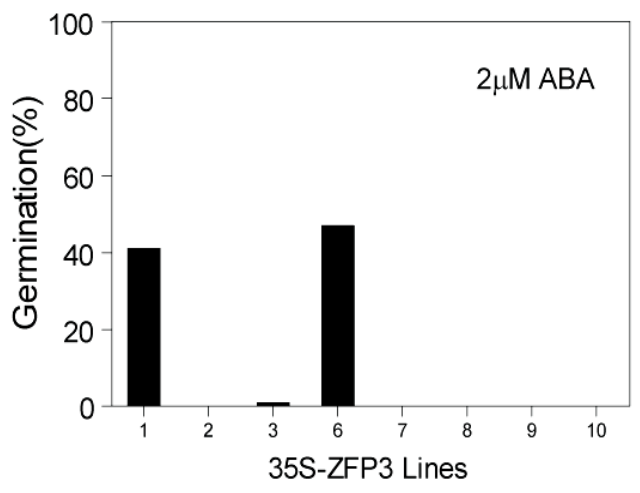

(D)

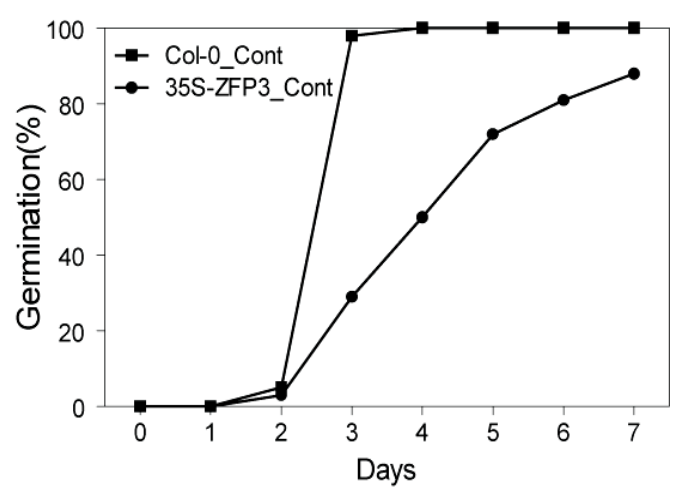

Figure 27: ABA insensitivity, seed yield and gene expression of 35S-ZFP3 lines. (A) Semi-quantitative PCR to confirm ZFP3 gene expression for the 10 individual lines. (B) Seed yield measured in milligrams of 10 individual 35S-ZFP3 lines. (C) Germination efficiency of 8 individual 35S-ZFP3 lines on $2 \mu \mathrm{M}$ ABA (line $4 \& 5$ had no seeds) as seen on day 25. (D) Germination of wild type (Col-0) and 35S-ZFP3_1 line on Control media

Seeds of 35S-ZFP3_1 segregating T2 line were further propagated in the greenhouse to confirm the lethal effect of ZFP3 over expression during growth. Samples from rosette stage plants that 
looked like Wild type (Col-0) and plants that looked smaller were collected for gene expression study (Figure 28A). The study showed that ZFP3 expression levels indeed negatively correlated with the size and development of these plants. Constitutive over expression also delays flowering with more rosette leaves compared to wild type (Figure $28 \mathrm{~B}, \mathrm{~F} \& \mathrm{G}$ ). Most of the siliques of the ZFP3 overexpressing plants were small and distorted, had only few seeds or were empty. However, they do produce very few normal siliques with seeds (Figure $28 \mathrm{C}, \mathrm{D} \& \mathrm{E}$ ). These pleiotropic effects suggest that ZFP3 does not only regulate ABA responses in germination but also plays a role in the control of vegetative and reproductive development.

(A)

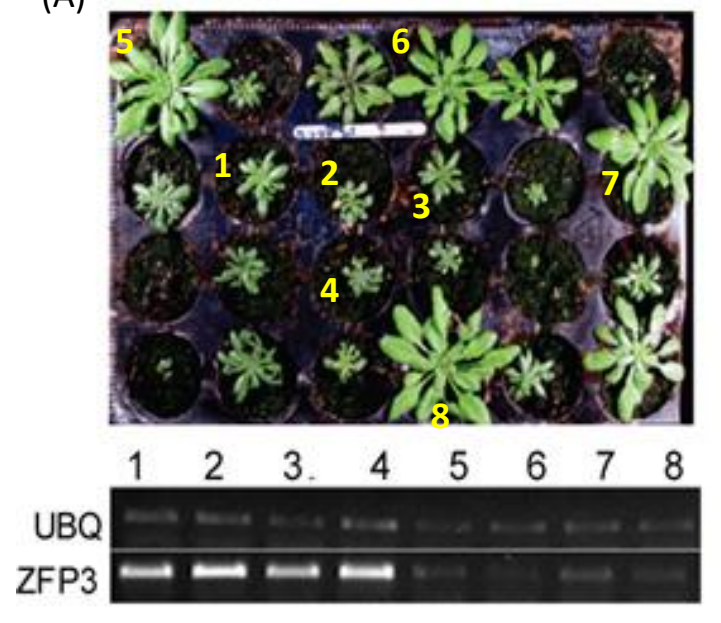

(F)

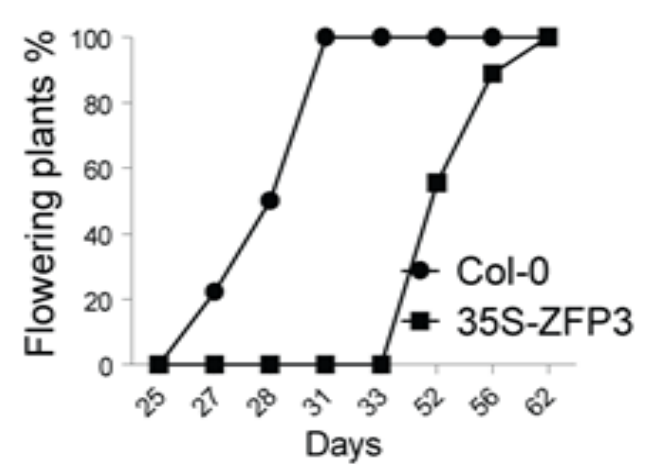

\section{Col-0 35S-ZFP3}
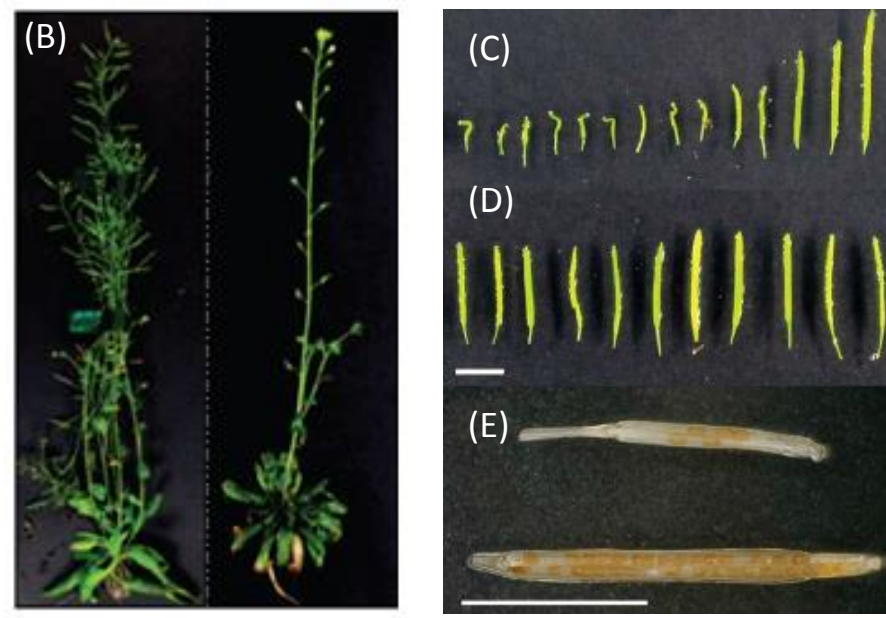

(D)

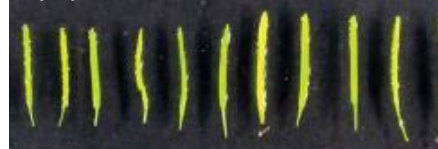

(E)

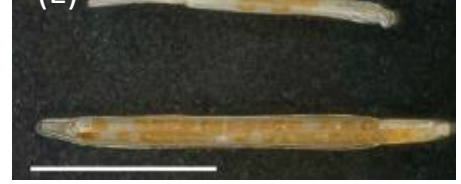

Figure 28: Constitutive ZFP3 over expression affects growth, development, flowering \& fertility. (A) ZFP3 gene expression level in T2 lines (1-8). B) Morphology of a flowering 35S-ZFP3 plant compared to Col-0. (C) Deformed siliques with few or no seeds when compared to Col-0; Siliques of 35S-ZFP3 (C) and wild type (D) plants. (E) Siliques and seeds of 35S-ZFP3 (upper silique) and wild type (lower silique) plants. Bar indicates 5mm). (F) Percentage of 35S-ZFP3 plants flowering compared to Col-0. (G) Number of rosette leaves was detected in long day photoperiod. 


\subsection{ZFP3 modulates ABA-regulated gene expression}

\subsubsection{Transcript profiling using in-depth sequencing (RNA-seq)}

Although the majority of known $\mathrm{C} 2 \mathrm{H} 2 \_\mathrm{Zn}$ finger proteins are transcriptional regulators, they can also be involved in other conserved biological processes, such as chromatin remodeling, RNA binding or protein-protein interactions (Riechmann , 2000; Englbrecht, 2004). To identify potential ZFP3-regulated genes, whole genome transcript profiling was performed twice with ZFP3ox and Col-0 seedlings germinated in the presence of $4 \mu \mathrm{M}$ Estradiol with or without 2.5 $\mu \mathrm{M}$ ABA (see materials \& methods). Seedlings with similar developmental stages, having emerged radicles but not open cotyledons, were used in both the experiments for transcript analysis. As knockout mutation lead only to a weak ABA sensitive phenotype, the $z f p 3$ mutant was not involved in this study. Transcript levels were determined by in-depth sequencing (RNAseq) and normalized expression values were compared from two experiments. Genes with lower than 30 reads were excluded from analysis, therefore the expression of 23932 genes was analyzed. ZFP3 overexpression resulted in up- and down-regulated expression of 222 and 153 genes, respectively (Figure 29).

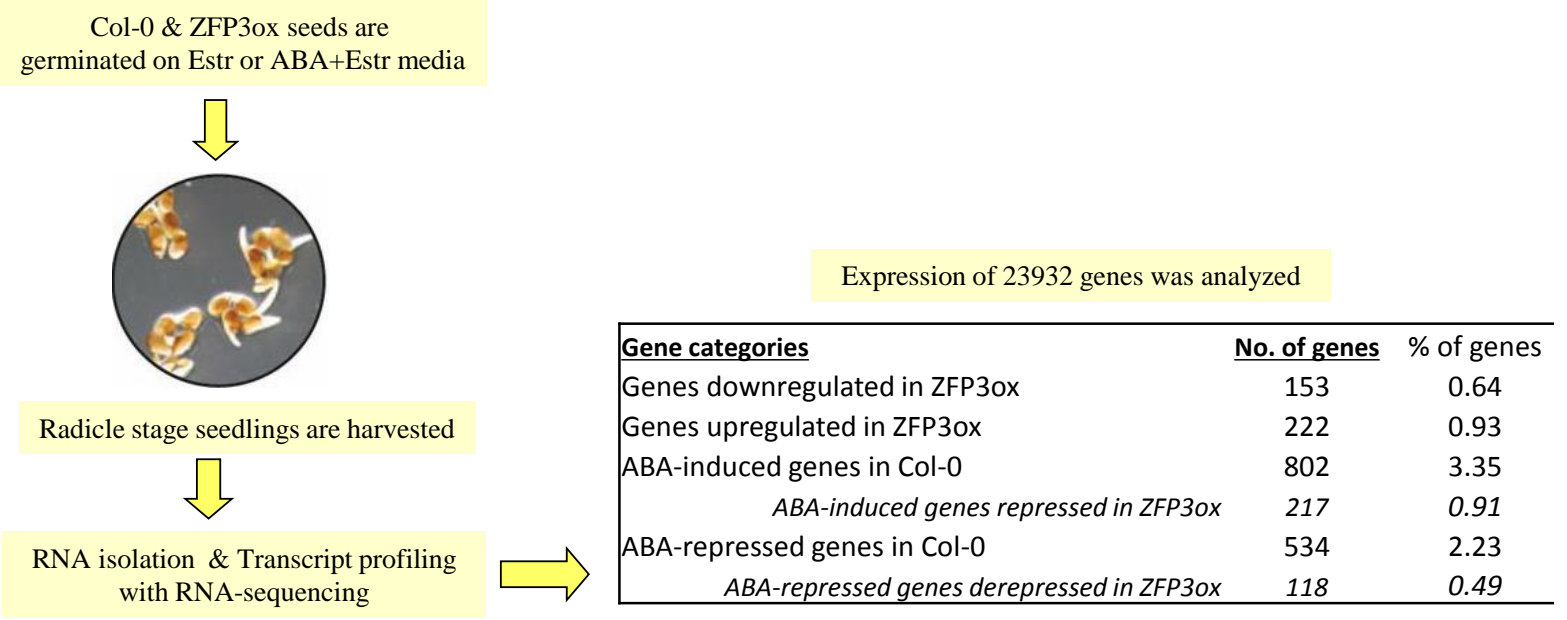

Figure 29: Differentially regulated genes identified in transcript profiling experiment

According to the Genevestigator database, many genes which are up or downregulated by ZFP3 are repressed or induced during germination. ZFP3 overexpression considerably modified 
expression profiles of many ABA-regulated genes (table 4). While in our experimental conditions, ABA enhanced expression of 802 genes, transcript levels of $27 \%$ of these genes (217) were reduced by at least 2-fold in ZFP3ox seedlings (Figure 29).

According to Gene Ontology (GO) classification, proteins that are involved in developmental regulations, such as embryo and seed development, response to desiccation, water deprivation and ABA stimulus, and localized in nuclei and mitochondria were overrepresented in this category (Figure 30). Numerous genes in this group were induced by ABA, drought and salt stress, upregulated in $\operatorname{csn} 3-1, \operatorname{csn} 4-1, \operatorname{csn} 5$, the quadruple $h s f a l a, 1 b, 1 d$, $1 e$, the quintuple phyABCDE mutants and repressed during germination, by white and red light, and in gedl and pif1,3,4,5 quadruple mutants (Table 5). Transcript levels of 534 genes were reduced in seedlings on ABA-containing medium, while 118 genes in this category (22\%) were less inhibited by ABA in ZFP3ox. Many of these genes are involved in photosynthesis and light responses (Table 6). GO terms of electron transport, energy and cell organization and plastid localization were overrepresented in this category (Figure 30). Most of the ABA-suppressed and ZFP3 derepressed genes are downregulated by stress conditions such as drought, pathogen infection and the elicitor FLG22 and in brx, ahg1-1, ahg3-1, csn3-1, csn4-1, csn5 and the quintuple phyABCDE mutants. Many genes in this category are activated during germination, shoot regeneration, by light and have enhanced expression in pad4, eds1-2 and pifl,3,4,5 quadruple mutants (Table 5). These results suggest that subset of genes which are inversely regulated by ABA and ZFP3 are also controlled by light through a phytochrome light receptor and one or more PIF transcription factors (Descriptions of the mutants and their references mentioned here are given in the Appendix). 
Table 4: 33 Most ABA-induced genes. 31 of these genes are less induced in ZFP3ox than in Col-0 background.

\begin{tabular}{|c|c|c|c|c|c|c|}
\hline Gene & $\begin{array}{c}A B A \\
(\mathrm{Col}-0)\end{array}$ & $\begin{array}{c}\text { ABA } \\
\text { (ZFP ox } \\
)\end{array}$ & $\begin{array}{l}\text { ZFPox } \\
\text { (contr) }\end{array}$ & $\begin{array}{l}\text { ZFPox } \\
\text { (ABA) }\end{array}$ & AGI & Protein \\
\hline RAB 18 & 45,8 & 16,4 & $-1,3$ & $-3,5$ & $A T S G 66400$ & Responsive to $A B A 18$ (RAB18) \\
\hline AT3G15670 & 42,8 & 15,9 & $-1,5$ & $-4,1$ & AT3G15670 & Late embryogenesis abundant protein (LEA) \\
\hline AT3G54940 & 38,9 & 4,9 & 1,5 & $-5,3$ & $A T 3 G 54940$ & Papain family cysteine protease \\
\hline OLEO 2 & 34,4 & 18,6 & 2,1 & 1,1 & $A T 5 G 40420$ & Oleosin 2 (OLEO2) \\
\hline AT3G02480 & 33,7 & 30,2 & $-2,0$ & $-2,2$ & $A T 3 G 02480$ & Late embryogenesis abundant protein (LEA) \\
\hline AT3G01570 & 31,8 & 7,2 & 1,8 & $-2,4$ & $A T 3 G 01570$ & Oleosinfamily protein \\
\hline AT3G17520 & 30,6 & 12,4 & $-1,4$ & $-3,5$ & AT3G17520 & Late embryogenesis abundant protein (LEA) \\
\hline LEA4-5 & 27,5 & 8,6 & $-1,0$ & $-3,3$ & ATSG06760 & Late embryogenesis abundant 4-5 (LEA4-5) \\
\hline GEA6 & 27,2 & 10,9 & $-1,2$ & $-3,0$ & $A T 2 G 40170$ & Late embryogenesis abundant 6 (GEAO) \\
\hline AT 4 G 36600 & 26,0 & 5,8 & 1,4 & $-3,3$ & $A T 4 G 36600$ & Late embryogenesis abundant protein (LEA) \\
\hline AT2G28490 & 26,0 & 7,2 & 1,0 & $-3,6$ & $A T 2 G 28490$ & RmIC-like cupins superfamily protein \\
\hline ATSG 35660 & 25,4 & 10,7 & $-1,5$ & $-3,6$ & $A T 5 G 35660$ & Glycine-rich protein \\
\hline AT1G04560 & 23,8 & 12,5 & $-2,1$ & $-3,9$ & $A T I G 04560$ & AWPM-19-1ike family protein \\
\hline EM1 & 23,6 & 6,0 & 1,5 & $-2,6$ & AT3G51810 & Late embryogenesis abundant 1 (EM1) \\
\hline OLEO1 & 22,1 & 7,8 & $-1,2$ & $-3,4$ & $A T 4 G 25140$ & Oleosin 1 (OLEO1) \\
\hline LEA1 \& & 21,9 & 11,7 & $-1,2$ & $-2,3$ & AT2G35300 & Late embryogenesis abundant 18 (LE.A18) \\
\hline PER1 & 20,8 & 5,8 & 1,5 & $-2,3$ & $A T I G 4 S 130$ & 1-cysteine peroxiredoxin 1 (PER1) \\
\hline LEA & 20,6 & 9,1 & $-1,5$ & $-3,5$ & ATIG52690 & Late embryogenesis abundant protein (LEA) \\
\hline ATSG51370 & 20,3 & 1,4 & 1,1 & $-13,0$ & $A T 5 G 51370$ & RNI-like superfamily protein \\
\hline PAP85 & 19,5 & 2,5 & 1,3 & $-6,2$ & $A T 3 G 22640$ & mitrient reservoir protein (PAPS5) \\
\hline AT3G52260 & 19,3 & 4,3 & 1,2 & $-3,6$ & $A T 3 G 52260$ & Pseudouridine synthase family protein \\
\hline AT3G50520 & 19,1 & 1,4 & 8,9 & $-1,5$ & AT3G50520 & Phosphoglycerate mutase family protein \\
\hline LEA & 18,8 & 4,2 & $-1,0$ & $-4,6$ & $A T 2 G 21490$ & DehydrinLEA (LEA) \\
\hline AT2G15010 & 18,1 & 3,0 & 2,0 & $-3,0$ & $A T 2 G 15010$ & PR (pathogenesis-related) protein \\
\hline GASA3 & 17,4 & 8,1 & 1,1 & $-2,0$ & $A T 4 G 09600$ & GAST1 protein homolog 3 (GASA3) \\
\hline AT5G 66780 & 17,1 & 6,0 & $-1,2$ & $-3,5$ & ATSG66780 & unknown protein \\
\hline TIP3;1 & 15,9 & 6,9 & 1,1 & $-2,2$ & $A T 1 G 73190$ & Alpha-tonoplast intrinsic protein (IIP $3 ; 1)$ \\
\hline CRA1 & 14,9 & 5,4 & $-1,4$ & $-3,9$ & $A T 5 G 44120$ & Cruciferina (CRA1) \\
\hline AT2G25890 & 14,1 & 5,5 & 1,1 & $-2,4$ & $A T 2 G 25890$ & Oleosinfamily protein \\
\hline AT3G03341 & 14,0 & 6,5 & $-1,4$ & $-3,0$ & $A T 3 G 03341$ & unknown protein \\
\hline AT1G54870 & 13,9 & 5,7 & $-1,1$ & $-2,7$ & ATIG54870 & ChlADR al dehyde reductase \\
\hline L TI65 & 13,4 & 8,6 & $-2,0$ & $-3,1$ & ATSG52300 & Low-temperature-induced 65 (LTI65) \\
\hline HVA22B & 13,3 & 4,0 & $-1,1$ & $-3,6$ & $A T 5 G 62490$ & HV $A 22$ homologue B (HVA22B) \\
\hline
\end{tabular}


Table 5: Expression profiles of ABA and ZFP3 regulated genes in Genevestigator transcript profiling database. Four groups of genes were analyzed with the Hierarchical Clustering tool of the Genevestigator database: those which were down or upregulated in ZFP3ox line induced by ABA but downregulated by ZFP3ox and repressed by ABA but upregulated by ZFP3ox. Percentage values (\%) indicate the proportion of genes similarly regulated by a given treatment or in a mutant. Descriptions of the listed mutants are given in the Appendix.

\begin{tabular}{|c|c|c|c|c|}
\hline Categories & $\begin{array}{c}\text { Genes } \\
\text { downregulat } \\
\text { ed by ZFP3 }\end{array}$ & $\begin{array}{c}\text { Genes } \\
\text { upregulated } \\
\text { by ZFP3 }\end{array}$ & $\begin{array}{c}\text { Genes induced by } \\
\text { ABA, downregulated } \\
\text { by ZFP3 }\end{array}$ & $\begin{array}{c}\text { Genes repressed by ABA, } \\
\text { upregulated by ZFP3 }\end{array}$ \\
\hline $\begin{array}{l}\text { Induced by } \\
\text { (treatments, } \\
\text { conditions) }\end{array}$ & $\begin{array}{l}\text { Germination } \\
(32 \%)\end{array}$ & $\begin{array}{l}\text { 5-AC }(17 \%) \\
\text { P.parasitica } \\
(12 \%)\end{array}$ & $\begin{array}{l}\text { ABA (57\%) } \\
\text { Drought (33\%) } \\
\text { Osmotic stress (33\%) } \\
\text { Salt stress }(26 \%)\end{array}$ & $\begin{array}{l}\text { Germination }(84 \%) \\
\text { Shoot regeneration }(60 \%) \\
\text { White light }(45 \%) \\
\text { Red light }(40 \%)\end{array}$ \\
\hline $\begin{array}{l}\text { Repressed } \\
\text { by } \\
\text { (treatments, } \\
\text { conditions) }\end{array}$ & $\begin{array}{l}5-A C(24 \%) \\
\text { Salt (root } \\
\text { pp.) (21\%) }\end{array}$ & $\begin{array}{l}\text { Germination } \\
(13 \%)\end{array}$ & $\begin{array}{l}\text { Germination (62\%) } \\
\text { Red light (37\%) } \\
\text { White light (34\%) }\end{array}$ & $\begin{array}{l}\text { ABA (81\%) } \\
\text { 5-AC (67\%) } \\
\text { PAC (64\%) } \\
\text { Drought (54\%) } \\
\text { Callus (59\%) } \\
\text { Hypoxia (59\%) } \\
\text { P.syringae (59\%) } \\
\text { FLG22 (50\%) } \\
\text { Norflurazon (48\%) }\end{array}$ \\
\hline $\begin{array}{l}\text { Induced in } \\
\text { (mutants, } \\
\text { lines) }\end{array}$ & $b r x(22 \%)$ & & $\begin{array}{l}\text { hsfa1a,1b,1d,1e (QK) } \\
\text { (50\%) } \\
\text { LEC1-Oxi (46\%) } \\
\text { 35S::amiR(MIR172a) } \\
(46 \%) \\
\text { phyABCDE (42\%) } \\
\text { csn4-1 (30\%) } \\
\text { csn3-1 (25\%) } \\
\operatorname{csn5}(25 \%)\end{array}$ & $\begin{array}{l}\text { pif1,3,4,5 (pifq) (52\%) } \\
\text { pad4 }(46 \%) \\
\text { eds1-2 }(36 \%)\end{array}$ \\
\hline $\begin{array}{l}\text { Repressed in } \\
\text { (mutants, } \\
\text { lines) }\end{array}$ & $\begin{array}{l}\text { toc } 1-1(12 \%) \\
\text { cpc-1 try-82 } \\
(11 \%)\end{array}$ & & $\begin{array}{l}\text { ged1, }(52 \%) \\
\text { pif1,3,4,5 (pifq) (37\%) } \\
\text { MPK6_1 (34\%) }\end{array}$ & $\begin{array}{l}\text { csn3-1 (66\%) } \\
\text { csn4-1 (67\%) } \\
\text { csn5 (65\%) } \\
\text { brx (57\%) } \\
\text { ahg1-1 (59\%) } \\
\text { ahg3-1 (50\%) } \\
\text { 35S::amiR(MIR172a) (47\%) } \\
\text { phyABCDE (40\%) }\end{array}$ \\
\hline
\end{tabular}




\section{Biological Process}

\section{Cellular Component}

\section{Molecular Functions}
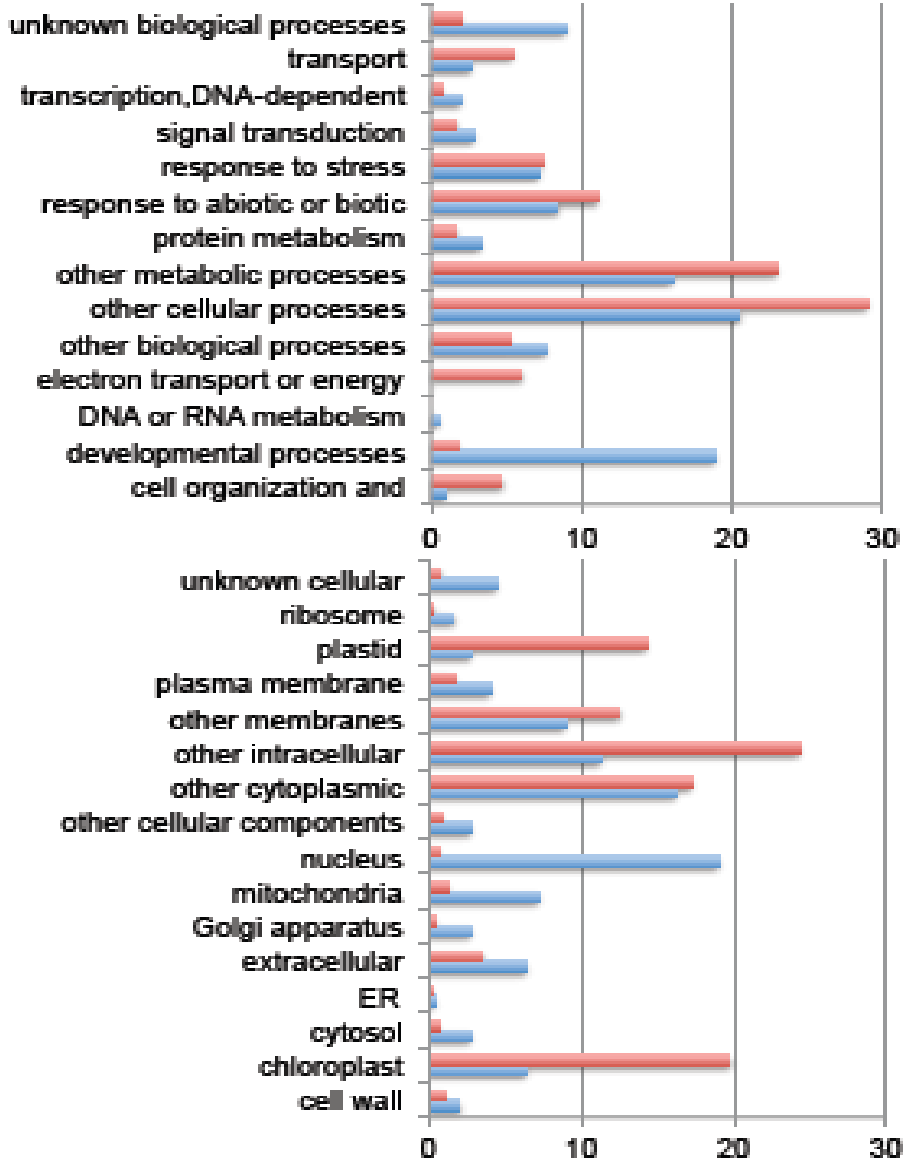

EABAdn/Zfp3up

EABAup/Zfp3dn

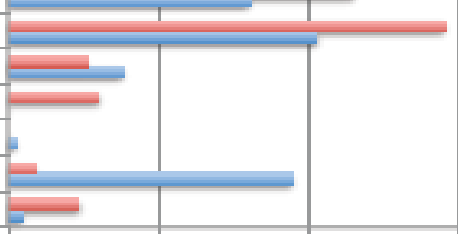

EABAdn/Zfp3up

-ABAup/Zfp3dn

ABAdn/Zfp3up

ABAup/Zfp3dn
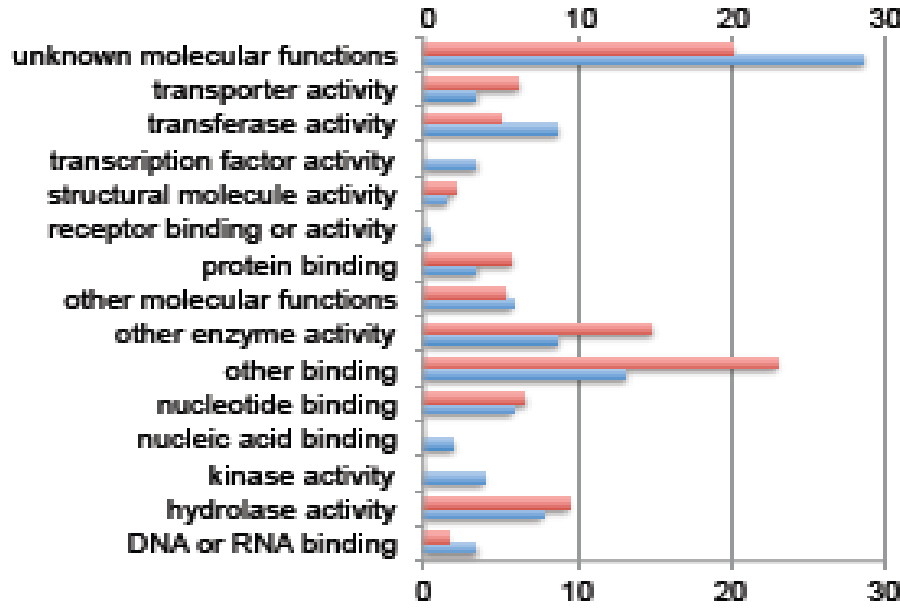

Figure 30: Gene Ontology terms of genes differentially regulated by ABA and ZFP3. ABAdn/Zfp3up: genes downregulated by ABA and enhanced by ZFP3 overexpression. ABAup/Zfp3dn: Genes which were enhanced by ABA and downregulated by ZFP3 overexpression. Analysis was made with the GO Annotation Search tool of the TAIR website (www.arabidopsis.org/tools/bulk/go/index.jsp). 
Table 6: Thirty three genes, which are most downregulated by ABA. Twenty eight of these genes are less suppressed in ZFP3ox seedlings.

\begin{tabular}{|c|c|c|c|c|c|c|}
\hline Gene & $\begin{array}{c}\mathrm{ABA} \\
(\mathrm{Col}- \\
0)\end{array}$ & $\begin{array}{c}\text { ABA } \\
(\mathrm{ZFP} \\
\text { ox })\end{array}$ & $\begin{array}{c}\text { ZFP } \\
\text { ox } \\
\text { (con } \\
\text { tr) }\end{array}$ & $\begin{array}{l}\text { ZFPox } \\
(\mathrm{ABA})\end{array}$ & AGI & Protein \\
\hline$L H C B 2.1$ & $-39,1$ & $-1,5$ & $-1,2$ & 21,5 & $A T 2 G 05100$ & $\begin{array}{l}\text { Photosystem II light harvesting complex } 2.1 \\
\text { (LHCB2.1) }\end{array}$ \\
\hline$C A B 1$ & $-29,8$ & $-2,4$ & 1,5 & 19,0 & AT1G29930 & $\begin{array}{l}\text { Chlorophyll a/b binding protein } 1(C A B 1) \\
\text { Photosystem II light harvesting complex B1B2 }\end{array}$ \\
\hline$L H B 1 B 2$ & $-25,8$ & $-1,6$ & $-1,2$ & 13,9 & $A T 2 G 34420$ & $\begin{array}{l}\text { (LHB1B2) } \\
\text { Photosystem II light harvesting complex } 2.2\end{array}$ \\
\hline LHCB2.2 & $-25,1$ & $-1,5$ & $-1,2$ & 13,5 & AT2G05070 & $\begin{array}{l}\text { (LHCB2.2) } \\
\text { Polyketide cyclase/dehydrase and lipid transport }\end{array}$ \\
\hline AT4G23680 & $-25,0$ & $-4,6$ & $-1,6$ & 3,5 & $A T 4 G 23680$ & $\begin{array}{l}\text { protein } \\
\text { Light-harvesting chlorophyll b-binding protein } 3\end{array}$ \\
\hline LHCB3 & $-19,4$ & $-2,1$ & $-1,1$ & 8,2 & AT5G54270 & $(L H C B 3)$ \\
\hline PSBO1 & $-19,3$ & $-2,5$ & 1,2 & 9,1 & AT5G66570 & PS II oxygen-evolving complex 1 (PSBO1) \\
\hline PORB & $-18,6$ & $-8,3$ & $-1,3$ & 1,8 & $A T 4 G 27440$ & Protochlorophyllide oxidoreductase B (PORB) \\
\hline LHCB5 & $-18,1$ & $-2,3$ & 1,2 & 9,9 & AT4G10340 & Photosystem II light harvesting complex 5 (LHCB5) \\
\hline PSAH2 & $-17,5$ & $-3,5$ & 1,0 & 5,0 & AT1G52230 & Photosystem I subunit H2 (PSAH2) \\
\hline DOT1 & $-17,3$ & $-2,5$ & $-3,3$ & 2,2 & AT2G36120 & Defectively organized tributaries 1 (DOT1) \\
\hline$R B C S 3 B$ & $-16,6$ & $-5,2$ & $-1,3$ & 2,4 & AT5G38410 & RUBISCO small subunit $3 B(R B C S 3 B)$ \\
\hline AT3G48140 & $-15,6$ & $-5,0$ & $-2,0$ & 1,5 & AT3G48140 & $B 12 D$ protein \\
\hline$R C A$ & $-15,3$ & $-3,7$ & $-1,3$ & 3,3 & AT2G39730 & RUBISCO activase (RCA) \\
\hline$C A B 2$ & $-14,8$ & $-2,0$ & 1,6 & 11,8 & AT1G29920 & $\begin{array}{l}\text { Chlorophyll a/b binding protein } 2 \text { (CAB2) } \\
\text { Caffeoyl coenzyme A o-methyltransferase } 1\end{array}$ \\
\hline CCOAOMT1 & $-14,6$ & $-3,2$ & $-1,9$ & 2,3 & AT4G34050 & (CCoAOMT1) \\
\hline $\begin{array}{l}\text { LHCA1 } \\
\text { GAMMA- }\end{array}$ & $-14,5$ & $-1,5$ & 1,1 & 10,4 & AT3G54890 & Photosystem I light harvesting complex 1 (LHCA1) \\
\hline$T I P$ & $-13,7$ & $-3,1$ & $-1,5$ & 2,9 & AT2G36830 & Gamma tonoplast intrinsic protein (GAMMA-TIP) \\
\hline LHCB6 & $-13,2$ & $-3,0$ & 1,5 & 6,5 & AT1G15820 & Photosystem II light harvesting complex 6 (LHCB6) \\
\hline AT1G09310 & $-13,2$ & $-3,9$ & $-1,3$ & 2,6 & AT1G09310 & Protein of unknown function \\
\hline$C A D 9$ & $-13,1$ & $-3,9$ & $-1,7$ & 1,9 & AT4G39330 & Cinnamyl alcohol dehydrogenase 9 (CAD9) \\
\hline AT1G29090 & $-13,0$ & $-4,9$ & $-2,8$ & $-1,0$ & AT1G29090 & Cysteine proteinases superfamily protein \\
\hline$A C O 2$ & $-12,8$ & $-3,5$ & $-1,7$ & 2,2 & AT1G62380 & ACC oxidase 2 (ACO2) \\
\hline LHCA2 & $-12,4$ & $-2,3$ & 1,3 & 6,9 & AT3G61470 & Photosystem I light harvesting complex 2 (LHCA2) \\
\hline$P S A L$ & $-12,0$ & $-2,4$ & 1,1 & 5,5 & AT4G12800 & Photosystem I subunit L (PSAL) \\
\hline PSAN & $-11,9$ & $-2,0$ & 1,0 & 6,0 & AT5G64040 & subunit of photosystem I (PSAN) \\
\hline$C A B 3$ & $-11,5$ & $-1,5$ & 1,2 & 9,6 & AT1G29910 & Chlorophyll a/b binding protein 3 (CAB3) \\
\hline TIP2 & $-11,4$ & $-3,7$ & $-1,2$ & 2,5 & AT3G26520 & Tonoplast intrinsic protein 2 (TIP2) \\
\hline$P S A O$ & $-11,2$ & $-2,0$ & 1,2 & 6,7 & $A T 1 G 08380$ & Photosystem I subunit $O(P S A O)$ \\
\hline LHCA3 & $-10,7$ & $-2,3$ & 1,0 & 4,7 & AT1G61520 & Photosystem I light harvesting complex 3 (LHCA3) \\
\hline$P I P 1 A$ & $-10,6$ & $-2,2$ & $-1,7$ & 2,8 & AT3G61430 & Plasma membrane intrinsic protein $1 A(P I P 1 A)$ \\
\hline LHCB4.1 & $-10,6$ & $-2,2$ & 1,1 & 5,6 & AT5G01530 & Photosystem II light harvesting complex (LHCB4.1) \\
\hline AT5G17820 & $-10,4$ & $-4,1$ & $-2,5$ & 1,0 & AT5G17820 & Peroxidase superfamily protein \\
\hline
\end{tabular}




\subsubsection{Confirmation of selected genes by quantitative PCR}

To further investigate the expression profiles of selected genes in wild type and ZFP3ox seedlings quantitative RT-PCR analysis was employed on RNA samples isolated from ZFP3ox seedlings. The seeds were plated on germination media containing $4 \mu \mathrm{M}$ Estradiol in the absence or presence of $2 \mu \mathrm{M} \mathrm{ABA}$, and gene expression was monitored in 1,2 and 3 day-old seedlings. Transcription of ZFP3 was enhanced by three magnitudes upon Estradiol treatment (Figure 31A). ABA-dependent activation of the dehydrin gene $R A B 18$ was characteristic in wild type seedlings, but was considerably lower in ZFP3ox seedlings in the presence of Estradiol (Figure $31 \mathrm{C}, \mathrm{D})$. Expression of the light-inducible gene $C A B 2$ was reduced in wild type seedlings in the presence of ABA, which was relieved in ZFP3ox (Figure 31E). The transcription factors ABI4, ABI5 are positive regulators of ABA-responsive genes, while RGL2 is a repressor of GA signal transduction. Transcript levels of these genes were enhanced by ABA in wild type seedlings, which was two to four times lower in ZFP3ox plantlets (Figure 31F-H). Western blot was performed from total protein extracts from the seedlings that were subjected to quantitative PCR. Bands with a molecular mass of approximately $35 \mathrm{kD}$ were detected with HA antibody (Figure $31 \mathrm{~B}$ ) indicating the presence of ZFP3 protein.

\subsubsection{Short-term gene regulation by ZFP3 induction}

To compare short-term activation of the tested genes in ZFP3ox and Col-0 plants, 3 daysold seedlings were treated by ABA in the presence of Estradiol and transcript levels were tested after 3 hours. ABA-dependent transcriptional activation of RAB18 was lower in ZFPox plantlets (Figure 32). Transcription of $A B I 4$ was also reduced by ZFP3 overexpression, while expression of $C A B 2, A B I 5$ and $R G L 2$ was not influenced by ZFP3 in these conditions (Figure 32). These results showed that ZFP3 can interfere with ABA signals in seedlings and young plants, modulating the ABA-dependent activation of a subset of genes. Other genes were probably not direct targets of ZFP3, but the difference in their transcript levels were due to developmental effects or were controlled by other ZFP3-regulated factors. 
(A)

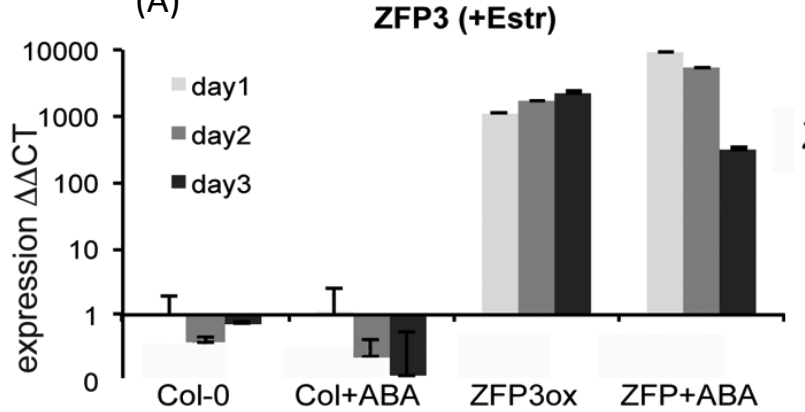

(B) Estradiol

days:

ZFP3-HA

Protein
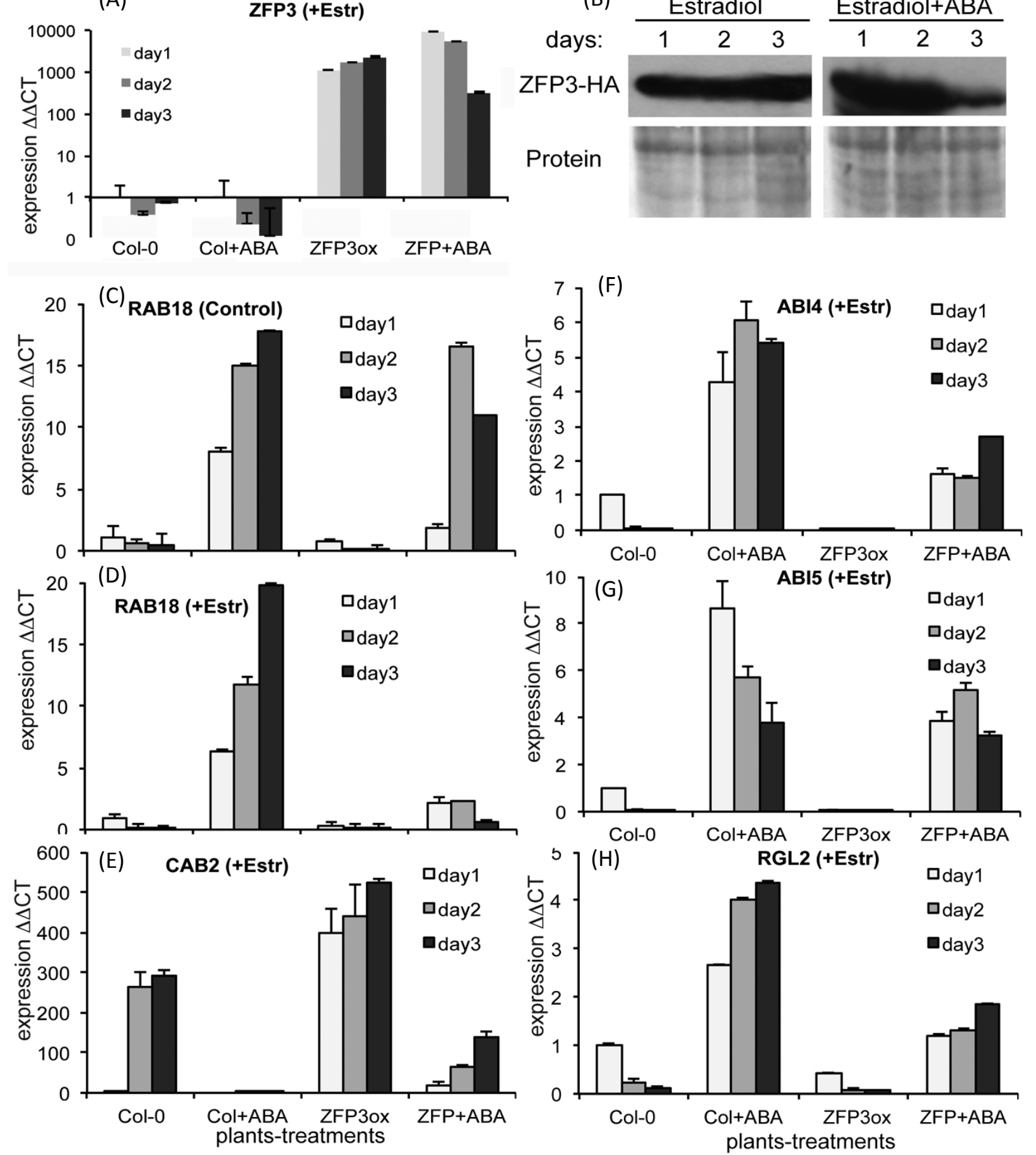

Figure 31: ZFP3 modulates ABA-controlled gene expression. A-H) Seedlings were germinated on 4 $\square \mathrm{M}$ estradiol-containing medium in the absence or presence of $2 \square \mathrm{M} \mathrm{ABA}$, and gene expression was monitored in 1, 2 and 3 days-old seedlings. A) Expression of ZFP3 in wild type and ZFP3ox seedlings. B) Western blot detection of HA-tagged ZFP3 in overexpressing seedlings. C, D) Transcript levels of RAB18 in germinating seedlings in the absence (C) or presence (D) of estradiol. E) Transcript levels of lightinduced $C A B 2$ gene, encoding a chlorophyll $\mathrm{AB}$ binding protein, in germinating seedlings treated with 
estradiol. F-H) Transcript levels of $A B I 4$ and $A B I 5(\mathrm{~F}, \mathrm{G})$ and $R G L 2(\mathrm{H})$ in germinating seedlings treated with estradiol. Expression was normalized to transcript levels at the start of ABA treatment. Error bars show standard error. GAPC2 (Atlg13440) was used as constitutive reference.

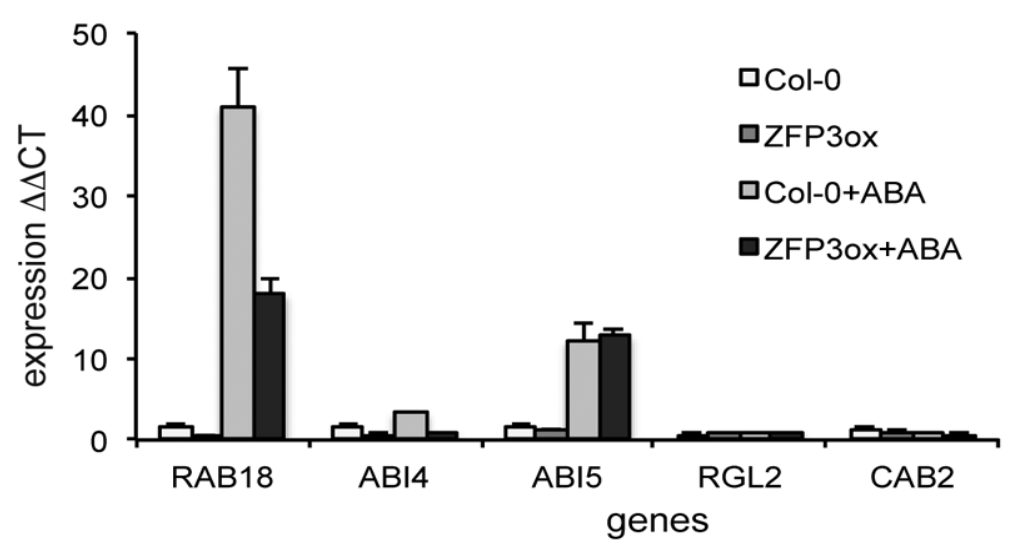

Figure 32: Expression of selected ZFP3-regulated genes in 3 days-old wild type (Col-0) and ZFP3ox plantlets induced by $25 \mu \mathrm{M}$ ABA for 3 hours. All plants were treated with $4 \mu \mathrm{M}$ Estradiol for 24 hours prior $\mathrm{ABA}$ induction. . Expression was normalized to transcript levels at the start of $\mathrm{ABA}$ treatment. Error bars show standard error. GAPC2 (At 1 g13440) was used as constitutive reference.

\subsection{ZFP3 modulates light responses in seedling development}

Transcript levels of many light-regulated genes were altered in ABA treated ZFP3ox seedlings, suggesting that ZFP3 overexpression can influence light signaling. Besides regulating the expression of photosynthetic genes, light controls photomorphogenesis and inhibits hypocotyl elongation. Although interactions between different hormones and light signaling have been studied extensively (Chen 2008; Hsieh 2012; Seo 2009; Lau 2010) our understanding of such complex regulation is still far from being complete.

\subsubsection{Hypocotyl growth is affected in ZFP3ox seedlings}

Visual inspection of young seedlings indicated that in the presence of Estradiol ZFP3ox plants produced shorter hypocotyls than the wild type plants, both in the dark and in white light (Figure 33A). This response was Estradiol-dependent, indicating that it is the result of ZFP3 overexpression (Figure 33B). 
(A)

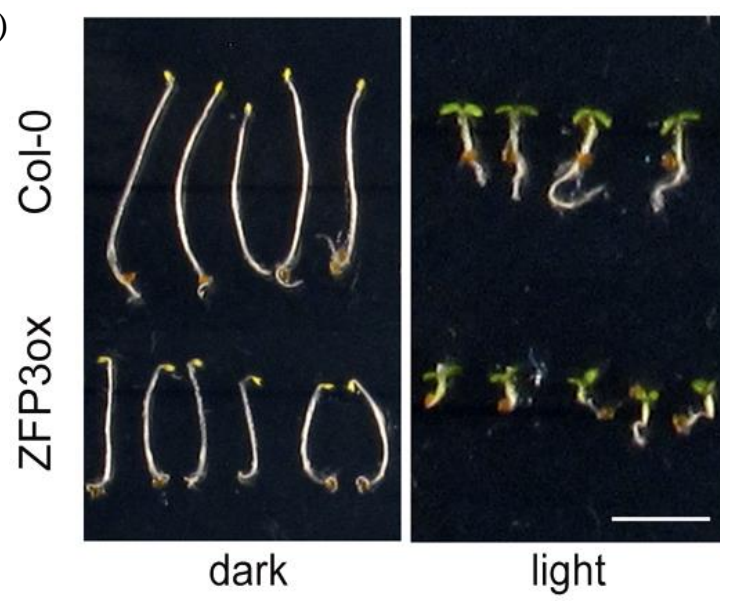

(B)

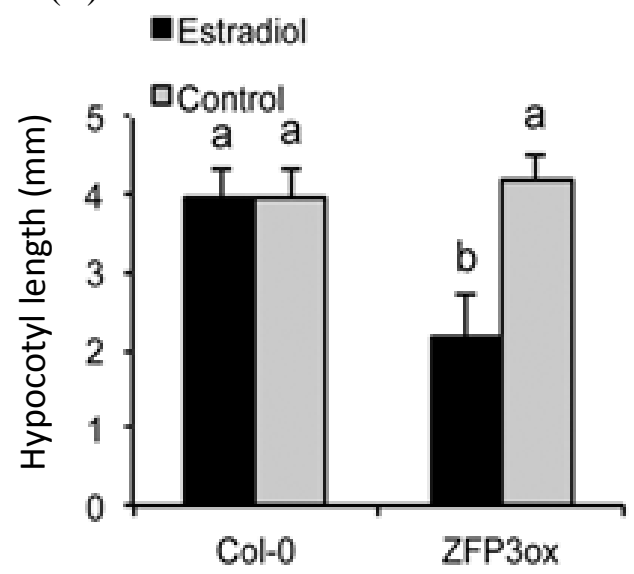

Figure 33: Light regulation on hypocotyl growth. (A) 3-day-old Col-0 wild type and ZFP3 overexpressing seedlings grown in the in dark and in the light. Seeds were germinated in the presence of 4 $\mu \mathrm{M}$ Estradiol. (B) Change of hypocotyl lengths in white light in the absence or presence of Estradiol. Different letters show significant differences at $\mathrm{p}<0.05$ (Duncan-test).

\subsubsection{Overexpression of ZFP related genes affects hypocotyl growth}

Estradiol-dependent shortening of hypocotyls was also observed in transgenic seedlings overexpressing ZFP1, ZFP4, ZFP6 and ZFP7 under the control of the Estradiol inducible expression system (Figure 34 A; Zuo 2000). Short hypocotyl phenotype of ZFP3ox and ZFP1ox seedlings could not be reversed with exogenously added gibberellin or epibrassinolide, hormones known to promote cell elongation (Figure $34 \mathrm{~B}$ ). In the dark, hypocotyl elongation of Col-0 seedlings was reduced by $50 \%$ on 1-Aminocyclopropane-1-carboxylic acid (ACC-the precursor of ethylene) containing plates, while hypocotyls of ZFP3ox and ZFP1ox seedlings were only $10 \%$ shorter (Figure $34 \mathrm{C}$ ). The apical hook of dark-germinated ZFP3ox and ZFP1ox seedlings was similar to that of Col-0 on ACC supplemented and control plates, respectively. The germination of ZFP3ox seeds however was not influenced by ACC or epibrassinolide (eBL), (data not shown). 
(A)

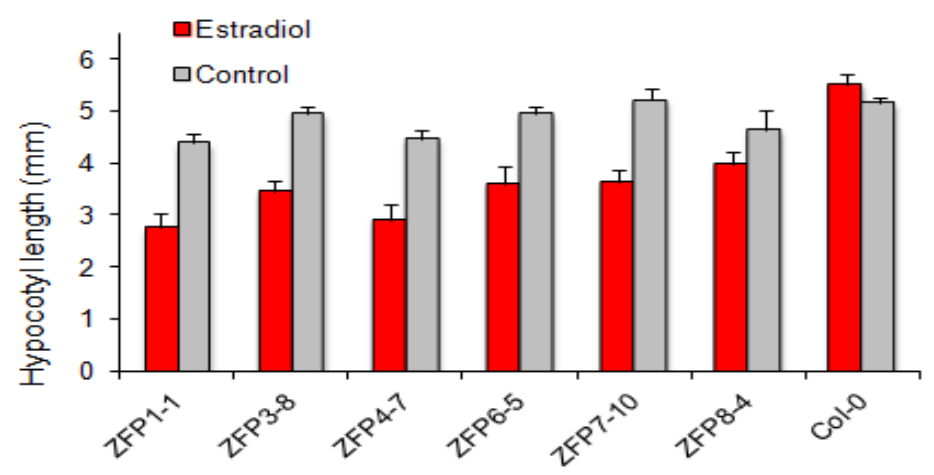

Transgenic lines

(B)

Light

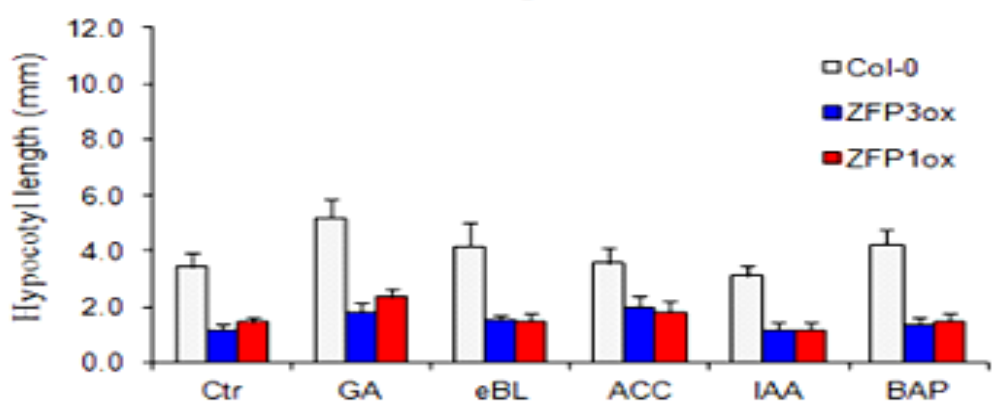

(C)

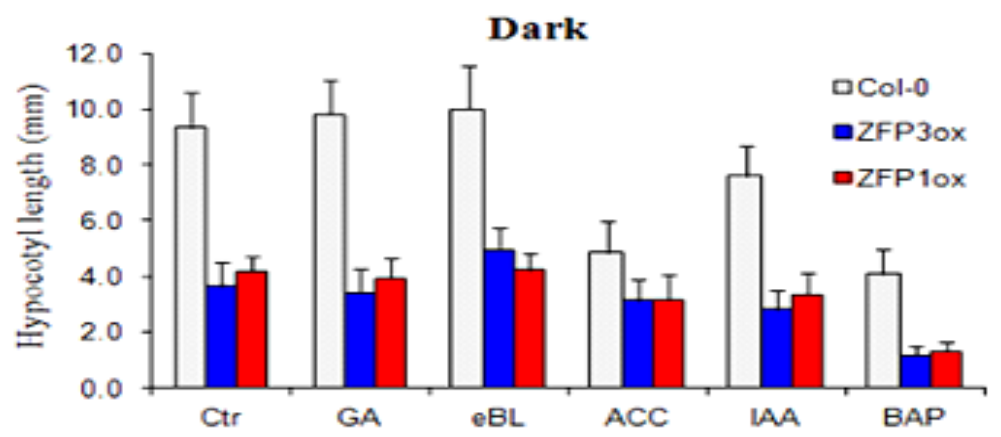

Hormones

Figure 34: Hypocotyl elongation of transgenic Arabidopsis lines overexpressing different ZFP-type cDNA in the Estradiol-inducible expression system. (A) Seeds were germinated on germination media in the presence or absence of $4 \mu \mathrm{M}$ Estradiol under $8 / 16 \mathrm{~h}$ light/dark condition. Hypocotyl length were scored in 7 days old seedlings. (B-C) Effect of plant hormones on hypocotyl elongation of wild type, ZFP1ox and ZFP3ox plants. Seedlings were grown on wet filter paper in light (B) and dark condition (C). Hormones were added in the following concentration: GA3-10 $\mu \mathrm{M}$; EBL-200 nM; ACC-10 $\mu \mathrm{M}$; IAA-5 $\mu \mathrm{M}$; BAP-5 $\mu \mathrm{M}$. Bars on diagrams indicate standard errors. 


\subsubsection{Monochromatic light specific response on hypocotyl growth}

Visible light perception is mainly mediated by photoreceptors including phytochromes absorbing red/far-red light phototropin and cryptochromes sensing blue light (Franklin and Quail 2010; Chaves 2011). To identify the particular light signaling pathway which is modulated by ZFP3, hypocotyl elongation was tested under different intensities of monochromatic light of different wavelengths. In order to reveal light-dependent effects of ZFP3, hypocotyl lengths were normalized to the average length of the corresponding dark-grown seedlings. Relative hypocotyl lengths of ZFP3ox seedlings were reduced in red light (Figure $35 \mathrm{~A}$ ), but were similar to wild type under far-red or blue light (Figure $35 \mathrm{~B}, \mathrm{C}$ ). In contrast, hypocotyl lengths of $z f p 3 z f p 4$ double mutants were identical to that of the wild type plants either in the dark or under different fluence rates of red light (Figure $35 \mathrm{D}, \mathrm{E}$ ). These data suggest that ZFP3 is implicated in red light-induced responses, but does not interfere with far-red or blue light signaling. The fact that overexpression of other ZFP genes reduced hypocotyl elongation, which was not altered in single or double zfp3 zfp4 mutants, suggests that members of this gene subfamily might compensate for the lack of ZFP function in a particular mutant and therefore can have overlapping functions in the control of photomorphogenesis. 

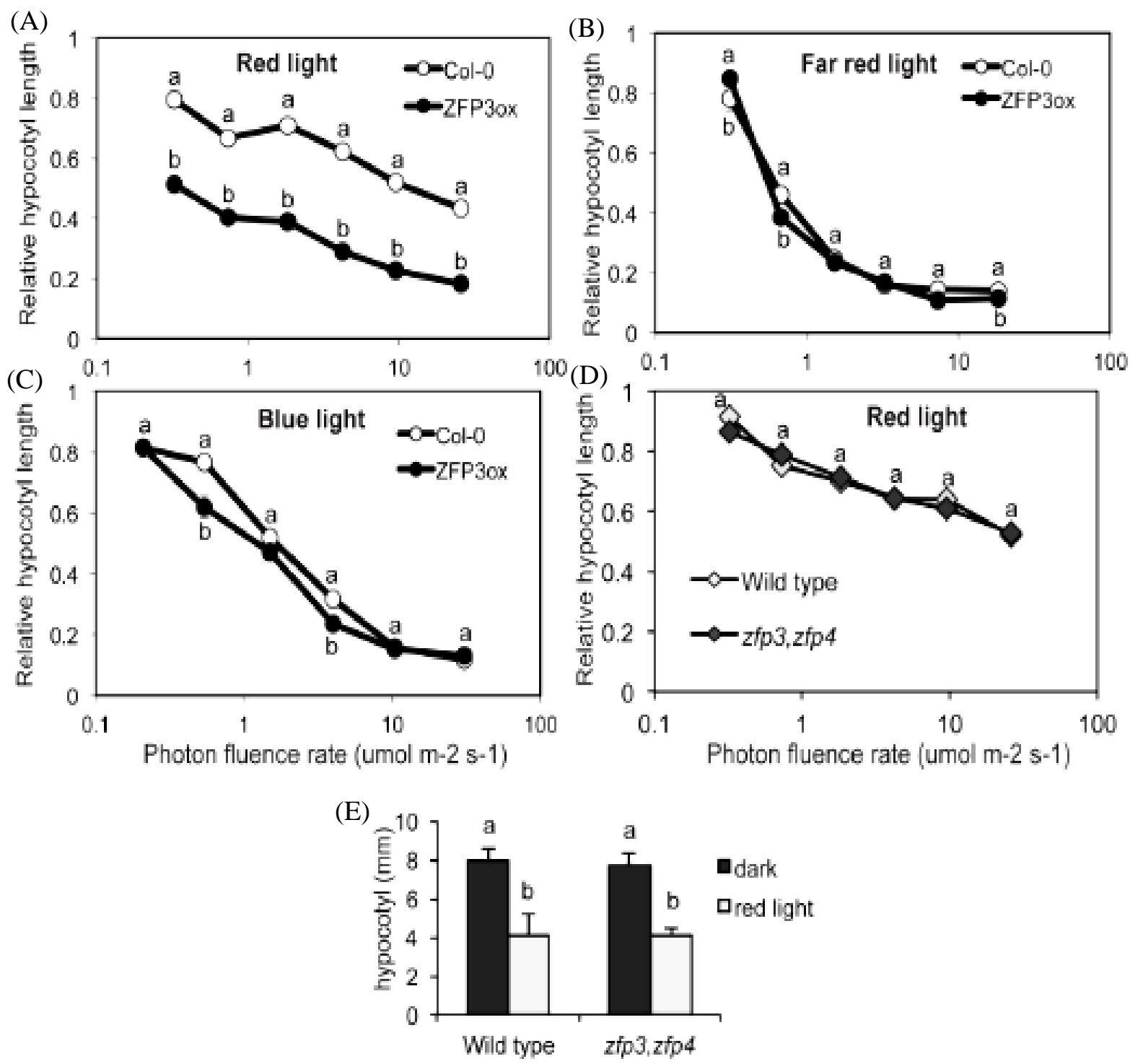

Figure 35: A-C) Relative hypocotyl lengths of wild type and ZFP3ox seedlings grown under different fluence rates of monochromatic red (A), far red (B) and blue (C) light. D) Relative hypocotyl lengths of wild type and $z f p 3 z f p 4$ double mutant germinated under different intensities of red light. E) Hypocotyl lengths of wild type and $z f p 3 z f p 4$ double mutant seedlings grown either in the dark or in red light at 35 $\mu \mathrm{mol} \mathrm{m} \mathrm{s}^{-1}$ fluence rate. Error bars indicate Standard Error (SE) values. Different letters show significant differences at $\mathrm{p}<0.05$ (Duncan-test) $(\mathrm{G})$, or Student t-test (A-D). A-D: Hypocotyl lengths were normalized to the corresponding dark-grown seedlings and the $x$ axes show logarithmic scale. 


\subsubsection{Genetic interaction of ZFP3 with PhyB and PhyA}

The far-red/red light absorbing phytochromes are encoded by a small multigene family in Arabidopsis. PhyA and B are considered the major receptors of far-red/red light signals, respectively (Franklin and Quail 2010). The fact that ZFP3ox showed no altered hypocotyl elongation in far-red or blue light, strongly suggested that ZFP3 does not function in PhyA or cryptochrome-dependent signal transduction. To investigate possible genetic interactions of ZFP3 with PhyB, hypocotyl elongation of $p h y B$ mutant, ZFP3ox and the crossed phyB/ZFP3ox seedlings was compared at different fluence rates of red light. Hypocotyl lengths of phyB mutant were longer than wild type or ZFP3ox seedlings and barely changed by different red light intensities, while overexpression of ZFP3 reduced hypocotyl lengths in both Col-0 and phyB backgrounds (Figure 36A). Importantly, hypocotyls of phyB/ZFP3ox seedlings were gradually shortened by increasing fluence rates of red light, similarly to wild type seedlings (Figure $36 \mathrm{~A}$ ). These results collectively suggest that ZFP3 is implicated in red light signaling independent of PhyB and indicate a role for ZFP3 in the amplification of red light signals from PhyC, PhyD or PhyE receptors. However, as a control ZFP3ox was also crossed with phyA mutant to confirm that the shortening of the hypocotyl is independent of far red light in the ZFP3ox seedlings (Figure 36 B). 
(A)
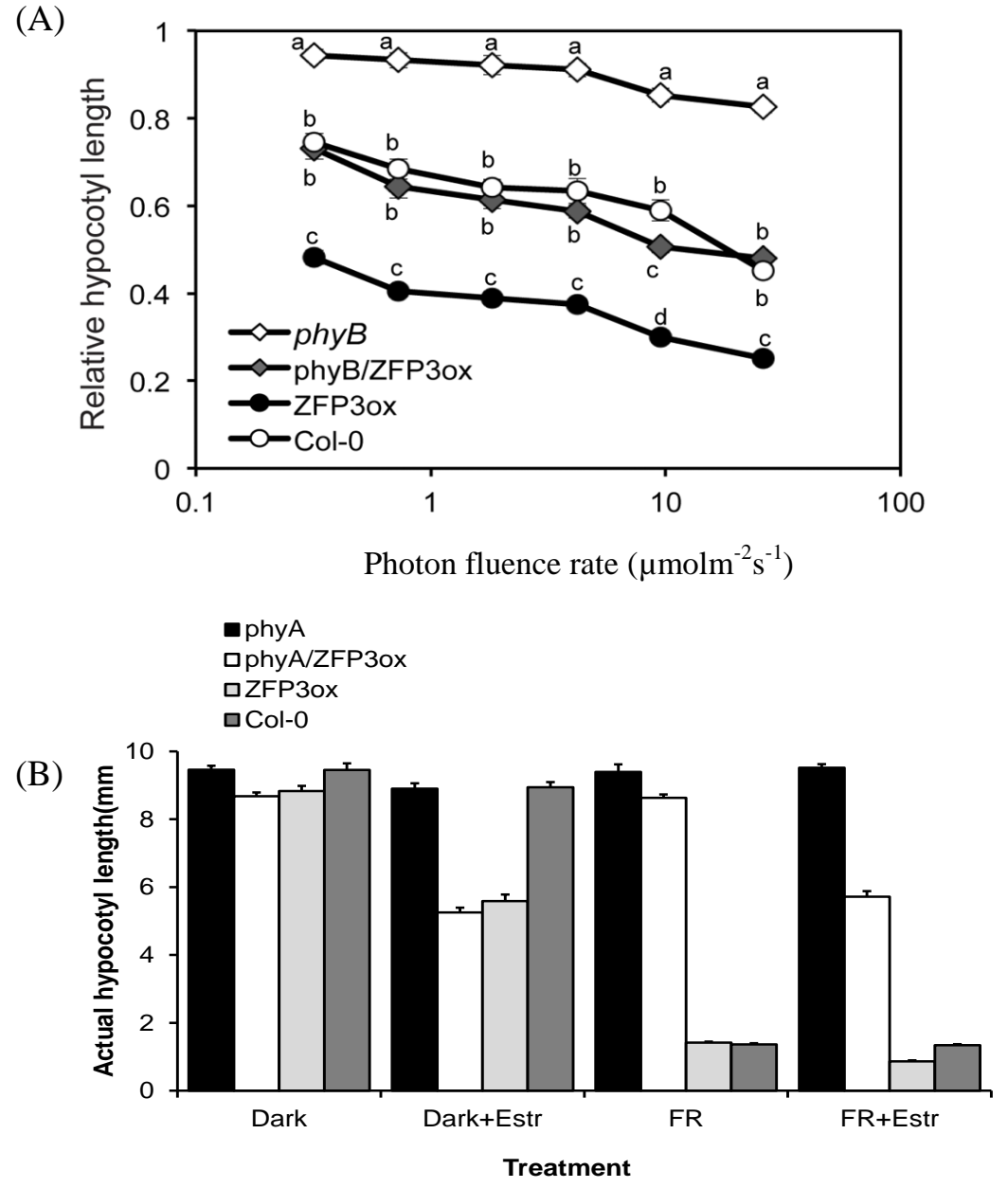

Figure 36: Genetic interaction of $Z F P 3$ with $p h y B$ and phyA signaling components. (A) Relative hypocotyl lengths of seedlings at different fluence rates of red light in the presence of $4 \mu \mathrm{M}$ Estradiol. Hypocotyl lengths were normalized to the corresponding dark-grown seedlings. The $x$ axes show logarithmic scale. Statistical tests were performed by one-way ANOVA, Tukey's test, different letters show significant differences at $p<0.05$. (B) Actual hypocotyl length of seedlings grown under far red (20 $\mu$ molm $\mathrm{s}^{-1}$ ) and dark in the presence or absence of Estradiol. Error bars indicate Standard Error (SE) values.

\subsubsection{Light specific genetic interaction of ZFP3 with abi genes}

In germination tests we showed, that ZFP3 overexpression increased ABA insensitivity of abi2-1, abi4-101 and abi5-1 mutants (Figure 9A-C). To investigate light responses of these ABA signaling mutants and to test if they are influenced by ZFP3, hypocotyls of the crossed abi/ZFP3ox lines were measured in the light and the dark. In white light, ZFP3 overexpression in Col-0, abi2-1, abi4-101 backgrounds reduced hypocotyl lengths by 50 to $60 \%$ while in abi5- 
1/ZFP3ox seedlings hypocotyls were only 10\% shorter than in abi5-1(Figure 37 A). Hypocotyl lengths in the dark were reduced by ZFP3 overexpression in all mutants, except for abi4-101, whose hypocotyls were $30 \%$ shorter than wild type and were barely influenced by ZFP3 overexpression (Figure $37 \mathrm{~B}$ ). The effect of red light on relative hypocotyl lengths (normalized to hypocotyls of dark-germinated seedlings) was comparable in abi2-1 and Col-0 seedlings, which were reduced to similar extent by ZFP3 overexpression (Figure 38 A). In contrast, inhibition of hypocotyl elongation in abi4-101 was less sensitive to red light, especially at lower fluence rates, whereas the abi4/ZFP3ox seedlings had significantly shorter hypocotyls than abi4101, but longer when compared to the ZFP3ox seedlings (Figure 38 B). Relative hypocotyl lengths Col-0, abi5-1 and abi5/ZFP3ox seedlings were similar at different fluence rates of red light. Interestingly, in contrast to the Col-0 background, ZFP3 overexpression could not reduce relative hypocotyl lengths in the abi5-1 mutant background upon red light illumination (Figure $38 \mathrm{C})$. The fact that abi5-1 prevents ZFP3-promoted hypocotyl shortening suggests that $A B I 5$ regulates this photomorphogenic response downstream of ZFP3 and is essential for the lightdependent function of ZFP3.

(A)

White Light

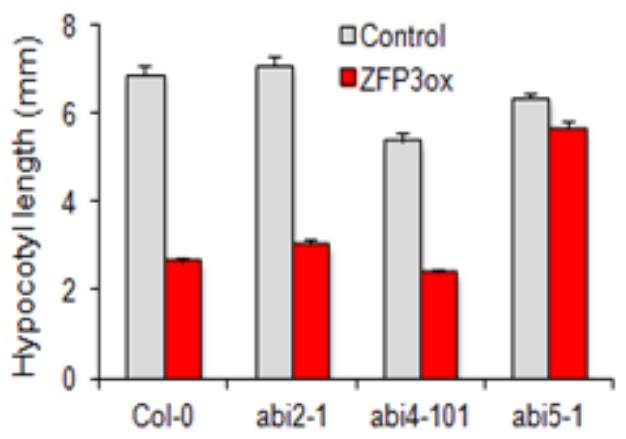

Mutant lines
(B)

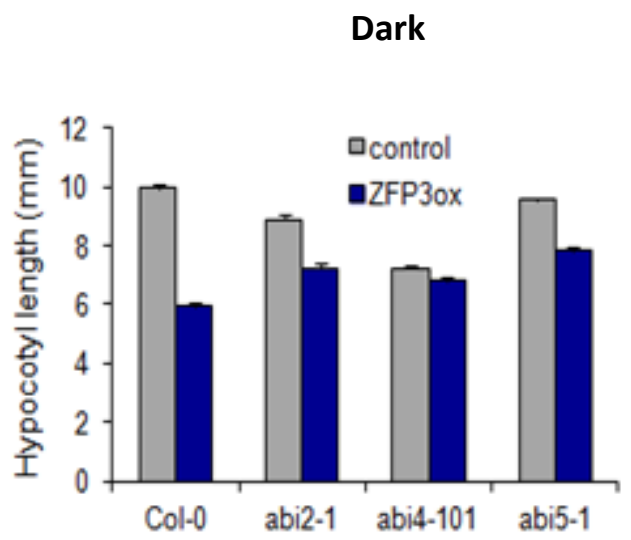

Mutant lines

Figure 37: Hypocotyl elongation of transgenic Arabidopsis ABA insensitive (abi) mutant lines overexpressing ZFP3. Seeds were germinated, in the presence of $5 \mu \mathrm{M}$ Estradiol, in white light (A) or dark (B). Bars on diagrams indicate standard errors. 

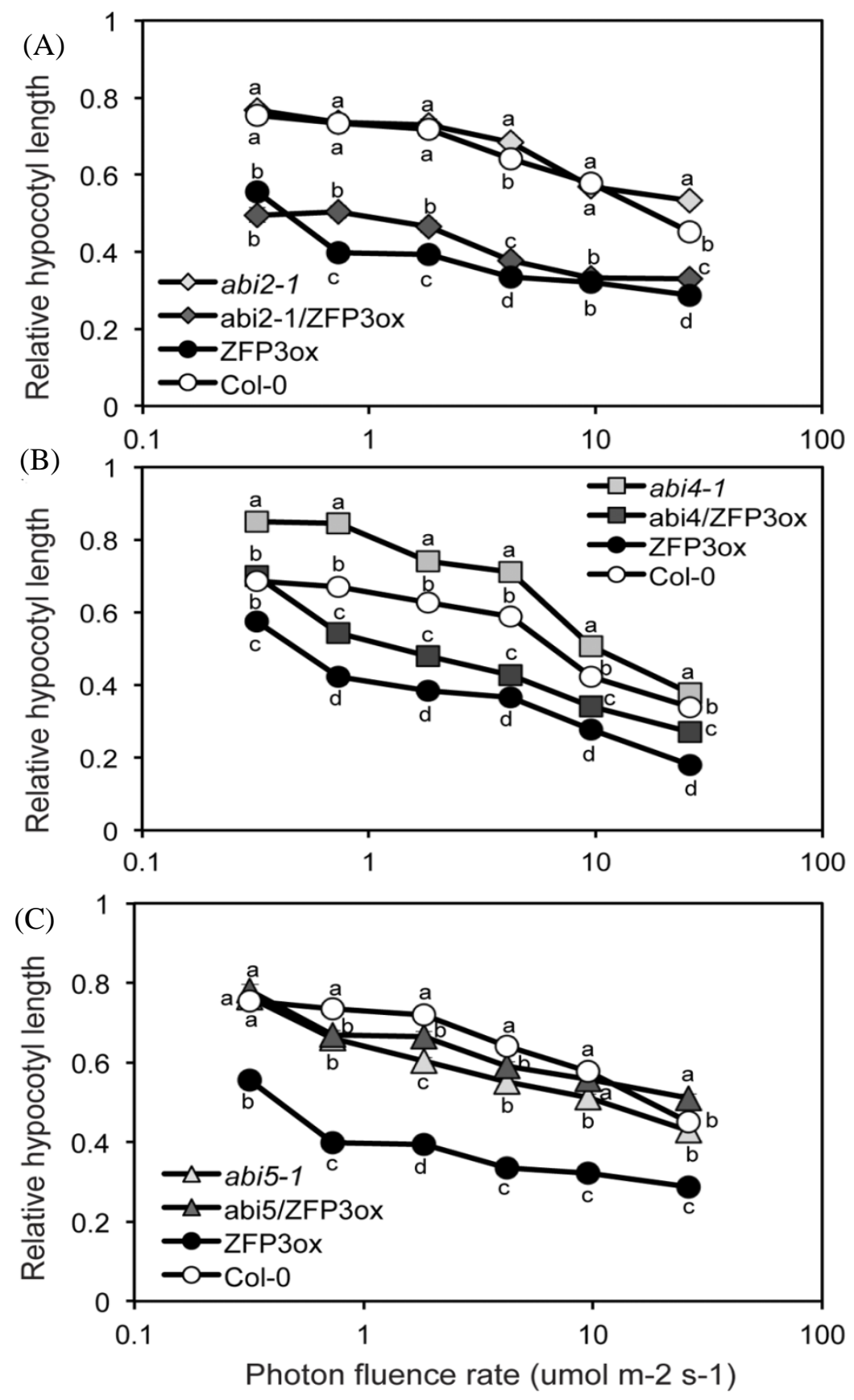

Figure 38: Genetic interaction of ZFP3 and ABA signaling components. A-C) Relative hypocotyl lengths of seedlings of the indicated genotypes at different fluence rates of red light in the presence of $4 \mu \mathrm{M}$ Estradiol. Hypocotyl lengths were normalized to the corresponding dark-grown seedlings. The $x$ axes show logarithmic scale. Statistical tests were performed by one-way ANOVA, Tukey's test, different letters show significant differences at $\mathrm{p}<0.05$. 


\section{DISCUSSION}

\subsection{Identification of genes involved in ABA regulation using the COS System}

The phytohormone ABA plays an important role during different processes of plant development such as seed dormancy, germination and early seedling growth. Additionally, ABA plays a vital role in the stress tolerance of plants, in particular drought or water deprivation. Although the physiological roles of ABA are well characterized, little is known about the molecular components and the mechanism by which ABA regulates these networks. Understanding these mechanisms is of great agricultural and biotechnological interest.

To get a deeper insight into these molecular mechanisms we used the COS library in a chemically inducible expression vector using Gateway technology, which offers precise transcriptional control and easy recloning of the cDNA inserts (Papdi 2008). The inducible system offered advantage compared to that of constitutive overexpression of cDNAs in stress signaling which can result in severe developmental deficiencies (Liu Q 1998; Kasuga 1999; Gilmour 2000). A number of lines has been identified with Estradiol-dependent ABA insensitivity, showing that the employed strategy is useful to isolate such genes (Figure 3). Moreover, identification of cDNA that has previously been reported to play a role in stress responses, such as Glutathione S-transferase, dehydrin family protein, alcohol dehydrogenase like and NAC family protein (Table 3) proves the efficiency and the reliability of this method (Bray 1993; De Bruxelles GL 1996; Michele W. Bianchi 2002; Tran LS 2004).

\subsection{Overexpression of AtHSP17.6A confers ABA insensitive seed germination}

Heat shock response is a conserved reaction of cells against elevated temperatures by transiently reprogramming cellular activities to cease normal protein synthesis and to synthesize a set of heat-shock proteins (Schöffl F 1998). It is well-documented that expression of small heat-shock proteins is induced by high temperature but some of them, including AtHSP 17.6A, are also produced in developing seeds and in response to osmotic stress (Vierling 1991; Wehmeyer N 1996). In particular, AtHSP17.6A was reported to be highly expressed during seed maturation and its seed specific expression was shown to be dependent on the ABI3 transcription factor (Wehmeyer N 1996; Sun W 2002) . However, the role of AtHSP17.6A in ABA regulation had 
not been reported so far. In our screen, the line A26 carried the cDNA encoding the small heat shock protein gene AtHSP17.6A (Figure 7 A \& B). Estradiol dependent gene induction conferred conditional ABA insensitivity in the transgenic plants (Figure $6 \mathrm{~A} \mathrm{~B} \mathrm{\&} \mathrm{C}$ ), pointing to a novel function of this gene. Sun et al. reported that overexpression of AtHSP17.6A confers salt and drought tolerance in transgenic plants, these results have also been confirmed by our experiments (Figure $8 \mathrm{D}$ ). ABA sensitivity of seed germination is controlled by the transcription factors $A B I 3$, $A B I 4$ and ABI5 (Finkelstein and Gibson 2002). ABI5 is a basic leucin zipper (bZIP) transcription factor, which controls ABA signaling during seed development and germination, and regulates the expression of a subset of ABA-induced genes. Transcription of $A B I 5$ is auto regulated and controlled by both $A B I 3$ and $A B I 4$, and ABI5 shows also molecular interaction with ABI3 ( Brocard 2002). Reduction of ABA-mediated induction of ABI5 by Estradiol-dependent coactivation of $H S P 17.6 A$ (Figure $8 \mathrm{~A}, \mathrm{~B} \& \mathrm{C}$ ) suggests that this small heat-shock protein interferes with transcriptional activation of ABI5, leading to a partial loss of function abi5 mutant phenotype and ABA-insensitivity of A26 seeds in the germination assay.

\subsection{Overexpression of $\mathrm{ZFP3}$ confers $\mathrm{ABA}$ insensitive seed germination}

The main aim of creating and employing the COS system in our laboratory was to identify a set of cDNAs conferring dominant stress-tolerance phenotype (Papdi 2008). Our primary objective was to identify novel regulators and to understand the molecular mechanisms underlying the complex network of gene products that localize, perceive, and integrate ABA and stress signals during plant development. From our screening we isolated 35 lines, among those the line A44 displayed highest level Estradiol-dependent ABA insensitivity. The identified full length cDNA in line A44 (Figure 10 A \& B) encoded the previously uncharacterized Zinc Finger Protein 3 (ZFP3, AT5G25160). Germination of A44 seeds on media containing ABA supplemented with Estradiol but not ABA alone suggested that regulated overexpression of the inserted ZFP3 cDNA is responsible for the observed phenotype (Figure 9 B \& D). Expression of ZFP3 as seen only in 2 weeks old A44 plantlets treated with Estradiol suggest that the gene induction is not being influenced by ABA (Figure 9E).

Germination is under tight control by the environmental factors, which are being affected by light quality, temperature and water potential (i.e. osmotic stress). These environmental 
factors eventually determine the relative levels of two phytohormones, GA and ABA, which exerts antagonistic effects on seed germination (Olszewski N 2002; Nambara E 2005). ABA induces dormancy during maturation and GA plays a key role in dormancy release and in the promotion of germination. Paclobutrazol (PAC) has been reported to inhibit GA biosynthesis in plants (Debeaujon I 2000). Germination of A44 seeds was insensitive to PAC (Figure 9C) suggesting that GA is not essential to initiate germination of this line. However, on the other hand inhibition of GA biosynthesis during seed development could also mimic the effect of exogenous ABA (White CN 2000).

The relationship between ZFP3 overexpression and ABA insensitive seed germination phenotype was further verified by re-transforming the cDNA in Col-0 background and testing

independent ZFP3 overexpressing lines for ABA insensitivity (Figure $11 \mathrm{~A} \& \mathrm{~B}$ ), which lead to the conclusion that the identified ZFP3 cDNA is indeed a novel negative regulator of ABA responses.

\subsection{ZFP3 modulates ABA sensitivity}

Our knowledge about the molecular basis of ABA responses was gathered by a combination of molecular-genetic, biochemical, and electrophysiological studies (Li and Assmann 1996; Umezawa 2004; Mori 2006; Seki 2007). Abscisic acid insensitive (abi) mutants were identified from a selection of germinating seedlings in the presence of ABA (Koornneef M 1984; Finkelstein 1994). Enhanced expression of ZFP3 seems to phenocopy the effects of ABA-insensitive abi mutations during germination. The PP2C-type protein phosphatases $\mathrm{ABI} 1$ and $\mathrm{ABI} 2$ are part of the $\mathrm{ABA}$ receptor complex and negatively regulate ABA responses, while transcription factors $\mathrm{ABI} 3, \mathrm{ABI} 4$ and $\mathrm{ABI} 5$ are positive regulators of ABA signals mediating different aspects of ABA responses (Klingler JP 2010; Fujita Y 2011; Finkelstein 2013). ZFP3 seems to modulate parallel regulatory pathways with ABI2, ABI4 and ABI5, as ZFP3 overexpression in abi2-1, abi4-101 and abi5-1 backgrounds additively enhances ABA insensitivity conferred by these mutations. ZFP3 may influence ABI5-dependent regulation as $\mathrm{ABA}$ insensitivity of abi5-1/ZFP3ox lines was only moderately enhanced at high ABA concentrations (Figure 12 A, B \&C). 


\subsection{ZFP3 belongs to $\mathrm{C} 2 \mathrm{H} 2$-type zinc-finger protein family}

ZFP3 belongs to the large zinc finger protein family (Figure 15). These are C2H2-type zinc-finger proteins (ZFPs), also called the TFIIIA-type zinc-finger proteins (Miller 1985). There are $176 \mathrm{C} 2 \mathrm{H} 2$-type zinc finger proteins in Arabidopsis thaliana with $81 \%$ of them being plant specific (Englbrecht 2004). Multiple sequence alignment of the most closely related proteins revealed high similarity between their conserved $\mathrm{ZnF} \_\mathrm{C} 2 \mathrm{H} 2$ domains and $\mathrm{C}$ terminal nuclear localization signals (NLS domains). Till date only a handful of the Zinc finger proteins have been characterized. In our study overexpression of ZFP1, ZFP4, ZFP6 and ZFP7 rendered ABA insensitivity in germination assays (Figure 17 B) and reduced hypocotyl lengths of germinated seedlings, which was comparable to the effect of ZFP3 overexpression (Figure 38A). Similar phenotype of the overexpressing lines suggested their redundant molecular functions.

Study of $z f p 3$ and zfp4 T-DNA insertion mutants added further details to our findings. The mutants did not show any difference in phenotype other than ABA sensitivity and early flowering, which was seen only in zfp3 mutant without any change in the rosette leaf numbers (Figure 26). However, as expected we could observe ABA sensitive phenotype in these mutants which could be more clearly seen in the $z f p 3$ zfp 4 double mutant (Figure 24 A\& B). The fact that zfp3 zfp4 double mutant was more sensitive to ABA when compared to $z f p 3$ or $z f p 4$ single mutant suggest that members of this family possess overlapping functions.

While ZFP3 has not yet been characterized in detail, some of the related factors were reported to control different aspects of plant development. ZFP1 was previously implicated in photomorphogenic responses, although precise function of this gene was not revealed (Chrispeels HE 2000). ZFP2 was shown to control floral abscission, as overexpressing plants enhanced retention of floral organs (Cai S 2008). ZFP5, ZFP6 and ZFP8 were shown to regulate differentiation of trichomes through integrating gibberellin and cytokinin signaling (Zhou Z 2013; Zhou Z 2011). We did not observe abnormalities in trichome morphology of ZFP3ox or zfp3 mutant seedlings (not shown). In our experimental system ZFP6 overexpression resulted in ABA insensitivity and shorter hypocotyls, while ZFP8 had only minor influence on these traits (Figure 17B, Figure 38A). Overexpression of ZFP10 and ZFP11 in Arabidopsis and tobacco 
resulted in dwarf plants with abnormal morphology and reduced fertility (Dinkins R 2002; Dinkins RD 2012).

\subsection{Pleiotropic effects of ZFP3 gene when expressed constitutively}

Similar features to ZFP10 and ZFP11 were characteristic to ZFP3 overexpressing plants, characterized by smaller rosette leaf size than wild type plants, (Figure 31A), with prominently late flowering phenotype (Figure $31 \mathrm{~F} \& \mathrm{G}$ ) and severely affected seed yields (Figure $30 \mathrm{~B}$ ). The siliques produced are crooked and small with no or very few seeds in them (Figure 31 B, C, D $\&$ E). Germination of seeds constitutively overexpressing ZFP3 in standard 1/2MS medium was reduced, while it showed ABA insensitivity similar to the A44 line (Figure $30 \mathrm{C} \& \mathrm{D}$ ). These data suggest that ZFP3 interferes with fertilization and seed germination. Ectopic expression of ZFP3-related $\mathrm{C} 2 \mathrm{H} 2$ zinc finger proteins resulted in pleiotropic morphological abnormalities indicating that they are important regulators of plant development. In contrast to the constitutively overexpressing lines, phenotypes of the zfp 3 and $z f p 4$ knockout mutants were similar to wild type plants suggesting certain degree of redundancy in the function of closely related ZFP genes.

The fact that constitutive overexpression of ZFP3 impaired fertility, justified the strategy to use regulated expression of the cDNA inserts in the COS system (Papdi 2008; Rigó G 2012), as uncontrolled overexpression of ZFP3 could have prevented the identification and/or recovery of fertile plants during the screen.

\subsection{Tissue specific expression and regulation by $\mathrm{ABA}$}

While molecular function of the most closely related ZFP genes can be similar and overlapping, considerable differences in their transcriptional regulation suggest certain degree of diversification. Different members of this gene family can have remarkable activity in particular organs, such as developing seeds (ZFP2), rosette leaves (ZFP8) or inflorescence stems (ZFP6) (Figure18). Spatial transcriptional regulation study of ZFP3 performed by testing the activity of the ZFP3 promoter GUS reporter gene construct (Figure 20) showed the stronger expression in roots, hypocotyl and the chalazal region of the developing embryo. 
As in the case for ZFP3, several ZFP genes are downregulated by ABA confirming negative interaction between these proteins and ABA regulation (Figure 13, 14 \& 19). Alterations in transcriptional regulation can therefore lead to certain differences in biological functions of the individual ZFP genes.

\subsection{ZFP3 is a nuclear protein}

Protein localization study of ZFP3 when fused to eGFP marker gene and expressed in cultured cells or transgenic plants under the control of the CaMV35S promoter and the analysis of the sub cellular fractions of cell suspension cultures carrying the ZFP3 gene fused to HAepitope at both $\mathrm{C}$ or $\mathrm{N}$ terminal revealed and confirmed that ZFP3 is a nuclear protein (Figure21). This can be correlated with the presence of NLS signal present in the ZFP3 and the related gene sequences (Figure 16).

\subsection{ZFP3 modulates ABA signaling network}

Transcript profiling data showed that ZFP3 modulates the expression of a set of ABAand light-regulated genes. Transcript levels of a number of ABA-induced genes including LEA and dehydrin genes were lower in ZFP3ox seedlings than in wild type when germinated in the presence of $\mathrm{ABA}$ (Table $4 \& 6$ ). These experiments however could not identify unambiguously the primary targets of ZFP3, which will require further studies including ChIP-seq, protein interaction studies and DNA binding assays. Reduced expression of ABA-regulated transcription factors such as ABI4 could contribute to ABA insensitivity of ZFP3ox lines (Figure 31). ABA insensitivity and tolerance to paclobutrazol (PAC) of ZFP3ox lines could be influenced by reduced transcription of the DELLA factor RGL2 in ZFP3ox seedlings, which is a negative regulator of GA responses (Lee S 2002; Tyler L 2004). RGL2 was shown to control germination by enhancing $\mathrm{ABA}$-dependent $\mathrm{ABI} 3$ and $\mathrm{ABI} 5$ activities, which act as final repressors of germination (Piskurewicz U 2008; Piskurewicz U 2009). Although transcript levels of ABI5 and RGL2 were lower in ZFP3ox seedlings, they are most probably not direct targets of ZFP3, as their expression was not altered by ZFP3 overexpression after short-term ABA induction (Figure 32). Expression of ABI4 however, was reduced by ZFP3ox, suggesting that this AP2/ERF type transcription factor can more directly be connected to developmental consequences of ZFP3 overexpression (Finkelstein RR 1998; Wind JJ 2013). ABI4 regulates the expression of 
numerous ABA-induced genes, often in synergistic action with other transcription factors such as ABI5 (Reeves WM 2011). Germination of ZFP3 overexpressing seeds may therefore be promoted by down regulation of $\mathrm{ABI} 4$, and the modulation of expression of a set of genes controlled by this transcription factor (Wind JJ 2013). ABI4 was shown to inhibit expression of photosynthetic genes (Acevedo-Hernández 2005). Enhanced expression of photosynthetic genes such as CAB2 in ZFP3ox seedlings can therefore be the consequence of reduced ABI4 levels (Table 6, Figure 31\& Figure 32). Nevertheless, ABI4 is likely only one of the targets of ZFP3 regulation, as ZFP3ox can still enhance ABA insensitivity in abi4 mutant background.

\subsection{ZFP3 interferes with red light signaling}

Apart from the hormonal regulation, seed germination and seedling development are also controlled by other factors, such as light (Seo M 2009). Light signals are perceived by different receptors, out of which phytochromes are dominant photoreceptors of red and far-red light, playing important roles in the regulation of germination and photomorphogenesis, including the inhibition of hypocotyl elongation (Franklin and Quail 2010; Li J 2011). Our data show, that ZFP3 and the closely related ZFP-type factors inhibit hypocotyl elongation displaying short hypocotyls in light and in darkness (Figure 33 B \& Figure 34A). However, this is not accompanied by other photomorphogenic traits like expansion of cotyledons or disappearance of the hypocotyl hook (Figure 33A). This suggests that over-expression of ZFP3 per se does not trigger light responses without illumination. Externally added $\mathrm{GA}_{3}$ and epibrassinolide were unable to complement the short hypocotyl phenotype of ZFP3ox seedlings (Figure 34 B \& C), suggesting that ZFP3 acts independently of the signaling networks of these growth regulators.

ZFP3 interferes with red, but not far-red or blue light signaling, manifested by inhibition of hypocotyl elongation specifically under red light (Figure 35). This suggests that ZFP3 functions as an amplifier of light signals originated from PhyB, PhyC, PhyD or PhyE receptors, but does not affect PhyA-mediated signaling (Figure 36B). The fact that long hypocotyls of $p h y B$ mutant seedlings were considerably reduced by ZFP3 overexpression in red light (Figure 36 A) indicated that ZFP3 can modulate photomorphogenic signals derived from red light receptors other than PhyB. Thus, we propose that ZFP3 is a positive component of red light signaling pathway(s). PIF transcription factors are negative regulators of red light signaling and promote 
scotomorphogenesis in dark-grown seedlings, controlling the expression of large set of target genes (Leivar P 2012; Zhang Y 2013). While transcript levels of PIF genes were not altered in ZFP3ox seedlings, many genes which were repressed or derepressed by ZFP3 overexpression were down and upregulated in the quadruple pifl,3,4,5 mutant, respectively (Table 5) (Leivar P 2012). These data indicate that a subset of ZFP3-regulated genes is also targets of PIF-dependent transcriptional regulation, suggesting that ZFP3 and PIFs control an overlapping signaling pathway.

\subsection{ZFP3- a link between ABA and light}

While close relationship between light and gibberellin signaling in early seedling development is well documented (Seo M 2009; Lau OS 2010; Li J 2011), the role of ABA in light regulated seedling morphogenesis is not well known. The ABI5 transcription factor is a component of the ABA signaling pathway in Arabidopsis whose expression is controlled by the light signaling component HY5, and can shorten hypocotyls in a light-dependent manner if overexpressed in Arabidopsis (Chen H 2008). While ectopic expression of ZFP3 in Col-0 background produced seedlings with short hypocotyl, light-dependent hypocotyl elongation in the abi5-1 mutant background was only minimally affected (Figure 37, Figure 38). This suggests that ZFP3 exerts its effect on light-controlled hypocotyl elongation exclusively through ABI5. Over-expression of ABI5 shortened hypocotyls under red, far-red and blue light illumination (Chen H 2008), whereas the control of light-dependent hypocotyl elongation by ZFP3 was more specific to red light. 


\section{Model of ZFP3 action in seed germination and plant development}

Based on our results and the literature related to our work, we propose the following model (Figure 39).

$\mathrm{ABA}$ is sensed by the receptor complexes containing PP4C-type protein phosphatases ABI1 and ABI2 which functions as negative regulators of ABA signals. SnRK2-type protein kinases and transcription factors $\mathrm{ABI} 4, \mathrm{ABI} 5$ are positive components of ABA signaling. Red light is perceived by Phytochromes phyB, C, D, E and light signals are controlled by transcription factors PIF1, 3, 4, 5. ZFP3 is negative regulator of ABA signals, promotes red light-dependent reduction of hypocotyl elongation and reduces plant growth and fertility. Transcription of ABI4 was repressed by ZFP3. ABI5 is induced by ABA, regulated by HY5 and seems to be epistatic to ZFP3 in reduction of red light-dependent hypocotyl elongation. Precise molecular function of ZFP3 is not known; therefore effect of this factor on other regulatory pathways is indicated with dashed lines.

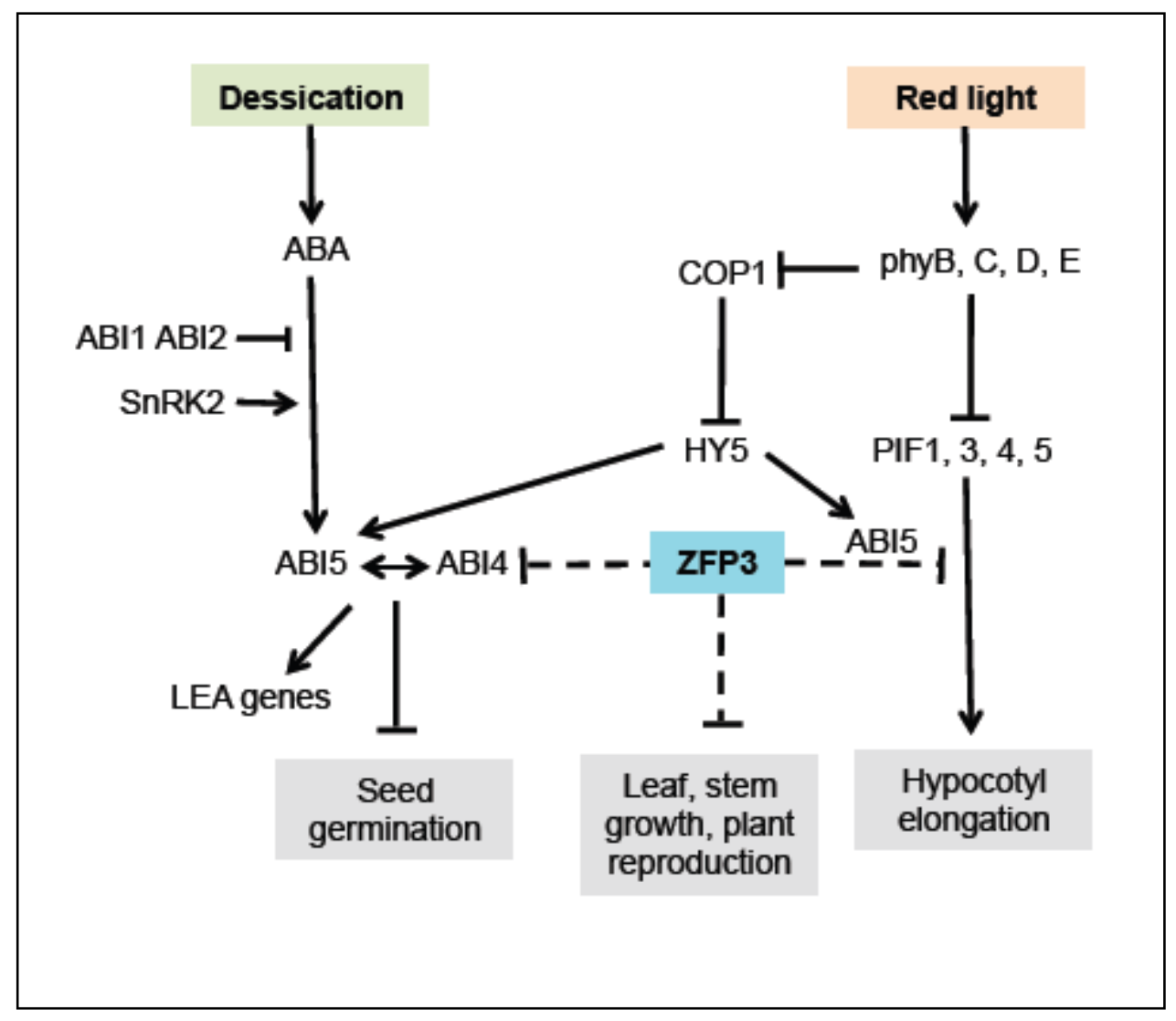

Figure 39: Model of ZFP3 action in seed germination and plant development 


\section{CONCLUSION}

(I) We have successfully developed and used the Controlled cDNA Overexpression System, (COS) to identify novel stress regulatory genes.

Characterization of a cDNA conferring insensitivity to ABA in germination assays has identified the coding region of the small heatshock protein HSP17.6A suggesting its implication in ABA signal transduction.

> Characterization of the Arabidopsis Zinc Finger Protein 3 (ZFP3), revealed that this nuclear protein acts as a negative regulator of $\mathrm{ABA}$ signalling.

(II) Further detailed characterization revealed that the Arabidopsis Zinc Finger Protein 3 (ZFP3), together with closely related ZFP factors- ZFP1, ZFP4, ZFP6 and ZFP7, is a negative regulator of $\mathrm{ABA}$ signaling.

$>\mathrm{We}$ have shown that $\mathrm{ZFP} 3$ belongs to the nuclear $\mathrm{C} 2 \mathrm{H} 2$ zinc finger protein family and acts as a negative regulator of ABA-suppressed seed germination and early seedling development.

$>$ Over-expression of ZFP3 and the closely related ZFP1, ZFP4, ZFP6 and ZFP7 zinc finger factors confers ABA insensitivity to seed germination while the $z f p 3$ zfp 4 double mutant displays enhanced ABA susceptibility.

Constitutive over-expression of ZFP3ox plants revealed multiple phenotypic alterations in Arabidopsis plants, such as semidwarf growth habit, defects in fertility and enhanced sensitivity of hypocotyl elongation to red but not to far-red or blue light.

Analysis of genetic interactions with phytochrome and abi mutants indicates that ZFP3 enhances red light signaling by photoreceptors other than phyA, and additively increases ABA insensitivity conferred by the $a b i 2, a b i 4$ and abi5 mutations. 
$>$ We have also shown through genetic studies that ABI5 seem to be epistatic to ZFP3 in control of red light-dependent repression of hypocotyl elongation.

$>$ From the transcriptomic studies we show that subset of genes which are inversely regulated by $\mathrm{ABA}$ and $\mathrm{ZFP} 3$ are also controlled by light throught a phytochrome light receptor and one or more PIF transcription factors. 


\section{LIST OF REFERENCES}

Acevedo-Hernandez GJ, Leon P, Herrera-Estrella LR (2005) Sugar and ABA responsiveness of a minimal RBCS light-responsive unit is mediated by direct binding of ABI4. The Plant journal : for cell and molecular biology 43 (4):506-519.

Acevedo-Hernández D, D. V., Monaco MK, Olsen A, Klein RR, Kumari S, Ware D, Klein PE (2011) Functional annotation of the transcriptome of Sorghum bicolor in response to osmotic stress and abscisic acid. BMC genomics 12:514.

Aharoni A, Dixit S, Jetter R, Thoenes E, van Arkel G, Pereira A (2004) The SHINE clade of AP2 domain transcription factors activates wax biosynthesis, alters cuticle properties, and confers drought tolerance when overexpressed in Arabidopsis. The Plant cell 16 (9):2463-2480.

An L, Zhou Z, Su S, Yan A, Gan Y (2012) GLABROUS INFLORESCENCE STEMS (GIS) is required for trichome branching through gibberellic acid signaling in Arabidopsis. Plant \& cell physiology 53 (2):457-469.

Arroyo A, Bossi F, Finkelstein RR, Leon P (2003) Three genes that affect sugar sensing (abscisic acid insensitive 4, abscisic acid insensitive 5, and constitutive triple response 1) are differentially regulated by glucose in Arabidopsis. Plant physiology 133 (1):231-242.

Bauer D, Viczian A, Kircher S, Nobis T, Nitschke R, Kunkel T, Panigrahi KC, Adam E, Fejes E, Schafer E, Nagy F (2004) Constitutive photomorphogenesis 1 and multiple photoreceptors control degradation of phytochrome interacting factor 3, a transcription factor required for light signaling in Arabidopsis. Plant Cell 16 (6):1433-1445.

Bechtold N EJ, Pelletier G. (1993) In planta Agrobacterium mediated gene transfer by infiltration of adult Arabidopsis thaliana plants. . C R Acad Sci Paris,Life Sciences 316:1194-1199.

Bentsink LaK, M. (2002) Seed dormancy and germination. In CR Somerville, EM Meyerowitz, The Arabidopsis Book. American Society of Plant Biologists, Rockville, MD,:pp 1-17.

Bereterbide A, Hernould M, Farbos I, Glimelius K, Mouras A (2002) Restoration of stamen development and production of functional pollen in an alloplasmic CMS tobacco line by ectopic expression of the Arabidopsis thaliana SUPERMAN gene. The Plant journal : for cell and molecular biology 29 (5):607-615.

Bertauche N, Leung J, Giraudat J (1996) Protein phosphatase activity of abscisic acid insensitive 1 (ABI1) protein from Arabidopsis thaliana. European journal of biochemistry / FEBS 241 (1):193-200. 
Bonetta D, Bayliss P, Sun S, Sage T, McCourt P (2000) Farnesylation is involved in meristem organization in Arabidopsis. Planta 211 (2):182-190.

Bowman JL, Sakai, H., Jack, T., Weigel, D., Mayer, U. and Meyerowitz, E. M. (1992) SUPERMAN, a regulator of floral homeotic genes in Arabidopsis. Development 114, :599-615.

Bray EA (1993) Molecular responses to water deficit. Plant Physiol Biochem 103:1035-1040

Bray EA (1997) Plant responses to water deficit. Trends Plant Sci 2:48-54.

Brocard IM, Lynch TJ, Finkelstein RR (2002) Regulation and role of the Arabidopsis abscisic acid-insensitive 5 gene in abscisic acid, sugar, and stress response. Plant Physiology 129 (4):1533-1543.

Bungard RA, Mcneil, D., Morton, J. D. (1997) Effects of chilling, light and nitrogen compounds on germination. Rate of Germination and seed inhibition of Clemanti vitalbal. . Journals of Botany 79,:643-650.

Cai S, and Lashbrook,C.C. (2008) Stamen Abscission Zone Transcriptome Profiling Reveals New Candidates for Abscission Control: Enhanced Retention of Floral Organs in Transgenic Plants Overexpressing Arabidopsis ZINC FINGER PROTEIN2. Plant physiology 146,:1305-1321.

Chandler PMaR, M. (1994) Gene expression regulated by abscisic acid and its relation to stress tolerance. . Annu Rev PlantPhysiol Plant Mol Biol 45, (113-141).

Chaudhury AM, Ming L, Miller C, Craig S, Dennis ES, Peacock WJ (1997) Fertilizationindependent seed development in Arabidopsis thaliana. Proceedings of the National Academy of Sciences of the United States of America 94 (8):4223-4228.

Chaves I, Pokorny R, Byrdin M, Hoang N, Ritz T, Brettel K, Essen LO, van der Horst GT, Batschauer A, Ahmad M. (2011) The cryptochromes: blue light photoreceptors in plants and animals. Annu Rev Plant Biol 62:335-364

Chen H, Zhang, J., Neff, M.M., Hong, S.W., Zhang, H., Deng, X.W., Xiong, L, . (2008) Integration of light and abscisic acid signaling during seed germination and early seedling development. Proc Natl Acad Sci USA 105,:4495-4500.

Chomczynski P1 MK ( 1995 ) Short technical reports. Modification of the TRI reagent procedure for isolation of RNA from polysaccharide- and proteoglycan-rich sources. Biotechniques 19(6) (Dec):942-945. 
Choudhary MK, Basu D, Datta A, Chakraborty N, Chakraborty S (2009) Dehydration-responsive nuclear proteome of rice (Oryza sativa L.) illustrates protein network, novel regulators of cellular adaptation, and evolutionary perspective. Molecular \& cellular proteomics : MCP.

Chrispeels HE OH, Janvier N, Tague BW. (2000) AtZFP1, encoding Arabidopsis thaliana C2H2 zinc-finger protein 1 , is expressed downstream of photomorphogenic activation. Plant Mol Biol 42:279-290.

Clarke JH, Tack D, Findlay K, Van Montagu M, Van Lijsebettens M (1999) The SERRATE locus controls the formation of the early juvenile leaves and phase length in Arabidopsis. The Plant journal : for cell and molecular biology 20 (4):493-501.

Colasanti J, Yuan, Z., Sundaresan, V. (1998) The INDETERMINATE gene encodes a zinc finger protein and regulates a leaf-generated signal required for the transition to flowering in maize. Cell 93,593-603.

Coleman JE (1992) Zinc proteins: enzymes, storage proteins, transcription factors, and replication proteins. Annu Rev Biochem 61, :897-946.

Cummins WR, Kende, H., Raschke, K. (1971) Specificity and reversibility of the rapid stomatal response to abscisic acid. Planta (Berl) 99, (347-351.)

Curtis MD, Grossniklaus U (2003) A gateway cloning vector set for high-throughput functional analysis of genes in planta. Plant Physiology 133 (2):462-469.

Cutler S, Ghassemian, M., Bonetta, D., Cooney, S., and McCourt, P. (1996) A protein farnesyl transferase involved in abscisic acid signal transduction in Arabidopsis. Science 273, :1239-1241.

Czechowski T, Bari RP, Stitt M, Scheible WR, Udvardi MK. (2004) Real-time RT-PCR profiling of over 1400 Arabidopsis transcription factors: unprecedented sensitivity reveals novel root- and shoot-specific genes. Plant J 38: 366-79

Czechowski T, Stitt M, Altmann T, Udvardi MK, Scheible WR. (2005) Genome-wide identification and testing of superior reference genes for transcript normalization in Arabidopsis. Plant Physiology 139: 5-17

De Bruxelles GL PW, Dennis ES, Dolferus R. (1996) Abscisic acid induces the alcohol dehydrogenase gene in Arabidopsis. Plant Physiol Biochem 111:381-391. 
Debeaujon I KM ( 2000) Gibberellin Requirement for Arabidopsis Seed Germination Is Determined Both by Testa Characteristics and Embryonic Abscisic Acid. Plant Physiology 122:415-424.

Dinkins R, Pflipsen C, Thompson A, Collins GB (2002) Ectopic expression of an Arabidopsis single zinc finger gene in tobacco results in dwarf plants. Plant Cell Physiol 43 (7):743750 .

Dinkins R, Pflipsen, C., Collins, G.B. (2003) Expression and deletion analysis of an Arabidopsis SUPERMAN-like zinc finger gene. Plant Sci 165,:33-41.

Dinkins R, Tavva, V., Palli, S., Collins, G.B. (2012) Mutant and overexpression analysis of a $\mathrm{C} 2 \mathrm{H} 2$ single zinc finger gene of Arabidopsis. Plant Molecular Biology Reporter 30,:99110.

Dinneny JR, Weigel D, Yanofsky MF (2006) NUBBIN and JAGGED define stamen and carpel shape in Arabidopsis. Development 133 (9):1645-1655.

Dinneny JR, Yadegari R, Fischer RL, Yanofsky MF, Weigel D (2004) The role of JAGGED in shaping lateral organs. Development 131 (5):1101-1110.

Englbrecht CC, Schoof H, Bohm S (2004) Conservation, diversification and expansion of C2H2 zinc finger proteins in the Arabidopsis thaliana genome. BMC genomics 5 (1):39.

Fairall L, Schwabe, J.W., Chapman, L., Finch, J.T, Rhodes, D. (1993) The crystal structure of a two zinc-finger peptide reveals an extension to the rules for zinc-finger/DNA recognition. Nature 366(6454): 483-487.

Ferrando A FR, Jásik J, Schell J, and Koncz C. (2000) Intron-tagged epitope: A tool for facile detection and purification of proteins expressed in Agrobacterium-transformed cells. Plant J 22:553-560.

Finkelstein RR, Somerville CR (1990) Three Classes of Abscisic Acid (ABA)-Insensitive Mutations of Arabidopsis Define Genes that Control Overlapping Subsets of ABA Responses. Plant physiology 94 (3):1172-1179.

Finkelstein RR (1994) Mutations at two new Arabidopsis ABA response loci are similar to the abi3 mutations. Plant J 5:765-771.

Finkelstein RR WM, Lynch TJ, Rao S, Goodman HM. (1998) The Arabidopsis abscisic acid response locus ABI4 encodes an APETALA 2 domain protein. Plant Cell 10:1043-1054 
Finkelstein R, and Lynch, T. (2000a) The Arabidopsis abscisic acid response gene ABI5 encodes a basic leucine zipper transcription factor. Plant Cell 12:599-609.

Finkelstein RR, Lynch TJ. (2000b) Abscisic acid inhibition of radicle emergence but not seedling growth is suppressed by sugars. Plant physiology 122 (4):1179-1186.

Finkelstein RR, Gibson SI. (2002) ABA and sugar interactions regulating development: crosstalk or voices in a crowd? Curr Opin Plant Biol 5 (1):26-32.

Finkelstein RR, Gampala SS, Rock CD. (2002) Abscisic acid signaling in seeds and seedlings. The Plant cell 14 Suppl:S15-45.

Finkelstein R. (2013) Abscisic Acid Synthesis and Response. Arabidopsis Book 11:e0166.

Franklin K.A., Quail P.H. (2010) Phytochrome functions in Arabidopsis development. J. Exp. Bot; 61:11-24.

Friesen WJD, M. K. (2001) Specific RNA binding by a single C2H2 zinc finger. J Biol Chem $276: 1968-1973$.

Fujita Y, Fujita M, Satoh R, Maruyama K, Parvez MM, Seki M, Hiratsu K, Ohme-Takagi M, Shinozaki K, Yamaguchi-Shinozaki K (2005) AREB1 is a transcription activator of novel ABRE-dependent ABA signaling that enhances drought stress tolerance in Arabidopsis. The Plant cell 17 (12):3470-3488.

Fujita Y FM, Shinozaki K, Yamaguchi-Shinozaki K. (2011) ABA-mediated transcriptional regulation in response to osmotic stress in plants. J Plant Res 124:509-525

Fukazawa J, Sakai T, Ishida S, Yamaguchi I, Kamiya Y, Takahashi Y. (2000) Repression of shoot growth, a bZIP transcriptional activator, regulates cell elongation by controlling the level of gibberellins. The Plant cell 12 (6):901-915

Furihata T, Maruyama K, Fujita Y, Umezawa T, Yoshida R, Shinozaki K, Yamaguchi-Shinozaki K. (2006) Abscisic acid-dependent multisite phosphorylation regulates the activity of a transcription activator AREB1. Proceedings of the National Academy of Sciences of the United States of America 103 (6):1988-1993.

Gaiser JC, Robinson-Beers K, Gasser CS. (1995) The Arabidopsis SUPERMAN Gene Mediates Asymmetric Growth of the Outer Integument of Ovules. The Plant cell 7 (3):333-345. 
Gan Y, Kumimoto R, Liu C, Ratcliffe O, Yu H, Broun P. (2006) GLABROUS INFLORESCENCE STEMS modulates the regulation by gibberellins of epidermal differentiation and shoot maturation in Arabidopsis. The Plant cell 18 (6):1383-1395.

Gan Y, Liu C, Yu H, Broun P. (2007) Integration of cytokinin and gibberellin signalling by Arabidopsis transcription factors GIS, ZFP8 and GIS2 in the regulation of epidermal cell fate. Development 134 (11):2073-2081.

Garcia-Maroto F, Ortega N, Lozano R, Carmona MJ. (2000) Characterization of the potato MADS-box gene STMADS16 and expression analysis in tobacco transgenic plants. Plant molecular biology 42 (3):499-513

Gilmour SJ, Sebolt AM, Salazar MP, Everard JD, Thomashow MF. (2000) Overexpression of the Arabidopsis CBF3 transcriptional activator mimics multiple biochemical changes associated with cold acclimation. Plant physiology 124 (4):1854-1865

Giraudat J, Hauge, B., Valon, C., Smalle, J., Parcy, F., and Goodman, H. (1992) Isolation of the Arabidopsis ABI3 gene by positional cloning. . Plant, cell \& environment 4:1251-1261.

Gosti F, Beaudoin N, Serizet C, Webb AA, Vartanian N, Giraudat J (1999) ABI1 protein phosphatase $2 \mathrm{C}$ is a negative regulator of abscisic acid signaling. The Plant cell 11 (10):1897-1910

Grigg SP, Canales C, Hay A, Tsiantis M (2005) SERRATE coordinates shoot meristem function and leaf axial patterning in Arabidopsis. Nature 437 (7061):1022-1026.

Grill E HA (1998) ABA signal transduction. Current opinion in plant biology 1:412-418

Gutierrez L, Van Wuytswinkel O, Castelain M, Bellini C (2007) Combined networks regulating seed maturation. Trends in plant science 12 (7):294-300.

Halliday KJaW, G. C. (2003) Changes in photoperiod or temperature alter the functional relationships between phytochromes and reveal roles for phyD and phyE. Plant Physiol 131:1913-1920.

Hasegawa PM, Bressan RA, Zhu JK, Bohnert HJ. (2000) Plant Cellular and Molecular Responses to High Salinity. Annual review of plant physiology and plant molecular biology 51:463-499.

Hennig L, Stoddart WM, Dieterle M, Whitelam GC, Schafer E. (2002) Phytochrome E controls light-induced germination of Arabidopsis. Plant physiology 128 (1):194-200 
Hewelt A, Prinsen, E., Schell, J., Van Onckelen, H., Schmulling. (1994) Promoter tagging with promoterless ipt gene leads to cytokinin-induced phenotypic variability in transgenic tobacco plants: implications of gene dosage effects. TPlant J 6,:879-891.

Hose E, Steudle E, Hartung W. (2000) Abscisic acid and hydraulic conductivity of maize roots: a study using cell- and root-pressure probes. Planta 211 (6):874-882

Hu J, Barlet X, Deslandes L, Hirsch J, Feng DX, Somssich I, Marco Y. (2008) Transcriptional responses of Arabidopsis thaliana during wilt disease caused by the soil-borne phytopathogenic bacterium, Ralstonia solanacearum. PloS one 3 (7):e2589.

Hubbard KE, Nishimura N, Hitomi K, Getzoff ED, Schroeder JI. (2010) Early abscisic acid signal transduction mechanisms: newly discovered components and newly emerging questions. Genes \& development 24 (16):1695-1708.

Hughes DW GG. (1989) Temporally modular gene expression during cotyledon development. Genes and Development 3,:358-369.

Huijser C, Kortstee A, Pego J, Weisbeek P, Wisman E, Smeekens S. (2000) The Arabidopsis SUCROSE UNCOUPLED-6 gene is identical to ABSCISIC ACID INSENSITIVE-4: involvement of abscisic acid in sugar responses. The Plant journal : for cell and molecular biology 23 (5):577-585

Ichikawa T. NM, Kawashima M., Iizumi H., Kuroda H., Kondou Y. (2006) The FOX hunting system: an alternative gain-of-function gene hunting technique. . Plant J 48,:974-985.

Ingram J, and Bartels, D. (1996) The molecular basis of dehydration tolerance in plants. . Annu Rev Plant Physiol Plant Mol Biol 47,:377-403.

Ingram J, Bartels D. (1996) The Molecular Basis of Dehydration Tolerance in Plants. Annual review of plant physiology and plant molecular biology 47:377-403. doi:10.1146/annurev.arplant.47.1.377

Jiang CJ, Aono M, Tamaoki M, Maeda S, Sugano S, Mori M, Takatsuji H (2008) SAZ, a new SUPERMAN-like protein, negatively regulates a subset of ABA-responsive genes in Arabidopsis. Mol Genet Genomics 279 (2):183-192.

Jin H, Cominelli E, Bailey P, Parr A, Mehrtens F, Jones J, Tonelli C, Weisshaar B, Martin C (2000) Transcriptional repression by AtMYB4 controls production of UV-protecting sunscreens in Arabidopsis. The EMBO journal 19 (22):6150-6161. 
Jones H.D. PNCB, Holdsworth M.J. (1997) Genotype and environment interact to control dormancy and differential expression of the VIVIPAROUS1 homologue in embryos of Avena fatua. . Plant J 12:911-920.

Kagale S, Links MG, Rozwadowski K. (2010) Genome-wide analysis of ethylene-responsive element binding factor-associated amphiphilic repression motif-containing transcriptional regulators in Arabidopsis. Plant physiology 152 (3):1109-1134.

Karssen CM (1982) Seasonal patterns of dormancy in weed seeds. In AA Kahn,ed,. The Physiology and Biochemistry of Seed Development, Dormancy and Germination. . Elsevier Biomedical, Amsterdam, The Netherlands:243-270.

Kasuga M, Liu Q, Miura S, Yamaguchi-Shinozaki K, Shinozaki K. (1999) Improving plant drought, salt, and freezing tolerance by gene transfer of a single stress-inducible transcription factor. Nature biotechnology 17 (3):287-291.

Khan AA. (1968) Inhibition of gibberellic acid-induced germination by abscisic acid and reversal by cytokinins. Plant Physiology 43,:1463-1465.

Ko JH, Yang SH, Han KH. (2006) Upregulation of an Arabidopsis RING-H2 gene, XERICO, confers drought tolerance through increased abscisic acid biosynthesis. The Plant journal : for cell and molecular biology 47 (3):343-355.

Klingler JP BG, Zhu J. ( 2010) ABA receptors: the START of a new paradigm in phytohormone signalling. J Exp Bot 61:3199-3210

Koncz C MN, Szabados L, Hrouda M, Bachmair A, Schell J. (1994) Specialized vectors for gene tagging and expression studies. Plant Molecular Biology Manual,Kluwer Academic Publishers, Dordrecht, The Netherlands, Vol 2.:pp B1-22

Koornneef M, Dellaert LW, van der Veen JH. (1982) EMS- and radiation-induced mutation frequencies at individual loci in Arabidopsis thaliana (L.) Heynh. Mutation research 93 (1):109-123

Koornneef M RG, Karssen CM. (1984) The isolation and characterization of abscisic acidinsensitive mutants of Arabidopsis thaliana. Physiologia plantarum 61:377-383

Koussevitzky S, Nott A, Mockler TC, Hong F, Sachetto-Martins G, Surpin M, Lim J, Mittler R, Chory J. (2007) Signals from chloroplasts converge to regulate nuclear gene expression. Science 316 (5825):715-719. 
Kuhn JM, Boisson-Dernier A, Dizon MB, Maktabi MH, Schroeder JI. (2006) The protein phosphatase AtPP2CA negatively regulates abscisic acid signal transduction in Arabidopsis, and effects of abh1 on AtPP2CA mRNA. Plant physiology 140 (1):127-139.

Kun Yuan and Joanna Wysocka-Diller. (2006) Phytohormone signaling pathways interact with sugars during seed germination and seedling development. J. Exp.Bot. 57(12): 33593367.

Laby RJ, Kincaid MS, Kim D, Gibson SI. (2000) The Arabidopsis sugar-insensitive mutants sis4 and sis5 are defective in abscisic acid synthesis and response. The Plant journal : for cell and molecular biology 23 (5):587-596.

Lau OS DX. (2010) Plant hormone signaling lightens up: integrators of light and hormones. Curr Opin Plant Biol 13:571-577.

Laubinger S, Sachsenberg T, Zeller G, Busch W, Lohmann JU, Ratsch G, Weigel D. (2008) Dual roles of the nuclear cap-binding complex and SERRATE in pre-mRNA splicing and microRNA processing in Arabidopsis thaliana. Proceedings of the National Academy of Sciences of the United States of America 105 (25):8795-8800.

LeClere S, Bartel B. (2001) A library of Arabidopsis 35S-cDNA lines for identifying novel mutants. Plant molecular biology 46 (6):695-703.

Lee S, Cheng H, King KE, Wang W, He Y, Hussain A, Lo J, Harberd NP, Peng J. (2002) Gibberellin regulates Arabidopsis seed germination via RGL2, a GAI/RGA-like gene whose expression is up-regulated following imbibition. Genes \& development 16 (5):646-658.

Leivar P TJ, Cohn MM, Monte E, Al-Sady B, Erickson E, Quail PH. (2012) Dynamic antagonism between phytochromes and PIF family basic helix-loop-helix factors induces selective reciprocal responses to light and shade in a rapidly responsive transcriptional network in Arabidopsis. Plant Cell 24:1398-1419.

Leube MP, Grill E, Amrhein N. (1998) ABI1 of Arabidopsis is a protein serine/threonine phosphatase highly regulated by the proton and magnesium ion concentration. FEBS letters 424 (1-2):100-104

Leung J, Bouvier-Durand, M., Morris, P.-C., Guerrier, D., Chefdor, F., and Giraudat, J. (1994) Arabidopsis ABA response gene ABI1: Features of a calcium-modulated protein phosphatase. Science $264: 1448-1452$. 
Leung J, Giraudat J (1998) Abscisic Acid Signal Transduction. Annual review of plant physiology and plant molecular biology 49:199-222.

Leung J, Merlot S, Giraudat J (1997) The Arabidopsis ABSCISIC ACID-INSENSITIVE2 (ABI2) and ABI1 genes encode homologous protein phosphatases $2 \mathrm{C}$ involved in abscisic acid signal transduction. The Plant cell 9 (5):759-771.

Li B FM (1997) Genetic and molecular control of seed dormancy. Trends in Plant Science 2,: 384-389.

Li J, Assmann SM (1996) An Abscisic Acid-Activated and Calcium-Independent Protein Kinase from Guard Cells of Fava Bean. The Plant cell 8 (12):2359-2368.

Li J LG, Wang H, Wang Deng X. (2011) Phytochrome signaling mechanisms. The Arabidopsis Book 9:e0148

Liu Q KM, Sakuma Y, Abe H, Miura S, Yamaguchi-Shinozaki K, Shinozaki K. (1998) Two transcription factors, DREB1 and DREB2, with an EREBP/AP2 DNA binding domain separate two cellular signal transduction pathways in drought- and low-temperatureresponsive gene expression, respectively, in Arabidopsis. Plant Cell Aug;10(8):13911406.

Lobbes D, Rallapalli G, Schmidt DD, Martin C, Clarke J. (2006) SERRATE: a new player on the plant microRNA scene. EMBO reports 7 (10):1052-1058.

López-Carbonell M GM, Jáuregui O. (2009) Enhanced determination of abscisic acid (ABA) and abscisic acid glucose ester (ABA-GE) in Cistus albidus plants by liquid chromatographymass spectrometry in tandem mode. Plant Physiol Biochem 47:256-261

Lopez-Molina L, Chua NH. (2000) A null mutation in a bZIP factor confers ABA-insensitivity in Arabidopsis thaliana. Plant \& cell physiology 41 (5):541-547

Lopez-Molina L, Mongrand S, Chua NH. (2001) A postgermination developmental arrest checkpoint is mediated by abscisic acid and requires the ABI5 transcription factor in Arabidopsis. Proceedings of the National Academy of Sciences of the United States of America 98 (8):4782-4787.

Lopez-Molina L, Mongrand S, McLachlin DT, Chait BT, Chua NH. (2002) ABI5 acts downstream of $\mathrm{ABI} 3$ to execute an ABA-dependent growth arrest during germination. The Plant journal : for cell and molecular biology 32 (3):317-328 
Luo M, Bilodeau, P., Koltunow, A., Dennis, E.S., Peacock, W.J., and Chaudhury, A.M. (1999) Genes controlling fertilization-independent seed development in Arabidopsis thaliana. Proc Natl Acad Sci USA 96, :296-301.

Luo M, Bilodeau, P., Dennis, E.S., Peacock, W.J., and Chaudhury, A.M. (2000) Expression and parent-of-origin effects for FIS2, MEA, and FIE in the endosperm and embryo of developing Arabidopsis seeds. . Proc Natl Acad Sci USA 97:10637-10642.

Machida S, Chen HY, Adam Yuan Y. (2011) Molecular insights into miRNA processing by Arabidopsis thaliana SERRATE. Nucleic acids research 39 (17):7828-7836.

Mathur J, Koncz C, Szabados L. (1995) A simple method for isolation, liquid culture, transformation and regeneration of Arabidopsis thaliana protoplasts. Plant cell reports 14 (4):221-226.

McCarty DR (1995) Genetic control and integration of maturation and germination pathways in seed development. . Annu Rev Plant Physiol Plant Mol Biol 46:71-93.

Merlot S, Gosti F, Guerrier D, Vavasseur A, Giraudat J (2001) The ABI1 and ABI2 protein phosphatases $2 \mathrm{C}$ act in a negative feedback regulatory loop of the abscisic acid signalling pathway. The Plant journal : for cell and molecular biology 25 (3):295-303.

Meyer K, Leube MP, Grill E (1994) A protein phosphatase 2C involved in ABA signal transduction in Arabidopsis thaliana. Science 264 (5164):1452-1455.

Michele W. Bianchi CRaNV (2002) Drought regulation of GST8, encoding the Arabidopsis homologue of ParC/Nt107 glutathione transferase/peroxidase. Physiologia Plantarum 116 (1): 96-105.

Milborrow BV (1974) The chemistry and physiology of abscisic acid. Annual Review of Plant Physiology, 25 (259-307).

Miller J, McLachlan, A.D. and Klug, A. (1985) Repetitive zincbinding domains in the protein transcription factor IIIA from Xenopus oocytes. . EMBO J 4,:1609-1614.

Mori IC, Murata Y, Yang Y, Munemasa S, Wang YF, Andreoli S, Tiriac H, Alonso JM, Harper JF, Ecker JR, Kwak JM, Schroeder JI (2006) CDPKs CPK6 and CPK3 function in ABA regulation of guard cell S-type anion- and $\mathrm{Ca}(2+)$-permeable channels and stomatal closure. PLoS biology 4 (10):e327. 
Nakagawa H, Ferrario, S., Angenent, G.C., Kobayashi, A., Takatsuji, H. (2004) The petunia ortholog of Arabidopsis SUPERMAN plays a distinct role in floral organ morphogenesis.Plant Cell, 16,:920-932.

Nakagawa H, Jiang CJ, Sakakibara H, Kojima M, Honda I, Ajisaka H, Nishijima T, Koshioka M, Homma T, Mander LN, Takatsuji H (2005) Overexpression of a petunia zinc-finger gene alters cytokinin metabolism and plant forms. The Plant journal : for cell and molecular biology 41 (4):512-523.

Nambara E, Hayama R, Tsuchiya Y, Nishimura M, Kawaide H, Kamiya Y, Naito S (2000) The role of ABI3 and FUS3 loci in Arabidopsis thaliana on phase transition from late embryo development to germination. Developmental biology 220 (2):412-423.

Nambara E, Marion-Poll A (2005) Abscisic acid biosynthesis and catabolism. Annual review of plant biology 56:165-185. doi:10.1146/annurev.arplant.56.032604.144046

Nandi AK, Kushalappa K, Prasad K, Vijayraghavan U (2000) A conserved function for Arabidopsis SUPERMAN in regulating floral-whorl cell proliferation in rice, a monocotyledonous plant. Current biology : CB 10 (4):215-218

Oh E, Kim J, Park E, Kim JI, Kang C, Choi G (2004) PIL5, a phytochrome-interacting basic helix-loop-helix protein, is a key negative regulator of seed germination in Arabidopsis thaliana. The Plant cell 16 (11):3045-3058.

Oh E, Yamaguchi S, Hu J, Yusuke J, Jung B, Paik I, Lee HS, Sun TP, Kamiya Y, Choi G (2007) PIL5, a phytochrome-interacting bHLH protein, regulates gibberellin responsiveness by binding directly to the GAI and RGA promoters in Arabidopsis seeds. The Plant cell 19 (4):1192-1208.

Oh E, Yamaguchi S, Kamiya Y, Bae G, Chung WI, Choi G (2006) Light activates the degradation of PIL5 protein to promote seed germination through gibberellin in Arabidopsis. The Plant journal : for cell and molecular biology 47 (1):124-139.

Ohno CK, Reddy GV, Heisler MG, Meyerowitz EM (2004) The Arabidopsis JAGGED gene encodes a zinc finger protein that promotes leaf tissue development. Development 131 (5):1111-1122.

Ohta M, Masui, K., Hiratsu, K., Shinshi, H., and Ohme-Takagi, M. (2001) Repression domains of class II ERF transcriptional repressors share an essential motif for active repression. . The Plant cell 13,:1959-1968.

Olszewski N, Sun TP, Gubler F. (2002) Gibberellin signaling: biosynthesis, catabolism, and response pathways. The Plant cell 14 Suppl:S61-80. 
Papdi C, Abraham E, Joseph MP, Popescu C, Koncz C, Szabados L. (2008) Functional identification of Arabidopsis stress regulatory genes using the controlled cDNA overexpression system. Plant physiology 147 (2):528-542.

Parcy F, Valon C, Raynal M, Gaubier-Comella P, Delseny M, Giraudat J. (1994) Regulation of gene expression programs during Arabidopsis seed development: roles of the ABI3 locus and of endogenous abscisic acid. The Plant cell 6 (11):1567-1582.

Pandey S, Assmann SM (2004) The Arabidopsis putative G protein-coupled receptor GCR1 interacts with the G protein alpha subunit GPA1 and regulates abscisic acid signaling. Plant Cell 16: 1616-1632

Payne T, Johnson SD, Koltunow AM. (2004) KNUCKLES (KNU) encodes a C2H2 zinc-finger protein that regulates development of basal pattern elements of the Arabidopsis gynoecium. Development 131 (15):3737-3749.

Paz-Ares J, Regia C. (2002) REGIA, an EU project on functional genomics of transcription factors from Arabidopsis Thaliana. Comparative and functional genomics 3 (2):102-108.

Pedone PV, Ghirlando R, Clore GM, Gronenborn AM, Felsenfeld G, Omichinski JG. (1996) The single Cys2-His2 zinc finger domain of the GAGA protein flanked by basic residues is sufficient for high-affinity specific DNA binding. Proceedings of the National Academy of Sciences of the United States of America 93 (7):2822-2826.

Pei Z-M, Ghassemian, M., Kwak, C.M., McCourt, P., and Schroeder, J.I. (1998) Role of farnesyltransferase in ABA regulation of guard cell anion channels and plant water loss. . Science 282:287-290.

Pei ZM, Kuchitsu K, Ward JM, Schwarz M, Schroeder JI. (1997) Differential abscisic acid regulation of guard cell slow anion channels in Arabidopsis wild-type and abi1 and abi2 mutants. The Plant cell 9 (3):409-423.

Penfield S, Li Y, Gilday AD, Graham S, Graham IA. (2006) Arabidopsis ABA INSENSITIVE4 regulates lipid mobilization in the embryo and reveals repression of seed germination by the endosperm. The Plant cell 18 (8):1887-1899.

Piskurewicz U, Jikumaru Y, Kinoshita N, Nambara E, Kamiya Y, Lopez-Molina L. (2008) The gibberellic acid signaling repressor RGL2 inhibits Arabidopsis seed germination by stimulating abscisic acid synthesis and ABI5 activity. The Plant cell 20 (10):2729-2745.

Piskurewicz U TV, Lacombe E, Lopez-Molina L. (2009) Far-red light inhibits germination through DELLA-dependent stimulation of ABA synthesis and ABI3 activity. EMBO J 28: $2259-2271$ 
Prigge MJ, and Wagner, D.R. (2001) The Arabidopsis SERRATE gene encodes a zinc-finger protein required for normal shoot development. The Plant cell $13: 1263-1279$.

Pritchard HWaS, P.T. (1993) Orchids seed storage: Historical perspective current status and future prospects for long-term conservation. Selbyana 14:89-104.

Quail PH (1998) The phytochrome family: dissection of functional roles and signalling pathways among family members. Philosophical transactions of the Royal Society of London Series B, Biological sciences 353 (1374):1399-1403.

Quesada V, Ponce MR, Micol JL. (2000) Genetic analysis of salt-tolerant mutants in Arabidopsis thaliana. Genetics 154 (1):421-436.

Ramon M, Rolland F, Thevelein JM, Van Dijck P, Leyman B. (2007) ABI4 mediates the effects of exogenous trehalose on Arabidopsis growth and starch breakdown. Plant molecular biology 63 (2):195-206.

Reeves WM LT, Mobin R, Finkelstein RR. (2011) Direct targets of the transcription factors ABA-Insensitive(ABI)4 and ABI5 reveal synergistic action by ABI4 and several bZIP ABA response factors. Plant Mol Biol 75:347-363.

Ren S, Johnston JS, Shippen DE, McKnight TD. (2004) TELOMERASE ACTIVATOR1 induces telomerase activity and potentiates responses to auxin in Arabidopsis. The Plant cell 16 (11):2910-2922.

Riechmann JL, Heard J, Martin G, Reuber L, Jiang C, Keddie J, Adam L, Pineda O, Ratcliffe OJ, Samaha RR, Creelman R, Pilgrim M, Broun P, Zhang JZ, Ghandehari D, Sherman BK, Yu G (2000) Arabidopsis transcription factors: genome-wide comparative analysis among eukaryotes. Science 290 (5499):2105-2110.

Riechmann JL, Ratcliffe OJ. (2000) A genomic perspective on plant transcription factors. Current opinion in plant biology 3 (5):423-434.

Rigó G PC, Szabados L. (2012) Transformation using controlled cDNA overexpression system. Methods Mol Biol 913:277-290.

Rock C (2000) Pathways to abscisic acid-regulated gene expression. New Phytol 148:357-396.

Rodriguez PL, Leube MP, Grill E. (1998) Molecular cloning in Arabidopsis thaliana of a new protein phosphatase $2 \mathrm{C}(\mathrm{PP} 2 \mathrm{C})$ with homology to $\mathrm{ABI} 1$ and $\mathrm{ABI}$. Plant molecular biology 38 (5):879-883. 
Rohde A, De Rycke R, Beeckman T, Engler G, Van Montagu M, Boerjan W. (2000) ABI3 affects plastid differentiation in dark-grown Arabidopsis seedlings. The Plant cell 12 (1):35-52.

Rook F, Hadingham SA, Li Y, Bevan MW. (2006) Sugar and ABA response pathways and the control of gene expression. Plant, cell \& environment 29 (3):426-434.

Ruggiero B, Koiwa H, Manabe Y, Quist TM, Inan G, Saccardo F, Joly RJ, Hasegawa PM, Bressan RA, Maggio A. (2004) Uncoupling the effects of abscisic acid on plant growth and water relations. Analysis of sto1/nced3, an abscisic acid-deficient but salt stresstolerant mutant in Arabidopsis. Plant physiology 136 (2):3134-3147.

Sakai H, Medrano, L. J. and Meyerowitz, E. M. (1995) Role of SUPERMAN in maintaining Arabidopsis floral whorl boundaries. Nature 378,: 199-201.

Sakuma Y, Maruyama K, Osakabe Y, Qin F, Seki M, Shinozaki K, Yamaguchi-Shinozaki K (2006a) Functional analysis of an Arabidopsis transcription factor, DREB2A, involved in drought-responsive gene expression. The Plant cell 18 (5):1292-1309.

Sakuma Y, Maruyama K, Qin F, Osakabe Y, Shinozaki K, Yamaguchi-Shinozaki K (2006b) Dual function of an Arabidopsis transcription factor DREB2A in water-stress-responsive and heat-stress-responsive gene expression. Proceedings of the National Academy of Sciences of the United States of America 103 (49):18822-18827.

Sankhla NaS, D.(1968) Reversal of $( \pm)$-abscisin H-induced inhibition of lettuce seed germination. Physiol Plant 62,:553-560.

Satoh-Nagasawa N, Nagasawa N, Malcomber S, Sakai H, Jackson D (2006) A trehalose metabolic enzyme controls inflorescence architecture in maize. Nature 441 (7090):227230.

Sawada Y, Aoki M, Nakaminami K, Mitsuhashi W, Tatematsu K, Kushiro T, Koshiba T, Kamiya Y, Inoue Y, Nambara E, Toyomasu T (2008) Phytochrome- and gibberellinmediated regulation of abscisic acid metabolism during germination of photoblastic lettuce seeds. Plant physiology 146 (3):1386-1396.

Schagger H, von Jagow G (1987) Tricine-sodium dodecyl sulfate-polyacrylamide gel electrophoresis for the separation of proteins in the range from 1 to $100 \mathrm{kDa}$. Analytical biochemistry 166 (2):368-379.

Schöffl F PR, Reindl A. (1998) Regulation of the heat-shock response. Plant Physiology 117:1135-1141. 
Schwartz SH, Leon-Kloosterziel KM, Koornneef M, Zeevaart JA (1997) Biochemical characterization of the aba2 and aba3 mutants in Arabidopsis thaliana. Plant physiology 114 (1):161-166.

Seo M, Hanada A, Kuwahara A, Endo A, Okamoto M, Yamauchi Y, North H, Marion-Poll A, Sun TP, Koshiba T, Kamiya Y, Yamaguchi S, Nambara E (2006) Regulation of hormone metabolism in Arabidopsis seeds: phytochrome regulation of abscisic acid metabolism and abscisic acid regulation of gibberellin metabolism. The Plant journal : for cell and molecular biology 48 (3):354-366.

Seo M NE, Choi G, Yamaguchi S (2009) Interaction of light and hormone signals in germinating seeds. Plant Mol Biol 69:463-472.

Serrano R GR (1994) Microbial models and salt stress tolerance in plants. . Crit Rev Plant Sci $13,: 121-138$.

Sheen J (1998) Mutational analysis of protein phosphatase 2C involved in abscisic acid signal transduction in higher plants. Proceedings of the National Academy of Sciences of the United States of America 95 (3):975-980.

Shinomura T, Nagatani A, Chory J, Furuya M (1994) The Induction of Seed Germination in Arabidopsis thaliana Is Regulated Principally by Phytochrome B and Secondarily by Phytochrome A. Plant physiology 104 (2):363-371.

Shinomura T, Nagatani A, Hanzawa H, Kubota M, Watanabe M, Furuya M (1996) Action spectra for phytochrome A- and B-specific photoinduction of seed germination in Arabidopsis thaliana. Proceedings of the National Academy of Sciences of the United States of America 93 (15):8129-8133.

Shinozaki K, Yamaguchi-Shinozaki K (1997) Gene Expression and Signal Transduction in Water-Stress Response. Plant physiology 115 (2):327-334.

Shinozaki K, Yamaguchi-Shinozaki K (2000) Molecular responses to dehydration and low temperature: differences and cross-talk between two stress signaling pathways. Current opinion in plant biology 3 (3):217-223.

Shinozaki K, Yamaguchi-Shinozaki K (2007) Gene networks involved in drought stress response and tolerance. Journal of experimental botany 58 (2):221-227. 
Soderman EM, Brocard IM, Lynch TJ, Finkelstein RR (2000) Regulation and function of the Arabidopsis ABA-insensitive4 gene in seed and abscisic acid response signaling networks. Plant physiology 124 (4):1752-1765.

Sun W BC, van de Cotte B, Van Montagu M, Verbruggen N. (2002) Small heat shock proteins and stress tolerance in plants. Biochim Biophys Acta, 1577 1-9.

Tague BW, Gallant P, Goodman HM (1996) Expression analysis of an Arabidopsis C2H2 zinc finger protein gene. Plant molecular biology 32 (5):785-796.

Tague BWaG, H. M. (1995. ) Characterization of a family of Arabidopsis zinc finger protein cDNAs. Plant MolBiol 28,: 267-279.

Takatsuji H (1998) Zinc-finger transcription factors in plants. CellMol Life Sci 54,: 582-596.

Takatsuji H (1999) Zinc-finger proteins: the classical zinc finger emerges in contemporary plant science. Plant molecular biology 39 (6):1073-1078.

Takeda S, Matsumoto, N., Okada, K. (2004) RABBIT EARS, encoding a SUPERMAN-like zinc-finger protein regulates petal development in Arabidopsis thaliana. Development, $131,: 425-434$.

Thomashow MF (1999) Plant cold acclimation: freezing tolerance genes and regulatory mechanisms. Annual review of plant physiology and plant molecular biology 50,:571599.

Thompson AJ, Andrews J, Mulholland BJ, McKee JM, Hilton HW, Horridge JS, Farquhar GD, Smeeton RC, Smillie IR, Black CR, Taylor IB (2007a) Overproduction of abscisic acid in tomato increases transpiration efficiency and root hydraulic conductivity and influences leaf expansion. Plant physiology 143 (4):1905-1917.

Thompson AJ, Mulholland BJ, Jackson AC, McKee JM, Hilton HW, Symonds RC, Sonneveld T, Burbidge A, Stevenson P, Taylor IB (2007b) Regulation and manipulation of ABA biosynthesis in roots. Plant, cell \& environment 30 (1):67-78.

Tran LS NK, Sakuma Y, Simpson SD, Fujita Y, Maruyama K, Fujita M, Seki M, Shinozaki K, Yamaguchi-Shinozaki K (2004) Isolation and functional analysis of Arabidopsis stressinducible NAC transcription factors that bind to a drought-responsive cis-element in the early responsive to dehydration stress 1 promoter. Plant Cell 16:2481-2498. 
Tyler L, Thomas SG, Hu J, Dill A, Alonso JM, Ecker JR, Sun TP (2004) Della proteins and gibberellin-regulated seed germination and floral development in Arabidopsis. Plant physiology 135 (2):1008-1019. doi:10.1104/pp.104.039578.

Umezawa T, Okamoto M, Kushiro T, Nambara E, Oono Y, Seki M, Kobayashi M, Koshiba T, Kamiya Y, Shinozaki K (2006) CYP707A3, a major ABA 8'-hydroxylase involved in dehydration and rehydration response in Arabidopsis thaliana. The Plant journal : for cell and molecular biology 46 (2):171-182.

Umezawa T, Yoshida R, Maruyama K, Yamaguchi-Shinozaki K, Shinozaki K (2004) SRK2C, a SNF1-related protein kinase 2, improves drought tolerance by controlling stressresponsive gene expression in Arabidopsis thaliana. Proc Natl Acad Sci U S A 101 (49):17306-17311.

Vartanian N, Marcotte L, Giraudat J (1994) Drought Rhizogenesis in Arabidopsis thaliana (Differential Responses of Hormonal Mutants). Plant physiology 104 (2):761-767.

Verslues PE, Zhu JK (2005) Before and beyond ABA: upstream sensing and internal signals that determine ABA accumulation and response under abiotic stress. Biochemical Society transactions 33 (Pt 2):375-379.

Viczián A KS, Fejes E, Millar AJ, Schäfer E, Kozma-Bognár L, Nagy F. (2005) Functional characterization of phytochrome interacting factor 3 for the Arabidopsis thaliana circadian clockwork. Plant \& cell physiology 46(10):1591-1602

Vierling E (1991) The Roles of Heat Shock Proteins in Plants. Annual Review of Plant Physiology and Plant Molecular Biology Vol. 42:579-620

Vollbrecht E, Springer PS, Goh L, Buckler ESt, Martienssen R (2005) Architecture of floral branch systems in maize and related grasses. Nature 436 (7054):1119-1126.

Wang,G.andH.Fang. (1998) Philosophy and technique of plant genetic engineering [M], Beijing: Science Press, China. pp. 351-353.

Wehmeyer N HL, Finkelstein R, Vierling E. (1996) Synthesis of small heat-shock proteins is part of the developmental program of late seed maturation.Plant Physiology Biochem 112:757-757

Weigel D. GJ (2002) Arabidopsis: A Laboratory Manual. Cold Spring Harbor, NY: Cold Spring Harbor Laboratory Press 
Weingartner M, Subert C, Sauer N (2011) LATE, a C(2)H(2) zinc-finger protein that acts as floral repressor. The Plant journal : for cell and molecular biology 68 (4):681-692.

White CN PW, Hedden P, Rivin CJ (2000) Gibberellins and seed development in maize. I. Evidence that gibberellin/abscisic acid balance governs germination versus maturation pathways. Plant Physiology 122:1081-1088

Wiborg J, O'Shea C, Skriver K. (2008) Biochemical function of typical and variant Arabidopsis thaliana U-box E3 ubiquitin-protein ligases. Biochem J 413: 447-457

Wind JJ PA, Snel B, Hanson J, Smeekens SC (2013) ABI4: versatile activator and repressor. Trends Plant Sci 18: 125-132.

Wolf I., Kircher S., Fejes E., Kozma-Bognár L., Schäfer E., Nagy F., Adám E. (2011). Lightregulated nuclear import and degradation of Arabidopsis phytochrome-A N-terminal fragments. Plant Cell Physiol.52: 361-372

Yamaguchi-Shinozaki K, Shinozaki K (2006) Transcriptional regulatory networks in cellular responses and tolerance to dehydration and cold stresses. Annual review of plant biology 57:781-803.

Yang L, Liu Z, Lu F, Dong A, Huang H (2006) SERRATE is a novel nuclear regulator in primary microRNA processing in Arabidopsis. The Plant journal : for cell and molecular biology 47 (6):841-850.

Yong-Qiang An JMM, Shurong Huang, Elizabeth C. McKinney, Sharon Chambliss andRichard B. Meagher (1996) Strong, constitutive expression of the Arabidopsis ACT2/ACT8 actin subclass in vegetative tissues. The Plant Journal 10 (1):107-121.

Zeng Y, Raimondi N, Kermode AR (2003) Role of an ABI3 homologue in dormancy maintenance of yellow-cedar seeds and in the activation of storage protein and Em gene promoters. Plant molecular biology 51 (1):39-49.

Zentella R, Zhang ZL, Park M, Thomas SG, Endo A, Murase K, Fleet CM, Jikumaru Y, Nambara E, Kamiya Y, Sun TP (2007) Global analysis of della direct targets in early gibberellin signaling in Arabidopsis. The Plant cell 19 (10):3037-3057.

Zhang JZ, Creelman RA, Zhu JK (2004) From laboratory to field. Using information from Arabidopsis to engineer salt, cold, and drought tolerance in crops. Plant physiology 135 (2):615-621. 
Zhang Y MO, Pfeiffer A, Shi H, Tepperman JM, Speed TP, Quail PH. (2013) A quartet of PIF bHLH factors provides a transcriptionally centered signaling hub that regulates seedling morphogenesis through differential expression-patterning of shared target genes in Arabidopsis. PLoS Genet 9:e1003244.

Zhou Z, An L, Sun L, Zhu S, Xi W, Broun P, Yu H, Gan Y (2011) Zinc finger protein5 is required for the control of trichome initiation by acting upstream of zinc finger protein8 in Arabidopsis. Plant Physiology 157 (2):673-682.

Zhou Z SL, Zhao Y, An L, Yan A, Meng X, Gan Y (2013) Zinc Finger Protein 6 (ZFP6) regulates trichome initiation by integrating gibberellin and cytokinin signaling in Arabidopsis thaliana. New Phytol 198:699-708.

Zhu JK (2002) Salt and drought stress signal transduction in plants. Annual review of plant biology 53:247-273.

Zhu J, Zheng AP, Wang SQ, Liu HN, Li P. (2010) Cloning and characterization of two novel crystal protein genes, cry4Cb1 and cry30Gal, from Bacillus thuringiensis strain HS181 Journal of Invertebrate Pathology 103 200-202

Zuo J, Niu QW, Chua NH (2000) Technical advance: An estrogen receptor-based transactivator XVE mediates highly inducible gene expression in transgenic plants. The Plant journal : for cell and molecular biology 24 (2):265-273.

Zuo J. \& Chua N H (2000) Chemical-inducible systems for regulated expression of plant genes. . Curr Opin Biotechnol 11:146 151. 


\section{ACKNOWLEDGEMENTS}

I would like to convey my heartfelt gratitude and sincere appreciation to Dr. Szabados László for giving me the opportunity to do my $\mathrm{PhD}$ under his supervision. He has been always patient, positive and encouraging with my success and failures. I would like to thank Prof. Dr. Koncz Csaba for his timely critical suggestions, help and reviews.

I also want to convey my deepest gratitude to my colleagues Dr. Papdi Csaba, Imma Pérez Salamó, Valkai Ildiko, Dr. Zsigmond Laura, Dr. Gábor Rigó, Dr. Ágnes Cséplő, Anna Mária Király, Mihály Dobó, Mariann, Kiss Edina, Kovács Hajni, Boros Bogi and Andrási Norbi for their help and support. I am very thankful to Dr. Ábrahám Edit for her teaching during the beginning of my $\mathrm{PhD}$.

My thankfulness to Dr. László Kozma Bognar for helping with the light experiments and Dr. Ferhan Ayaydin for assistance in microscopy, Balázs Horváth for his contribution in transcript profiling and Prof. Dr. Ferenc Nagy for valuable discussion and correction of the manuscript.

I want to show my sincere appreciation towards Dr. Éva Ádám for her comments in improving my my thesis.

My completion of this project could not have been accomplished without the support of my friends here in Szeged, my extended church family, my ITC friends, my brother Dr. Vinod Vijayakumar and Soujanya Kuntum and my loving parents.

Finally, to my caring, loving, and supportive husband, Badri Prashad Aekbote for helping me with my experiments during my maternity and my daughter Nivedya Aekbote who has been my motivation to complete this $\mathrm{PhD}$. 


\section{SUMMARY}

Abscisic acid regulates numerous processes such as seed desiccation, germination and responses to drought. Controlled cDNA Overexpression System (Papdi 2008) was employed to identify novel genes coding for important factors controlling ABA regulation. Screening for ABA insensitive germination of the transgenic plant population, transformed with the COS library, lead to the of identification several stress regulatory genes. Most pronounced Estradiol dependent ABA insenstitive germination was detected in A26 or A44 lines carrying either the full-length cDNAs, the small heat-shock protein HSP17.6A-cII (Papdi 2008) or a previously uncharacterized zinc-finger domain containing transcription factor protein. We have shown that ZFP3, a nuclear $\mathrm{C} 2 \mathrm{H} 2$ zinc finger protein acts as a negative regulator of ABA- suppressed germination. Accordingly, regulated over-expression of ZFP3 and the closely related ZFP1, ZFP4, ZFP6 and ZFP7 zinc finger factors confers ABA insensitivity to seed germination while the $z f p 3$ z.fp4 double mutant displays enhanced ABA susceptibility. Reduced expression of several ABA-induced genes, such as RAB18 and ABI4 in ZFP3ox seedlings suggests that ZFP3 negatively regulates ABA signaling. ZFP3ox plants showed multiple phenotypic alterations, such as semidwarf growth habit, defects in fertility and enhanced sensitivity of hypocotyl elongation to red but not to far-red or blue light. Analysis of genetic interactions between phytochrome and abi mutants indicates that ZFP3 enhances red light signaling by photoreceptors other than phyA, and additively increases ABA insensitivity conferred by the abi2, abi4 and abi5 mutations. These data support the conclusion that ZFP3 and other members of the ZFP subfamily regulate light and $\mathrm{ABA}$ responses during germination and early seedling development. 


\section{ÖSSZEFOGLALÁS}

Az abszcizinsav (ABA) számos élettani folyamatot szabályoz, mint például a mag érését, a csírázást, és a szárazságtürést. Laboratóriumunkban egy cDNS túltermelő rendszert (Controlled cDNA Overexpression System, COS) alkalmaztunk az ABA jelátvitelben eddig ismeretlen faktorok azonosítása céljából. Egy csírázási szürést alkalmazva ABA érzéketlen transzgenikus vonalakat sikerült izolálnunk amelyekből több, eddig ismeretlen, az ABA jelátvitelt illetve stresszválaszt szabályozó gént azonosítottunk. A legmagasabb szintủ ABA toleranciát mutató két vonalban egy kis hősokk fehérjét (HSP17.6-cII) illetve egy $\mathrm{C} 2 \mathrm{H} 2$ cink-ujj domén fehérjét (ZFP3) kódoló cDNS-t azonosítottunk. Kísérletesen bizonyítottuk, hogy ZFP3 a csírázást gátoló ABA hormon jelátvitel negatív szabályozó faktora. A ZFP3-hoz hasonló ZFP1, ZFP4, ZFP6, és ZFP7 cink-ujj domén fehérjék túltermelése szintén csökkenti a csírázás ABA gátlását, míg a zfp3 zfp4 dupla mutáns fokozott $\mathrm{ABA}$ érzékenységet mutatott. Több ismert $\mathrm{ABA}$ által indukált gén (pl. RAB18, ABI4) expressziója alacsonyabb szintű volt a ZFP3 túltermelő vonalakban. A ZFP3 túltermelése pleiotróp hatással járt, ami apró, rövid hipokotillal rendelkező, csökkent termékenységü növényeket eredményezett. A ZFP3 túltermelés a hipokotil megnyúlás gátlását a vörös fénnyel szembeni érzékenység fokozásán keresztül érte el. A fitokróm mutánsokkal való genetikai kölcsönhatások vizsgálata alapján elmondhatjuk, hogy a ZFP3 a vörös fény jelátvitelt valószínüleg nem a phyA receptoron keresztül befolyásolja. A ZFP3 túltermelés képes volt az ABA jelátvitelt befolyásoló abi2, abi4 és abi5 mutánsok ABA érzékenységét is megemelni, ami arra utal, hogy ZFP3 ezektől a génektől független szabályozási utakat befolyásol. Eredményeink alapján elmondhatjuk, hogy ZFP3 illetve a közeli rokon ZFP fehérjék a csírázást és csíranövény fejlődést befolyásoló fény és ABA jelátvitel közös szabályozó faktorai. 


\section{PUBLICATION LIST (MTMT ID:10025024)}

1) Mary P. Joseph, Csaba Papdi, László Kozma-Bognár, István Nagy, Marta LópezCarbonell, Gábor Rigó, Csaba Koncz, and László Szabados (2014) The Arabidopsis Zinc Finger Protein 3 interferes with ABA and light signaling in seed germination and plant development. Plant Physiology, 165: 1203-1220. IF:6.555

2) Papdi Cs, Leung, J, Joseph MP, Pérez-Salamó I, Szabados L (2010) Genetic screens to identify plant stress genes. In: Methods in Molecular Biology, vol. 639. New York:

Humana Press. 639: 121-139.

3) Papdi C, Joseph MP, Pérez Salamó I, Sabina Vidal, Szabados L (2009) Genetic technologies for the identification of plant genes controlling environmental stress responses. Funct. Plant Biol, 36, 696-720. IF: 2.471

4) Papdi C, Ábrahám E, Joseph MP, Popescu C, Koncz C, Szabados L (2008) Functional identification of Arabidopsis stress regulatory genes using the Controlled cDNA Overexpression System. Plant Physiology, 147: 528-542. IF:6.110

5) Ábrahám E, Papdi C, Joseph MP, Koncz C, Szabados L (2008) Identification of Arabidopsis stress regulatory genes using the Controlled cDNA Overexpression System. Acta Biol Szeged, 52: 45-48.

\section{Patent:}

Szabados L, Koncz C, Ábrahám E, Papdi C, Joseph MP (2009) CONTROLLED cDNA OVEREXPRESSION SYSTEM IN ARABIDOPSIS. European Patent: No.

PCT/EP2009054946: 24.04.09 


\section{APPENDIX}

\section{Mutants listed in Table 5.}

\section{BRX, BREVIS RADIX, NLM9 AGI: AT1G31880}

BRX encodes a key regulator of cell proliferation and elongation in the root, which has been implicated in the brassinosteroid (BR) pathway as well as regulation of auxin-responsive gene expression. Also involved in cytokinin-mediated inhibition of lateral root initiation.

Brx mutant: enhanced response to ABA-mediated inhibition of root growth, short primary root and more branched root system.

\section{References:}

Beuchat J, Scacchi E, Tarkowska D, Ragni L, Strnad M, Hardtke CS (2010) BRX promotes Arabidopsis shoot growth. New Phytol 188: 23-29

Santuari L, Scacchi E, Rodriguez-Villalon A, Salinas P, Dohmann EM, Brunoud G, Vernoux T, Smith RS, Hardtke CS (2011) Positional information by differential endocytosis splits auxin response to drive Arabidopsis root meristem growth. Curr Biol 21: 1918-1923

TOC1, TIMING OF CAB EXPRESSION 1, PRR1, PSEUDO-RESPONSE REGULATOR 1, AGI: AT5G61380

Pseudo response regulator involved in the generation of circadian rhythms. TOC1 appears to shorten the period of circumnutation speed. TOC1 contributes to the plant fitness (carbon fixation, biomass) by influencing the circadian clock period.

Mutant: semidominant; aberrant cycling pattern of the cab2::luc reporter; shortens the period of two distinct circadian bioluminescence rhythms, the expression of chlorophyll a/b-binding protein $(\mathrm{CAB})$ genes and the movements of primary leaves; seedlings grown in light or dark and mature light-grown plants are indistinguishable from the 2CAC transgenic parent (CS3755). 


\section{References:}

Harmon F, Imaizumi T, Gray WM (2008) CUL1 regulates TOC1 protein stability in the Arabidopsis circadian clock. Plant J 55: 568-579

Gendron JM, Pruneda-Paz JL, Doherty CJ, Gross AM, Kang SE, Kay SA (2012) Arabidopsis circadian clock protein, TOC1, is a DNA-binding transcription factor. Proc Natl Acad Sci U S A 109: $3167-3172$

HSFA1A, CLASS A HEAT SHOCK FACTOR 1A, AGI: AT4G17750

DNA interaction is modulated by phosphorylation and is heat-shock inducible

HSFA1B, CLASS A HEAT SHOCK FACTOR 1B, AGI: AT5G16820

Required early in the stress response for transient expression of heat shock genes.

HSFA1D, HEAT SHOCK TRANSCRIPTION FACTOR A1D, AGI: AT1G32330

Member of Heat Stress Transcription Factor (Hsf) family. Negatively regulated by HSP90.2.

HSFA1E, HEAT SHOCK TRANSCRIPTION FACTOR A1E, AGI: AT3G02990

Member of Heat Stress Transcription Factor (Hsf) family.

Reference of hsfala hsfalb, hsfald, hsfale quadruple mutant:

Yoshida T, Ohama N, Nakajima J, Kidokoro S, Mizoi J, Nakashima K, Maruyama K, Kim JM, Seki M, Todaka D, Osakabe Y, Sakuma Y, Schoffl F, Shinozaki K, Yamaguchi-Shinozaki K (2011) Arabidopsis HsfA1 transcription factors function as the main positive regulators in heat shock-responsive gene expression. Mol Genet Genomics 286: 321-332

CSN3, CONSTITUTIVE PHOTOMORPHOGENIC 13, COP13, COP9 SIGNALOSOME SUBUNIT 3, AGI: AT5G14250

subunit 3 of the COP9 signalosome. 
csn3-1 mutant: constitutive photomorphogenesis, loss of CSN function leads to constitutive photomorphogenic (cop) seedling development and a post-germination growth arrest

\section{CSN4, COP9 SIGNALOSOME SUBUNIT 4, CONSTITUTIVE PHOTOMORPHOGENIC 8, COP14, COP8, COP9 SIGNALOSOME SUBUNIT 4, AGI: AT5G42970}

encodes subunit 4 of COP9 signalosome complex. sequence is similar to a subunit of the 19S regulatory particle of the $26 \mathrm{~S}$ proteasome. recessive mutation causes derepression of photomorphogenesis.

CSN5A, AJH1, ARABIDOPSIS JAB1 HOMOLOG 1, COP9 SIGNALOSOME 5A, AGI: AT1G22920

Encodes a subunit of the COP9 complex that is involved in protein deneddylation. Plants with mutations in CSN5A and CSN5B have a de-etiolated phenotype.

\section{References of CSN genes, mutants:}

Kwok SF, Piekos B, Misera S, Deng XW (1996) A complement of ten essential and pleiotropic arabidopsis COP/DET/FUS genes is necessary for repression of photomorphogenesis in darkness. Plant Physiology 110: 731-742

Peng Z, Serino G, Deng XW (2001) A role of Arabidopsis COP9 signalosome in multifaceted developmental processes revealed by the characterization of its subunit 3. Development 128: $4277-4288$

Toorop PE, Barroco RM, Engler G, Groot SP, Hilhorst HW (2005) Differentially expressed genes associated with dormancy or germination of Arabidopsis thaliana seeds. Planta 221: 637647

Dohmann EM, Levesque MP, Isono E, Schmid M, Schwechheimer C (2008) Auxin responses in mutants of the Arabidopsis CONSTITUTIVE PHOTOMORPHOGENIC9 signalosome. Plant Physiology 147: 1369-1379 


\section{PHYB, PHYTOCHROME B, AGI: AT2G18790}

Red/far-red photoreceptor involved in the regulation of de-etiolation. Exists in two interconvertible forms: Pr and Pfr (active). Involved in the light-promotion of seed germination and in the shade avoidance response. Promotes seedling etiolation in both the presence and absence of phytochrome A. Overexpression results in etiolation under far-red light. Accumulates in the nucleus after exposure to far red light. The phosphorylation state of the Ser-86 residue of the phytochrome B molecule alters dark reversion of the molecule.

phyB mutant: elongated hypocotyl, pale green plant, far-red light inhibits elongation, red does not.

\section{PHYC, PHYTOCHROME C, AGI: AT5G35840}

Encodes the apoprotein of phytochrome; one of a family of photoreceptors that modulate plant growth and development.

\section{PHYD, PHYTOCHROME D, AGI: AT4G16250}

Encodes a phytochrome photoreceptor with a function similar to that of phyB that absorbs the red/far-red part of the light spectrum and is involved in light responses. It cannot compensate for phyB loss in Arabidopsis but can substitute for tobacco phyB in vivo.

PHYE, PHYTOCHROME E, AGI: AT4G18130- member of Histidine Kinase

\section{References in Phytochrome signaling:}

Leivar P, Monte E, Cohn MM, Quail PH (2012) Phytochrome signaling in green Arabidopsis seedlings: impact assessment of a mutually negative phyB-PIF feedback loop. Mol Plant 5: 734749

Li J, Li G, Wang H, Wang Deng X (2012) Phytochrome signaling mechanisms. Arabidopsis Book 9: e0148 
Gonzalez CV, Ibarra SE, Piccoli PN, Botto JF, Boccalandro HE (2012) Phytochrome B increases drought tolerance by enhancing ABA sensitivity in Arabidopsis thaliana. Plant Cell Environ 35: 1958-1968

Lee KP, Piskurewicz U, Tureckova V, Carat S, Chappuis R, Strnad M, Fankhauser C, LopezMolina L (2012) Spatially and genetically distinct control of seed germination by phytochromes A and B. Genes Dev 26: 1984-1996

\section{LEAFY COTYLEDON 1, LEC1, NF-YB9, AGI: AT1G21970}

Transcriptional activator of genes required for both embryo maturation and cellular differentiation, mediates the switch between embryo and vegetative development.

lec1-1: Embryo lethal; viviparous embryos with cotyledons partially transformed into leaves; embryos sensitive to abscisic acid; embryos have reduced hypocotyl, cotyledons that remain green late in development;

\section{References:}

Vicient CM, Bies-Etheve N, Delseny M (2000) Changes in gene expression in the leafy cotyledon1 (lec1) and fusca3 (fus3) mutants of Arabidopsis thaliana L. J Exp Bot 51: 995-1003

Baumbusch LO, Hughes DW, Galau GA, Jakobsen KS (2004) LEC1, FUS3, ABI3 and Em expression reveals no correlation with dormancy in Arabidopsis. J Exp Bot 55: 77-87

Sugliani M, Rajjou L, Clerkx EJ, Koornneef M, Soppe WJ (2009) Natural modifiers of seed longevity in the Arabidopsis mutants abscisic acid insensitive3-5 (abi3-5) and leafy cotyledon1-3 (lec1-3). New Phytol 184: 898-908

\section{PIF1, PHY-INTERACTING FACTOR 1, PHYTOCHROME INTERACTING FACTOR 3-LIKE 5, PIF1, PIL5, AGI: AT2G20180}

Encodes a novel Myc-related bHLH transcription factor that has transcriptional activation activity in the dark. It is a key negative regulator of phytochrome-mediated seed germination and acts by inhibiting chlorophyll biosynthesis, light-mediated suppression of hypocotyl elongation 
and far-red light-mediated suppression of seed germination, and promoting negative gravitropism in hypocotyls. Light reduces this activity in a phy-dependent manner. The protein preferentially interacts with the Pfr forms of Phytochrome A (PhyA) and Phytochrome B (PhyB), is physically associated with APRR1/TOC1 and is degraded in red (R) and far-red (FR) light through the ubiquitin (ub)-26S proteasome pathway to optimize photomorphogenic development in Arabidopsis. It also negatively regulates GA3 oxidase expression.

\section{PIF3, PHYTOCHROME INTERACTING FACTOR 3, PHYTOCHROME-ASSOCIATED PROTEIN 3, PIF3, POC1, AGI: AT1G09530}

Transcription factor interacting with photoreceptors phyA and phyB. Forms a ternary complex in vitro with G-box element of the promoters of LHY, CCA1. Acts as a negative regulator of phyB signalling. It degrades rapidly after irradiation of dark grown seedlings in a process controlled by phytochromes. Does not play a significant role in controlling light input and function of the circadian clockwork. Binds to G- and E-boxes, but not to other ACEs. Binds to anthocyanin biosynthetic genes in a light- and HY5-independent fashion. PIF3 function as a transcriptional activator can be functionally and mechanistically separated from its role in repression of PhyB mediated processes.

\section{PIF4, PHYTOCHROME INTERACTING FACTOR 4, AGI: AT2G43010}

Isolated as a semidominant mutation defective in red -light responses. Encodes a nuclear localized bHLH protein that interacts with active PhyB protein. Negatively regulates phyB mediated red light responses. Involved in shade avoidance response. Protein abundance is negatively regulated by PhyB.

\section{PIF5, PHYTOCHROME INTERACTING FACTOR 3-LIKE 6, PHYTOCHROME- INTERACTING FACTOR 5, PIF5, PIL6, AGI: AT3G59060}

Encodes a novel Myc-related bHLH transcription factor, which physically associated with APRR1/TOC1 and is a member of PIF3 transcription factor family. Involved in shade avoidance. Functions as negative regulator of PhyB. Protein levels are modulated by phytochrome B. 


\section{References of PIF factors}

Lau OS, Deng XW (2010) Plant hormone signaling lightens up: integrators of light and hormones. Curr Opin Plant Biol 13: 571-577

Leivar P, Monte E, Oka Y, Liu T, Carle C, Castillon A, Huq E, Quail PH (2008) Multiple phytochrome-interacting bHLH transcription factors repress premature seedling photomorphogenesis in darkness. Curr Biol 18: 1815-1823

Liu Z, Zhang Y, Liu R, Hao H, Wang Z, Bi Y (2011) Phytochrome interacting factors (PIFs) are essential regulators for sucrose-induced hypocotyl elongation in Arabidopsis. J Plant Physiology 168: $1771-1779$

Pfeiffer A, Nagel MK, Popp C, Wust F, Bindics J, Viczian A, Hiltbrunner A, Nagy F, Kunkel T, Schafer E (2012) Interaction with plant transcription factors can mediate nuclear import of phytochrome B. Proc Natl Acad Sci U S A 109: 5892-5897

Lee KP, Piskurewicz U, Tureckova V, Carat S, Chappuis R, Strnad M, Fankhauser C, LopezMolina L (2012) Spatially and genetically distinct control of seed germination by phytochromes A and B. Genes Dev 26: 1984-1996

Zhang Y, Mayba O, Pfeiffer A, Shi H, Tepperman JM, Speed TP, Quail PH (2013) A quartet of PIF bHLH factors provides a transcriptionally centered signaling hub that regulates seedling morphogenesis through differential expression-patterning of shared target genes in Arabidopsis. PLoS Genet 9: e1003244

\section{Mutant ged1:}

able to green and contains more transcripts of photosynthesis genes, but fewer transcripts of seed protein genes when transferred to light after germination and growth in extended darkness (6-10 days); germination is sensitive to $\mathrm{ABA}$;

\section{Reference:}


Choy MK, Sullivan JA, Theobald JC, Davies WJ, Gray JC (2008) An Arabidopsis mutant able to green after extended dark periods shows decreased transcripts of seed protein genes and altered sensitivity to abscisic acid. J Exp Bot 59: 3869-3884

\section{MPK6, MAP KINASE 6, MAPK6, AGI: AT2G43790}

Encodes a MAP kinase induced by pathogens, ethylene biosynthesis, oxidative stress and osmotic stress.Also involved in ovule development. Homozygous mutants in a MPK3 heterozygous background are female sterile due to defects in integument development.MPK6 appears to be associated with the microsomal compartment and may be involved in mediating secretory processes.

\section{References:}

Asai T, Tena G, Plotnikova J, Willmann MR, Chiu WL, Gomez-Gomez L, Boller T, Ausubel FM, Sheen J (2002) MAP kinase signalling cascade in Arabidopsis innate immunity. Nature 415: 977-983

Takahashi F, Yoshida R, Ichimura K, Mizoguchi T, Seo S, Yonezawa M, Maruyama K, Yamaguchi-Shinozaki K, Shinozaki K (2007) The mitogen-activated protein kinase cascade MKK3-MPK6 is an important part of the jasmonate signal transduction pathway in Arabidopsis. Plant Cell 19: 805-818

Wang H, Liu Y, Bruffett K, Lee J, Hause G, Walker JC, Zhang S (2008) Haplo-insufficiency of MPK3 in MPK6 mutant background uncovers a novel function of these two MAPKs in Arabidopsis ovule development. Plant Cell 20: 602-613

Xing Y, Jia W, Zhang J (2009) AtMKK1 and AtMPK6 are involved in abscisic acid and sugar signaling in Arabidopsis seed germination. Plant Mol Biol 70: 725-736

Nguyen XC, Kim SH, Lee K, Kim KE, Liu XM, Han HJ, Hoang MH, Lee SW, Hong JC, Moon YH, Chung WS (2012) Identification of a C2H2-type zinc finger transcription factor (ZAT10) from Arabidopsis as a substrate of MAP kinase. Plant Cell Rep 31: 737-745 


\section{RPS4: RESISTANT TO P. SYRINGAE 4, AGI: AT5G45250}

RPS4 belongs to the Toll/interleukin-1 receptor (TIR)-nucleotide binding site (NBS)-Leu-rich repeat (LRR) class of disease resistance $(\mathrm{R})$ genes. Confers specific resistance to Pseudomonas syringae pv. tomato carrying the avirulence gene AvrRPS4.

\section{References:}

Lee J, Nam J, Park HC, Na G, Miura K, Jin JB, Yoo CY, Baek D, Kim DH, Jeong JC, Kim D, Lee SY, Salt DE, Mengiste T, Gong Q, Ma S, Bohnert HJ, Kwak SS, Bressan RA, Hasegawa PM, Yun DJ (2007) Salicylic acid-mediated innate immunity in Arabidopsis is regulated by SIZ1 SUMO E3 ligase. Plant J 49: 79-90

Heidrich K, Wirthmueller L, Tasset C, Pouzet C, Deslandes L, Parker JE (2011) Arabidopsis EDS1 connects pathogen effector recognition to cell compartment-specific immune responses. Science 334: 1401-1404

\section{EDS1: ENHANCED DISEASE SUSCEPTIBILITY 1, AGI: AT3G48090}

Component of $\mathrm{R}$ gene-mediated disease resistance in Arabidopsis thaliana with homology to eukaryotic lipases.

eds1-2 mutant: Highly susceptible to downy mildew pathogen, significant flg22-induced reduction in bacterial growth

\section{References:}

Straus MR, Rietz S, Ver Loren van Themaat E, Bartsch M, Parker JE (2010) Salicylic acid antagonism of EDS1-driven cell death is important for immune and oxidative stress responses in Arabidopsis. Plant J 62: 628-640

Heidrich K, Wirthmueller L, Tasset C, Pouzet C, Deslandes L, Parker JE (2011) Arabidopsis EDS1 connects pathogen effector recognition to cell compartment-specific immune responses. Science 334: 1401-1404 
Wituszynska W, Slesak I, Vanderauwera S, Szechynska-Hebda M, Kornas A, Van Der Kelen K, Muhlenbock P, Karpinska B, Mackowski S, Van Breusegem F, Karpinski S (2013) Lesion simulating disease1, enhanced disease susceptibility1, and phytoalexin deficient 4 conditionally regulate cellular signaling homeostasis, photosynthesis, water use efficiency, and seed yield in Arabidopsis. Plant Physiology 161: 1795-1805

\section{PAD4: PHYTOALEXIN DEFICIENT 4, AGI: AT3G52430}

lipase-like gene that is important for salicylic acid signaling and function in resistance (R) genemediated and basal plant disease resistance

pad4 mutant: enhanced susceptibility to the bacterial pathogen Pseudomonas syringae

\section{References:}

Rusterucci C, Aviv DH, Holt BF, 3rd, Dangl JL, Parker JE (2001) The disease resistance signaling components EDS1 and PAD4 are essential regulators of the cell death pathway controlled by LSD1 in Arabidopsis. Plant Cell 13: 2211-2224

Ng G, Seabolt S, Zhang C, Salimian S, Watkins TA, Lu H (2011) Genetic dissection of salicylic acid-mediated defense signaling networks in Arabidopsis. Genetics 189: 851-859

Wituszynska W, Slesak I, Vanderauwera S, Szechynska-Hebda M, Kornas A, Van Der Kelen K, Muhlenbock P, Karpinska B, Mackowski S, Van Breusegem F, Karpinski S (2013) Lesion simulating disease1, enhanced disease susceptibility1, and phytoalexin deficient 4 conditionally regulate cellular signaling homeostasis, photosynthesis, water use efficiency, and seed yield in Arabidopsis. Plant Physiology 161: 1795-1805

\section{ABA-HYPERSENSITIVE GERMINATION 1, AHG1, AGI: AT5G51760}

AHG1 (ABA-hypersensitive germination 1), a putative protein phosphatase 2C (PP2C). Expressed in seeds. AHG1 functions in seed development and germination.

Mutant: ABA hypersensitive, grows poorly in the presence of ABA 


\section{References:}

Nishimura N, Yoshida T, Murayama M, Asami T, Shinozaki K, Hirayama T (2004) Isolation and characterization of novel mutants affecting the abscisic acid sensitivity of Arabidopsis germination and seedling growth. Plant Cell Physiology 45: 1485-1499

Nishimura N, Yoshida T, Kitahata N, Asami T, Shinozaki K, Hirayama T (2007) ABAHypersensitive Germination1 encodes a protein phosphatase 2C, an essential component of abscisic acid signaling in Arabidopsis seed. Plant J 50: 935-949

Antoni R, Gonzalez-Guzman M, Rodriguez L, Rodrigues A, Pizzio GA, Rodriguez PL (2012) Selective inhibition of clade A phosphatases type 2C by PYR/PYL/RCAR abscisic acid receptors. Plant Physiology 158: 970-980

\section{AHG3, PROTEIN PHOSPHATASE 2CA, ATPP2CA, PP2CA, AGI: AT3G11410}

Negative regulator of ABA signalling. Expressed in seeds during germination. mRNA upregulated by drought and $\mathrm{ABA}$.

PP2CAox: ABA-insensitive phenotype

\section{References:}

Yoshida T, Nishimura N, Kitahata N, Kuromori T, Ito T, Asami T, Shinozaki K, Hirayama T (2006) ABA-hypersensitive germination3 encodes a protein phosphatase 2C (AtPP2CA) that strongly regulates abscisic acid signaling during germination among Arabidopsis protein phosphatase 2Cs. Plant Physiology 140: 115-126

Antoni R, Gonzalez-Guzman M, Rodriguez L, Rodrigues A, Pizzio GA, Rodriguez PL (2012) Selective inhibition of clade A phosphatases type 2C by PYR/PYL/RCAR abscisic acid receptors. Plant Physiology 158: 970-980 